\title{
Boosted Fast Flux Loop Alternative Cooling Assessment
}

Glen R. Longhurst Donna Post Guillen James R. Parry Douglas L. Porter Bruce W. Wallace

August 2007

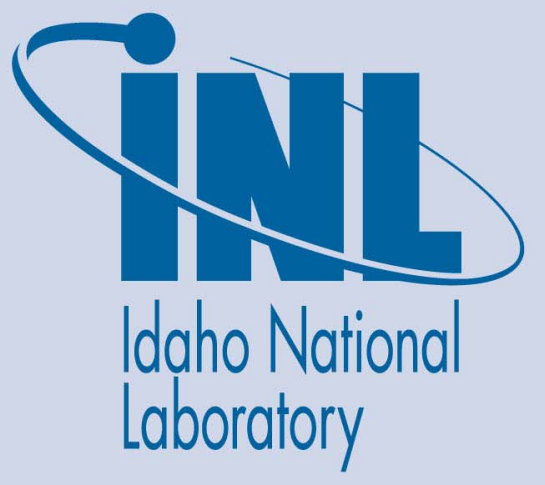

The INL is a U.S. Department of Energy National Laboratory operated by Battelle Energy Alliance 


\title{
Boosted Fast Flux Loop Alternative Cooling Assessment
}

\author{
Glen R. Longhurst \\ Donna Post Guillen \\ James R. Parry \\ Douglas L. Porter \\ Bruce W. Wallace
}

August 2007

\section{Idaho National Laboratory \\ Fuels and Materials Performance Department \\ Idaho Falls, Idaho 83415}



This page intentionally blank 


\section{ABSTRACT}

The Gas Test Loop (GTL) Project was instituted to develop the means for conducting fast neutron irradiation tests in a domestic radiation facility. It made use of booster fuel to achieve the high neutron flux, a hafnium thermal neutron absorber to attain the high fast-to-thermal flux ratio, a mixed gas temperature control system for maintaining experiment temperatures, and a compressed gas cooling system to remove heat from the experiment capsules and the hafnium thermal neutron absorber. This GTL system was determined to provide a fast $(\mathrm{E}>0.1 \mathrm{MeV})$ flux greater than $1.0 \mathrm{E}+15 \mathrm{n} / \mathrm{cm} 2-\mathrm{s}$ with a fast-to-thermal flux ratio in the vicinity of 40 . However, the estimated system acquisition cost from earlier studies was deemed to be high. That cost was strongly influenced by the compressed gas cooling system for experiment heat removal. Designers were challenged to find a less expensive way to achieve the required cooling. This report documents the results of the investigation leading to an alternatively cooled configuration, referred to now as the Boosted Fast Flux Loop (BFFL). This configuration relies on a composite material comprised of hafnium aluminide $\left(\mathrm{Al}_{3} \mathrm{Hf}\right)$ in an aluminum matrix to transfer heat from the experiment to pressurized water cooling channels while at the same time providing absorption of thermal neutrons. Investigations into the performance this configuration might achieve showed that it should perform at least as well as its gas-cooled predecessor. Physics calculations indicated that the fast neutron flux averaged over the central $40 \mathrm{~cm}$ (16 inches) relative to ATR core mid-plane in irradiation spaces would be about $1.04 \mathrm{E}+15 \mathrm{n} / \mathrm{cm} 2-\mathrm{s}$. The fastto-thermal flux ratio would be in excess of 40. Further, the particular configuration of cooling channels was relatively unimportant compared with the total amount of water in the apparatus in determining performance. Thermal analyses conducted on a candidate configuration showed the design of the water coolant and Al-Hf alloy heat sink system is capable of maintaining all system components below their maximum temperature limits. The maximum temperature of this conduction cooling system, $224.2^{\circ} \mathrm{C}\left(435.6^{\circ} \mathrm{F}\right)$ occurs in a small, localized region in the heat sink structure near the core mid-plane. The total coolant flow rate requirement for this configuration is $207 \mathrm{~L} / \mathrm{min}$ (54.7 gpm). The calculated Flow Instability Ratio and Departure from Nucleate Boiling Ratio for this configuration under nominal conditions are 6.5 and 8.0, respectively, which safely exceed the minimum values of 2.0. Materials and fabrication issues inspection revealed that the neutron absorber would probably best be made from powdered $\mathrm{Al}_{3} \mathrm{Hf}$ mixed with aluminum powder and extruded or hot isostatically pressed. Although $\mathrm{Al}_{3} \mathrm{Hf}$ has not been specifically studied extensively, its mechanical and chemical properties should be very much like $\mathrm{Al}_{3} \mathrm{Zr}$, which has been studied. Its behavior under irradiation should be very satisfactory, and resistance to corrosion will be investigated to a limited extent in planned miniplate irradiation tests in ATR. Pressurized water systems needed to effect heat removal are already available in the ATR complex, and mixed gas temperature control systems needed to trim experiment temperatures have been engineered and need only be fabricated and installed. In sum, it appears the alternately cooled configuration arrived at can be very successful. The cost estimate for this configuration indicates total project costs between $\$ 50 \mathrm{M}$ and $\$ 75 \mathrm{M}$, including more than $\$ 11 \mathrm{M}$ for neutron charges, which is a saving of $25 \%$ over the previous configuration. 


\section{CONTENTS}

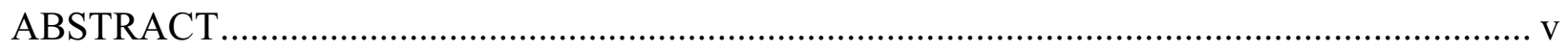

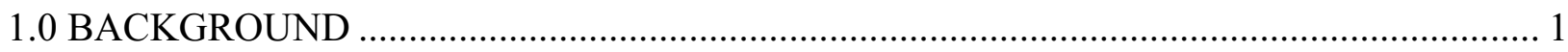

2.0 APPROACH

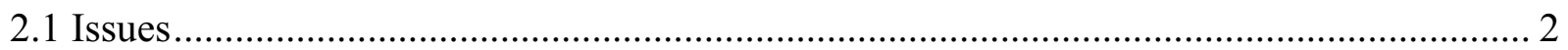

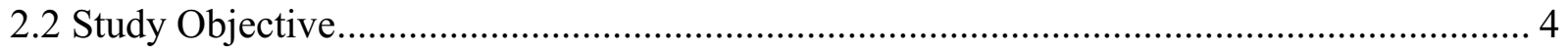

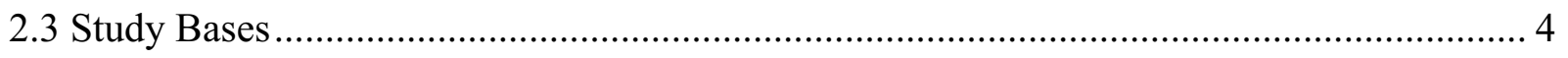

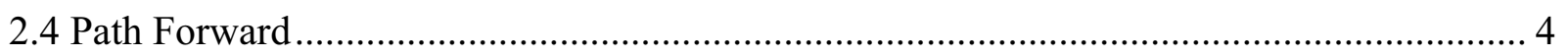

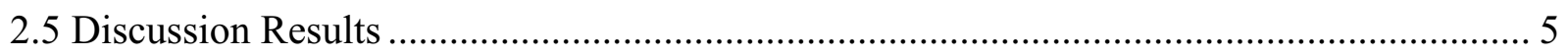

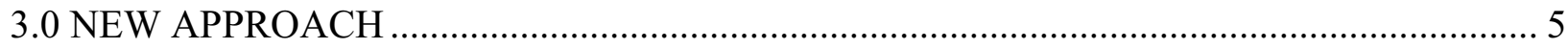

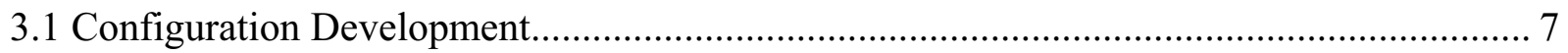

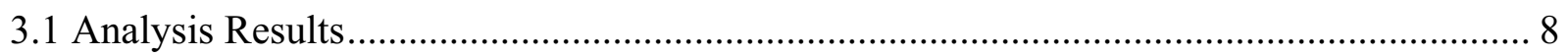

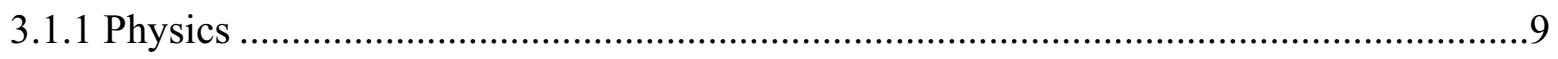

3.1.2 Thermal/hydraulic Analysis.............................................................................13

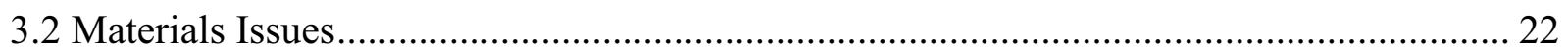

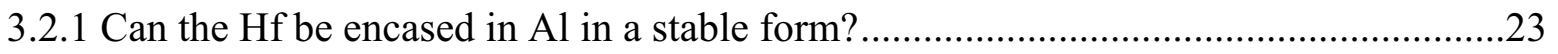

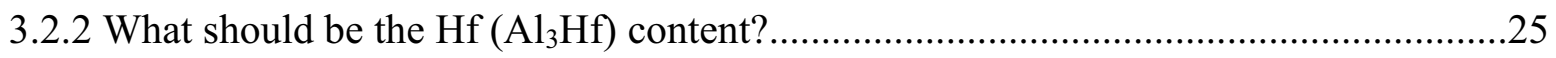

3.2.3 What should be the Hf distribution (particle size and distribution)?...........................25

3.2.4 Can a machinable block of the composite material be fabricated and /or can the block be machined or fabricated with coolant channels? ......................................26

3.2.5 What are the thermal/mechanical properties of the component materials? ..................26

3.2.6 Will the composite be susceptible to corrosion as water passes through it? ................28

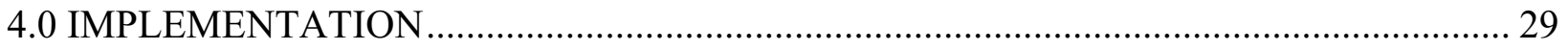

4.1 Secondary Coolant System ……………………….................................................. 29

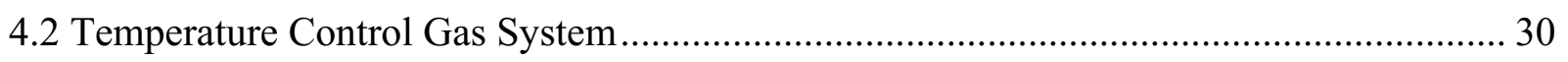

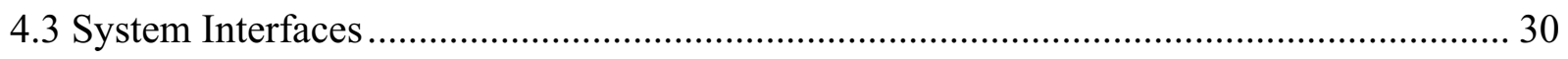

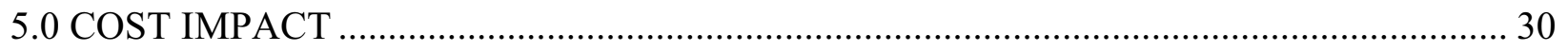

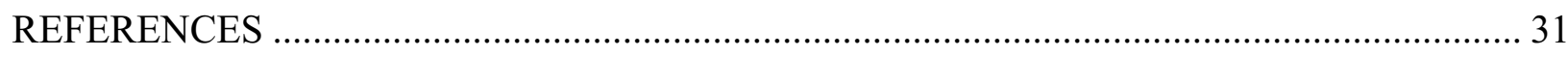

APPENDIX A DETAILED CALCULATIONS USED IN THERMAL ANALYSIS................... 35

APPENDIX B ALTERNATE THERMAL CALCULATIONS.................................................... 45

APPENDIX C TOTAL PROJECT COST SUMMARY ……………........................................ 49 


\section{FIGURES}

Figure 1. Cross section of the Gas Test Loop configuration arrived at during the conceptual design activity. 1

Figure 2. Elements of the gas systems required for the GTL design generated during conceptual design activity.

Figure 3. First configuration of a pressurized water cooled concept for fast flux irradiation testing. 6

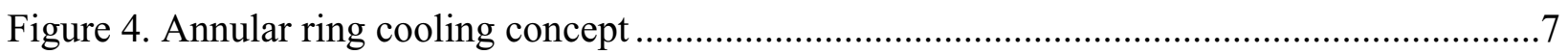

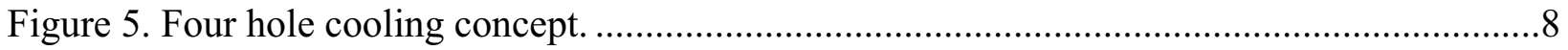

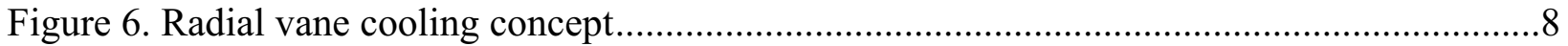

Figure 7. MCNP model of the reference configuration, used to establish a physics baseline. .10

Figure 8. First modification to MCNP model to explore hafnium content effects on performance.

Figure 9. Sensitivity of fast-to-thermal ratio and fast flux intensity to hafnium content in the aluminum central filler piece (absorber).

Figure 10. The heating rate and heat density of the hafnium-aluminum averaged over the central $40 \mathrm{~cm}$ (16 inches) of the core height.

Figure 11. Effect of water presence on the performance of the hafnium-aluminum thermal neutron absorber.

Figure 12. Proposed BFFL Conduction Cooling Configuration (not to scale)

Figure 13. Temperature distribution $\left({ }^{\circ} \mathrm{F}\right)$ on inner surface of envelope tube (base case).............17

Figure 14. Temperature distribution $\left({ }^{\circ} \mathrm{F}\right)$ on outer surface of pressure tube (base case)..............17

Figure 15. Radial temperature distribution $\left({ }^{\circ} \mathrm{F}\right)$ in the heat sink (base case)..............................18

Figure 16. Axial temperature distribution $\left({ }^{\circ} \mathrm{F}\right)$ in the hafnium aluminum absorber (base case).

Figure 17. Temperature distribution $\left({ }^{\circ} \mathrm{F}\right)$ in the oxide layers (base case)................................19

Figure 18. Temperature distribution $\left({ }^{\circ} \mathrm{F}\right)$ in the water coolant (base case). ..............................19

Figure 19. Distribution of surface heat flux $\left(\mathrm{BTU} / \mathrm{s}-\mathrm{in}^{2}\right)$ at the pressure tube (base case)..........20

Figure 20. Distribution of surface heat flux $\left(\mathrm{BTU} / \mathrm{s}-\mathrm{in}^{2}\right)$ at the oxide surfaces (base case).........21

Figure 21. Aluminum-Hafnium Phase Diagram..............................................................24

Figure 22. Free energy of formation of aluminum, uranium, neptunium, and hafnium oxides as a function of temperature. 


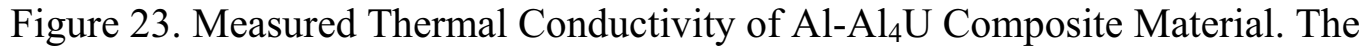
percentage of $\mathrm{Al}_{4} \mathrm{U}$ is presented in at.\%, or vol. $\%$ if the density can be approximated by rule of mixtures of the two elements, $\mathrm{U}$ and $\mathrm{Al}$.

\section{TABLES}

Table 1. ATR power distribution assumed for initial physics calculations.

Table 2. Average heat loads for each model component. ........................................................16

Table 3. Computed water channel outlet temperatures......................................................20

Table 4. Computed maximum surface heat flux.................................................................20

Table 5. Computed water channel outlet temperatures for the alternate (added heat flux) configuration.

Table 6. Computed maximum surface heat flux for the alternate (added heat flux) configuration.

Table 7. Thermal Conductivity of Candidate Materials for Thermal Neutron Absorber

\section{ACRONYMS}

$\begin{array}{ll}\text { ATR } & \text { Advanced Test Reactor } \\ \text { BFA } & \text { Booster Fuel Assembly } \\ \text { BFFL } & \text { Boosted Fast Flux Loop } \\ \text { CD-0 } & \text { Critical Decision 0 (mission need establishment) } \\ \text { DNBR } & \text { Departure from Nucleate Boiling Ratio } \\ \text { FIR } & \text { Flow Instability Ratio } \\ \text { GTL } & \text { Gas Test Loop } \\ \text { HFRI } & \text { High Flux Isotope Reactor } \\ \text { ITV } & \text { Irradiation Test Vehicle } \\ \text { LANSCE } & \text { Los Alamos Neutron Science Center } \\ \text { MTS } & \text { Materials Test Station } \\ \text { NW } & \text { Northwest }\end{array}$




\subsection{BACKGROUND}

In 2004, a Mission Need (CD-0) was established for an augmentation to an existing nuclear facility that would enable the testing of advanced reactor fuels and materials under fast-flux irradiation conditions.[1] The Gas Test Loop (GTL) Project was established at the Idaho National Laboratory in response to that need. Technical and Functional Requirements[2] were developed for a system that would accomplish the mission identified in the Mission Need document.

A survey was subsequently performed of a large number of reactors and accelerators where such a capability could be developed.[3] After a preliminary review, five facilities were considered for a more detailed evaluation. These included the JOYO fast reactor in Japan, the BOR-60 in Russia, the High Flux Isotope Reactor (HFIR) at Oak Ridge National Laboratory, and the Advanced Test Reactor (ATR) at the Idaho National Laboratory as well as the proposed Materials Test Station (MTS) at the LANSCE accelerator at Los Alamos National Laboratory. The conclusion of this investigation was that the facility best suited to meeting the established functional requirements was the ATR.

The conceptual design of the GTL, based on using one of the ATR corner lobes, was initiated in 2005. The conceptual design report[4] showed that of the more than 20 different configurations examined, the design with the best performance was the one shown in Figure 1 below.

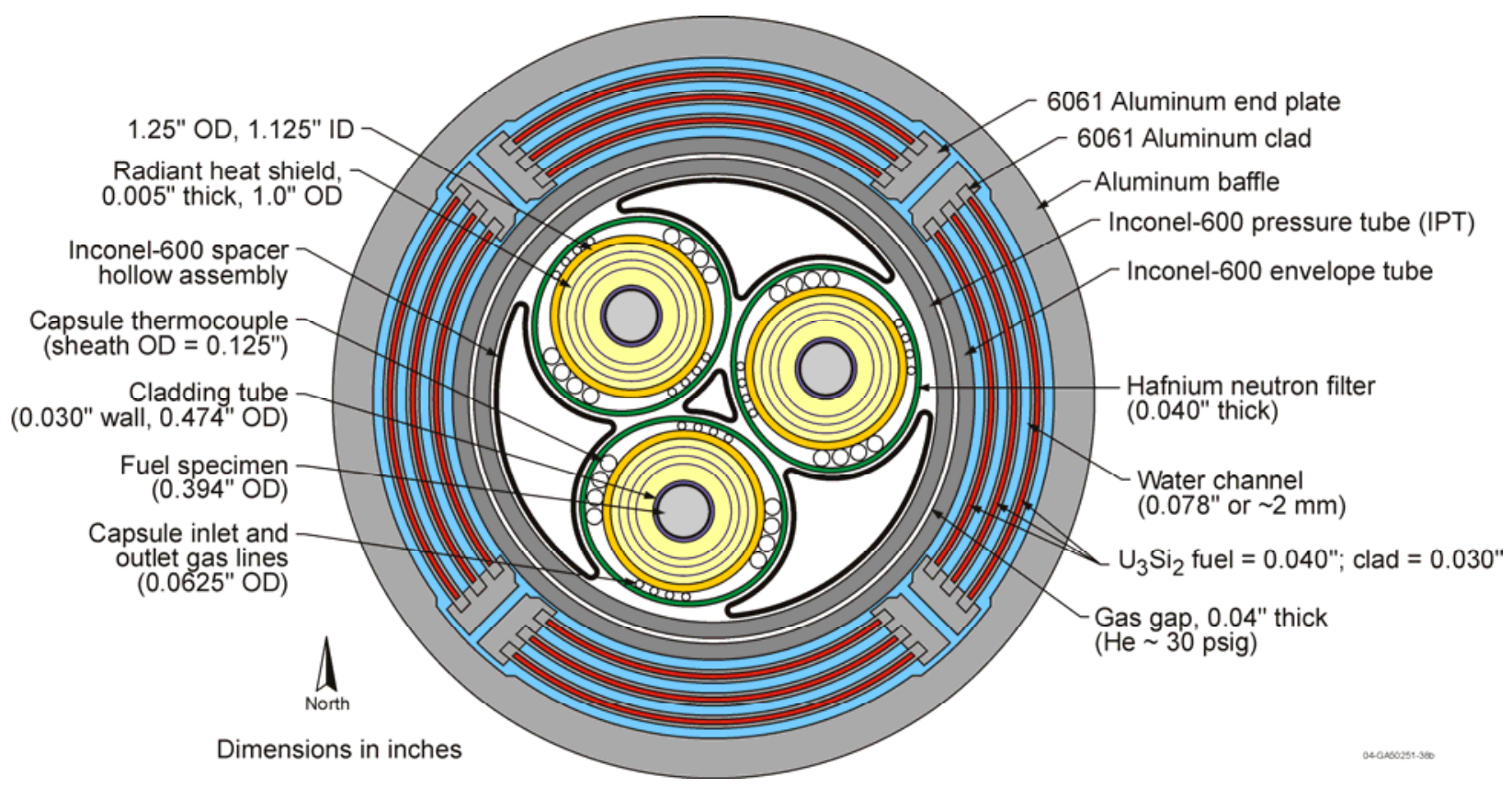

Figure 1. Cross section of the Gas Test Loop configuration arrived at during the conceptual design activity.

Main features of that design included the booster fuel located inside the lobe flow baffle, a double in-pile tube pressure boundary, three experimental positions each surrounded by a hafnium filter for capturing thermal neutrons, and two associated gas systems. The first gas 
system was for temperature control through a variable conductance gas gap. That gap is indicated in Figure 1. The second was a pressurized helium system for removing heat generated in the experiment targets and the hafnium filter. It passed through the central region of the experiment chamber, as shown in Figure 1, but much of the central region volume was filled with a gas displacer, allowing the cooling gas to flow over the hot surfaces at much higher velocities and thus be more efficient in removing the heat.

The overall system configuration is shown in Figure 2, illustrating the elements of the gas cooling system and the other significant components of the design.

The estimated cost of the GTL system was between $\$ 85 \mathrm{M}$ and $\$ 100 \mathrm{M}$. While that is relatively expensive for a fuel development program to support, it is much less than the cost of a new fastflux test reactor. It could also be brought on line in approximately 5 or 6 years, which is much faster than a new test reactor can be built. It would provide a fast-flux test capability in the time before a fast-flux research reactor could be built. That notwithstanding, support for the GTL concept was sparse, in part because of its relatively high cost.

A review of the cost estimate basis showed that approximately $30 \%$ of the total system cost was associated with the gas systems. It was supposed that if a way could be found to remove the heat from the experiment chamber that did not involve the pressurized gas system, the overall project cost could be reduced substantially, and the concept would be more attractive to potential users.

This report documents the results of the investigation into an alternately cooled version of the GTL. For definiteness, this system is referred to as the Boosted Fast Flux Loop (BFFL). In the sections that follow will be presented the methods used in seeking for an alternately cooled approach, the results of that search, physics and thermalhydraulic analyses to assess the functional viability of the concept arrived at, materials and fabrication concerns, and a discussion of the cost impact this configuration may have on the establishment of a fast-flux test capability in the ATR.

\subsection{APPROACH}

This section presents the approach used in arriving at an alternately cooled concept. It begins with the issues faced, the objective definition, and bases used for concept deliberations.

\subsection{Issues}

Conflicting technical requirements led to the selection of pressurized gas as the experiment coolant in the original GTL design. One requirement is that in order to have a good fast-tothermal neutron flux ratio, there must not be any significant neutron thermalizer between the hafnium filter and the experiment target. Water, which is typically used as a heat sink in the ATR, is a strong thermalizer. Another requirement is that we meet the fast flux intensity goal. This means substantial heating of the targets, particularly if they are fuel targets, as well as a large amount of heat being generated in the hafnium filter from the $(n, \gamma)$ neutron absorption reactions. That heat must be carried away to limit experiment temperatures. A final consideration is ATR operating safety and the concern that exists about use of liquid metals and molten salts in the ATR reactor. 


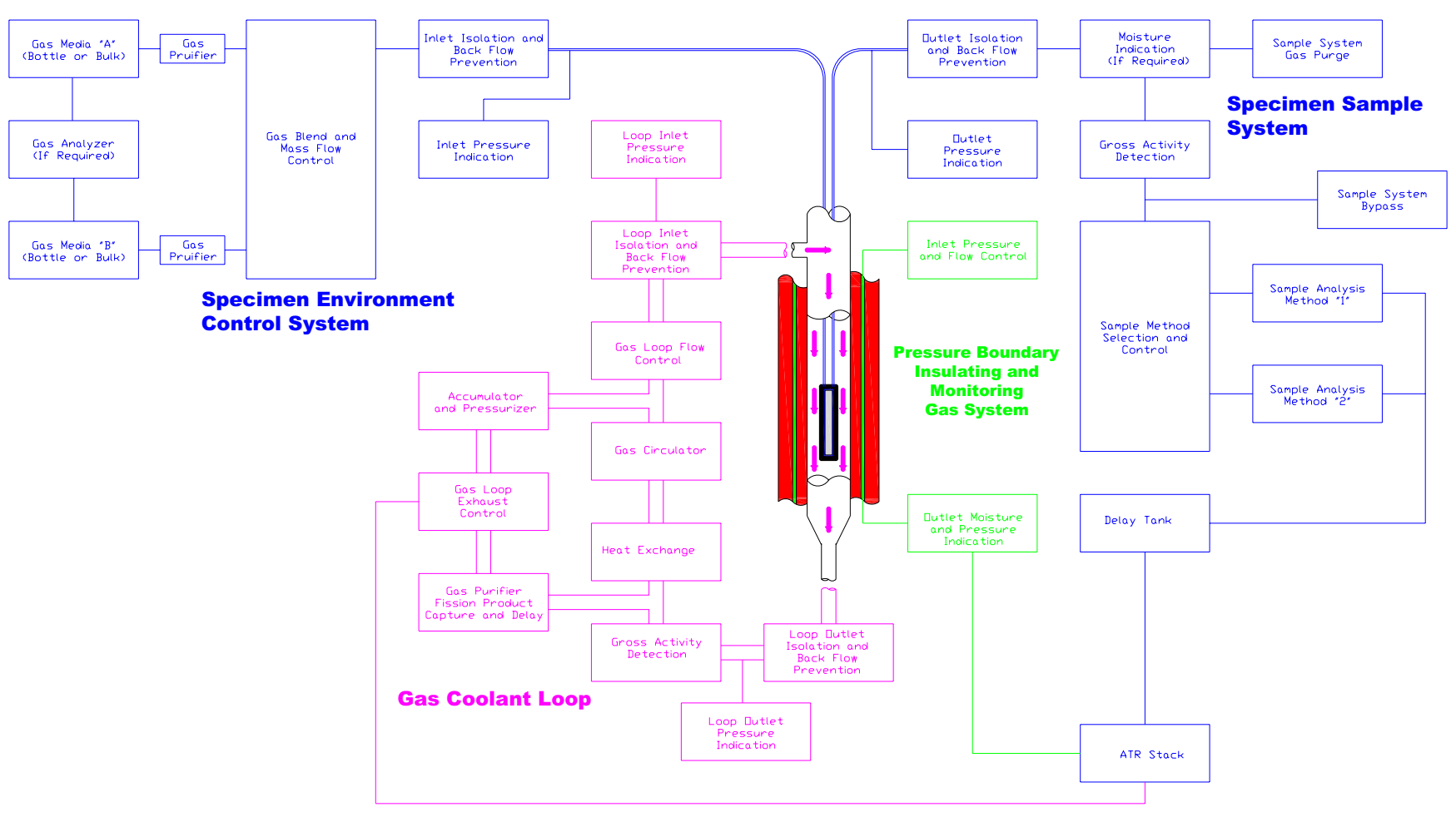

Figure 2. Elements of the gas systems required for the GTL design generated during conceptual design activity. 


\subsection{Study Objective}

The specific objective of this study was to see if it is possible to adequately cool the experiments using some means of experiment cooling other than pressurized gas.

\subsection{Study Bases}

To provide a point of departure for this study, it was assumed, that BFFL will be located in an ATR large flux trap and retain the booster fuel configuration shown in Figure 1. This booster fuel configuration was determined through rather extensive comparisons to provide the most optimal generation of the high flux intensity needed to achieve BFFL performance targets.

This assumption fixed the outer diameter of the in-pile tube that will be needed to contain the experiment. That diameter is $9.128 \mathrm{~cm}$ (3.593 inches). If an in-pile tube provides a pressure boundary for the primary coolant, it must be a double boundary, and existing engineering codes and standards will need to be applied in its design.

It was assumed that the primary BFFL users will be developers of advanced fuels and materials such that typical experiments will consist of fuel specimens, nominally $1 \mathrm{~cm}$ in diameter and with axial heating rates up to $2.3 \mathrm{~kW} / \mathrm{cm}(70 \mathrm{~kW} / \mathrm{ft})$ with a total heat load from test articles to be up to $200 \mathrm{~kW}$ (see Ref. 2). Cooling needed to be capable of maintaining test article surface temperatures at $500^{\circ} \mathrm{C}$ but the cooling system should be compatible with $1,100^{\circ} \mathrm{C}$ as a possible test article surface temperature (if it is practical).

For economy of operation, the original design had 3 parallel test columns. While this was desirable to maintain, this study also looked at a different number of test columns to evaluate feasibility.

While hafnium is a very attractive thermal neutron filter because of the many sequential absorption reactions it undergoes, it was not required that it be maintained as the filter material. However, some kind of filter was required to keep the fast-to-thermal ratio greater than 15.

There are specific guidelines as to material limitations in the ATR [5] Potential designs should be screened against materials acceptance criteria to be sure that no design would compromise ATR operational safety.

\subsection{Path Forward}

The first step was to become creative and synthesize alternative configurations that may provide the needed performance. This was aided by a review of work that has been done in the past, as documented in Ref. [4] and other project documents and files. Concept synthesis was initiated in a brainstorming session.

The plan was that concepts developed should then be reduced to sketches with specified dimensions and materials.

Neutronics codes such as MCNP should then be exercised to determine flux levels achieved with those designs and material heating rates.

Thermal/hydraulic analyses should be performed on the designs with appropriate heating rates and heat transfer parameters to determine the ability of each design to meet the required 
performance. Analysis tools that were thought to be particularly useful for thermal/hydraulic analyses include RELAP-5 and ABAQUS.

Findings of these investigations were discussed in follow-up meetings. While some variations in design were recommended, it was not necessary to initiate further iterations of the basic design process.

\subsection{Discussion Results}

The first meeting to synthesize a new concept was held on May 9, 2007. After reviewing the meeting objectives, participants first reviewed the current design and the considerations that led to it.

They discussed possible cooling schemes. There are only two ways to get the heat out of the test specimens and the hafnium filter: convection and conduction. Radiation can play a non-trivial role at high target temperatures.

Convection requires a fluid. A number of fluids were discussed including molten metal, molten salt, gases other than He, organics, and water. It was supposed that the cost of molten metal or molten salt systems would be comparable to or greater than that of pressurized gas systems. Furthermore, there are safety concerns about putting into the reactor any fluid that could react with the primary coolant, and it did not appear practical to make use of a fluid that must be kept hot to prevent structural damage. When working with gases, convective performance is the product of mass flow rate and specific heat. The molar specific heats of most gases are not very different and don't really change until high temperatures excite rotation and vibration modes, which do not exist in noble gases. The volumetric specific heat is increased by pressurization. Hence the way to increase cooling is to increase flow. High temperature gas reactors (Ft. St. Vrain for example) have experienced major problems with circulators and other components. Even though there are a few gas-cooled reactors operating outside the U.S., it seemed prudent to look elsewhere than gas convection for this application. There may be support from other programs or projects to participate in developing gas system technology that could be used, but they were not to be counted on.

The most viable liquid for use in ATR seemed to be water, where a major concern is fast neutron thermalization.

Basic problems with conduction have included getting the heat from the experiment specimens and the hafnium out through the pressure boundary. This is driven in large measure by conduction gaps at material interfaces. This is usually mitigated by increasing surface area available for heat transfer and providing thermal bonding agents.

\subsection{NEW APPROACH}

With the above points in mind, it was suggested that we may be able to use a novel approach that involves both conduction and water convection. The first implementation of this concept is shown graphically in Figure 3.

The key to this approach is the use of a novel material for the basic fill of the test space. This would be a hafnium-aluminum composite, manufactured from powder of either hafnium, hafnium aluminide intermetallic, or hafnium oxide, mixed with aluminum powder and pressed or 
extruded. This material would retain the high thermal conductivity of aluminum but have the thermal neutron absorption properties of hafnium. We would have to determine what the best hafnium loading would be, but from a materials perspective, there should be no major technological barrier to making it.

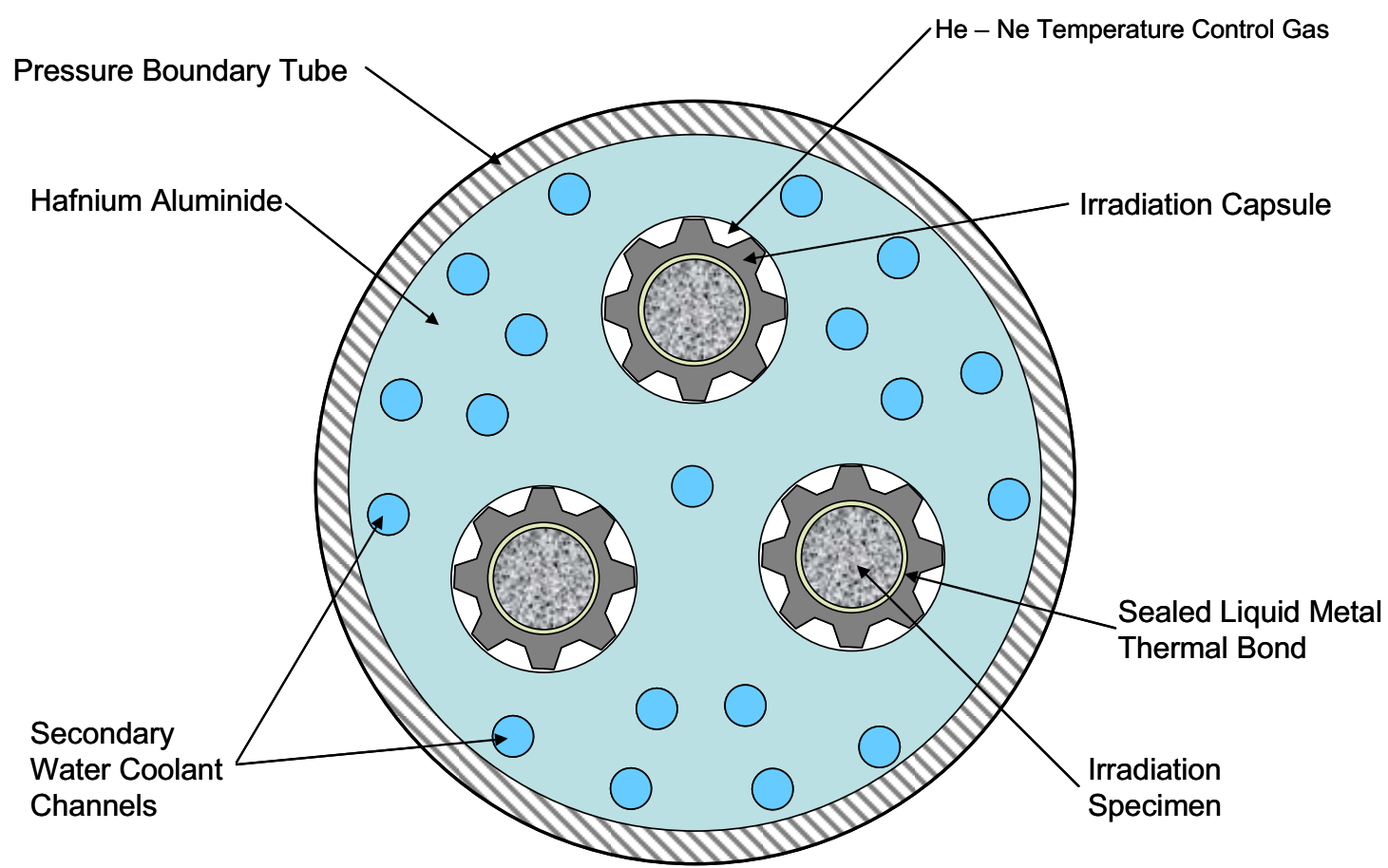

Figure 3. First configuration of a pressurized water cooled concept for fast flux irradiation testing.

An early concept was that the hafnium aluminum would be penetrated by small ( $6-\mathrm{mm})$ cooling channels of pressurized water from a secondary cooling system. These cooling channels would need to be located sufficiently far from the irradiation capsules that the hafnium in the matrix would provide adequate absorption of thermal neutrons born in the water channels. Earlier analysis showed that as little as 1-mm of solid Hf would provide adequate filtering. Therefore, if the $\mathrm{Hf}$ in the matrix were $10 \%$ atomic fraction, then $10 \mathrm{~mm}$ spacing should be adequate. A key to performance for heat removal is the high thermal conductivity of the aluminum in the hafnium aluminum. This could carry the heat to the cooling channels with only small temperature gradients, resulting in more or less circumferentially uniform cooling of the experiments.

It was pointed out that there is already a task in progress to restore the pressurized water system in the $2 \mathrm{~A}$ cubicle, as part of the INL master contract agreement. There is no particular customer identified for this system, except that it is to be used to restore testing capability to the ATR. Another, possibly less expensive option is to make use of the pressurized water system already serving the ATR NW Lobe.

Another important issue is the transfer of heat to the hafnium aluminum absorber. We supposed that the fuel would be thermally bonded to the experiment capsule using molten metal, such as $\mathrm{Na}$ or Li. This is done routinely in other ATR fuel experiments. The capsule will need to be 
made of a more or less refractory metal, such as Inconel to withstand the high temperatures of anticipated fuel experiments. At issue, then, is heat transfer from the capsule to the hafnium aluminum absorber and the ability to apply temperature control. Shown in Figure 3 is a configuration only representative of the approach. The basic conduction would be provided through thick fins or lands that would have a close tolerance fit to the aluminide. Trim in conductance would be provided by a standard $\mathrm{He}-\mathrm{Ne}$ gas mixture that would be slowly flowed through the gaps (shown exaggerated in thickness in Figure 3) between the fins or lands. Considerably more thermal analysis was needed to determine land width and number, gap spacing and such things. If needed, the fins or lands could fit into conforming grooves in the hafnium aluminum, like a spline gear set, to provide greater area for heat transfer to take place. Mechanical issues of separating the temperature control gas mixture from the secondary coolant water would need to be dealt with, but should not be overly difficult. It was also noted that the architecture of a multi-channel temperature control gas system is being designed by the TMIST project and the BFFL would only need to populate the basic framework with specific mass flow controllers, etc. to have a functioning system. Another option is the restoration of the Irradiation Test Vehicle (ITV) [6] gas temperature control system.

An interesting and novel suggestion was that if heat transfer from the capsules to the hafnium aluminum is rate limiting, it may be possible to make use of a heat-pipe effect to distribute heat vertically along the experiment such that it could enter the hafnium aluminum in regions well above or below the core mid-plane where heating will be much less. It is likely that many experiments would only make active use of the few inches above and below the mid-plane to achieve vertical flux uniformity in the test specimens.

\subsection{Configuration Development}

As thermal and physics analyses were conducted, three additional cooling configurations were examined. These are shown in Figures 4 to 6 . A fourth additional concept is a combination of the annular ring and four-hole concepts (Figures 4 and 6).

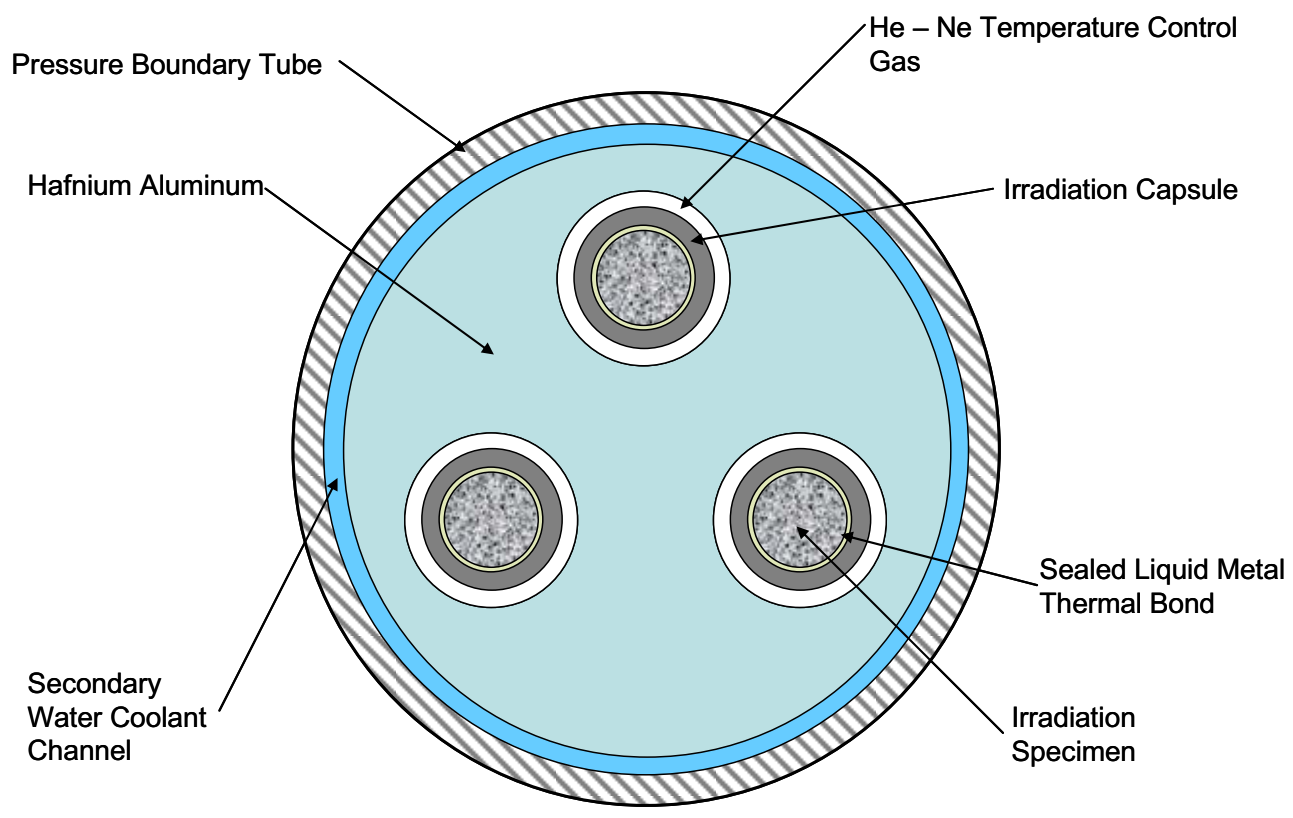

Figure 4. Annular ring cooling concept 


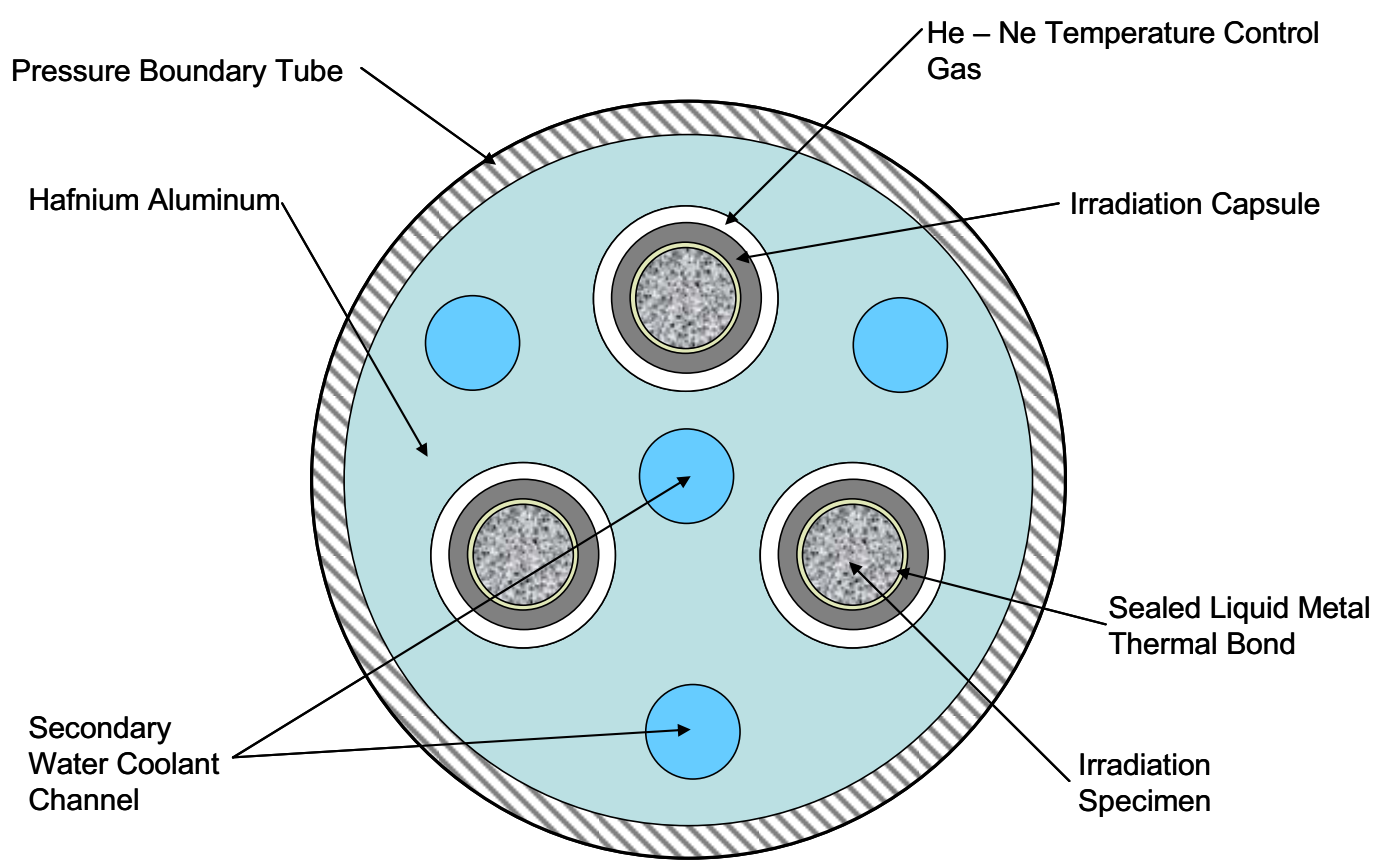

Figure 5. Four hole cooling concept.

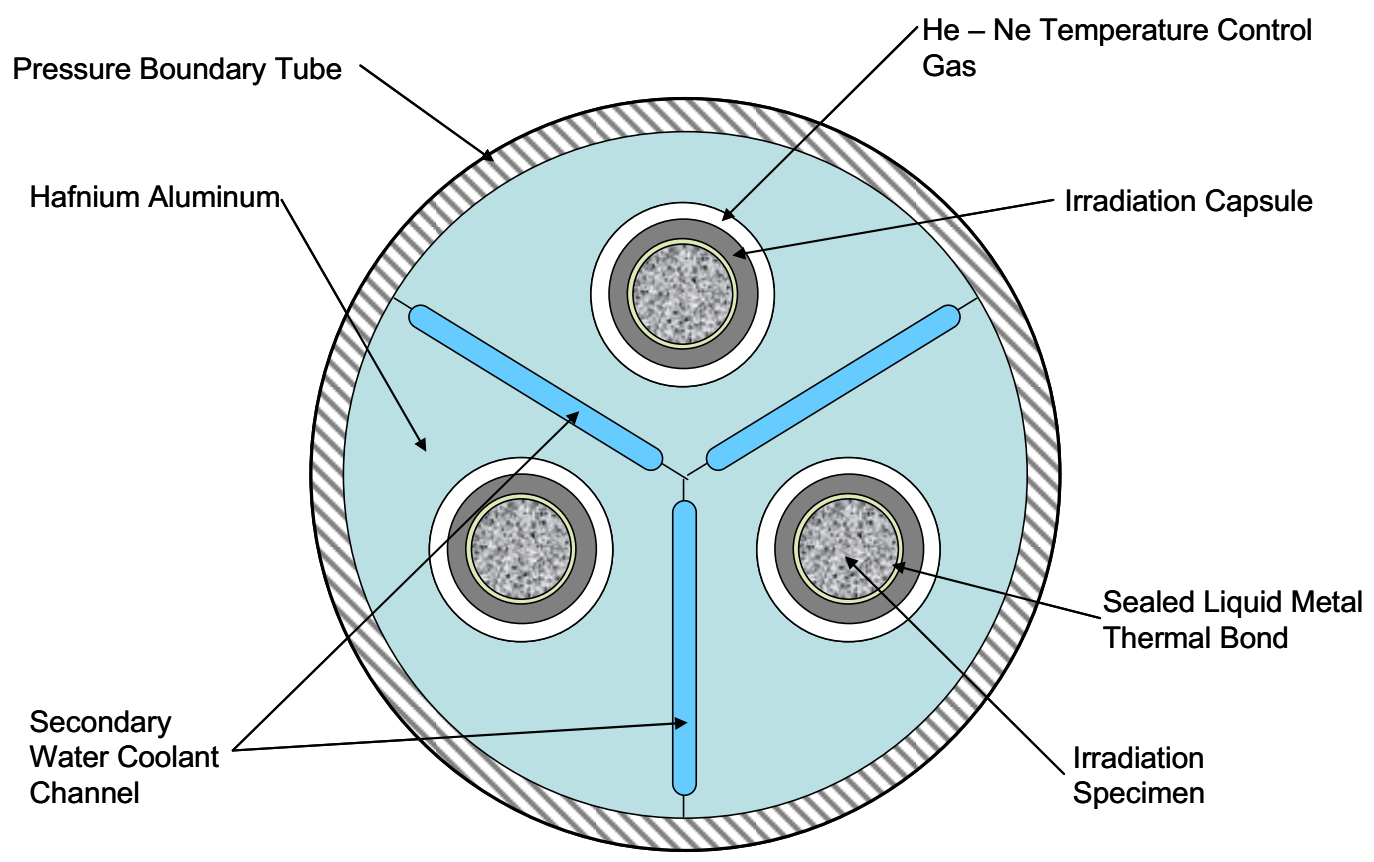

Figure 6. Radial vane cooling concept.

\subsection{Analysis Results}

With basic configurations in mind, the next step was developing and exercising numerical models of these structures to examine physics issues of criticality and neutron flux intensity, and heating rates for the targets and neutron absorbing material. 


\subsubsection{Physics}

Physics analyses were performed with the objective of determining the optimum hafnium content in the aluminum neutron absorber and determining heating rates in the structure. The first physics analysis was performed on a configuration identical to that of Figure 1, used as a baseline or starting point. That model had the following features relative to previous ones that had been used.

- Removed Hf filter from the outside of the pressure tube, increasing envelope tube thickness to compensate.

- Changed Booster Fuel Assembly (BFA) plate loadings to 1.7, 3.0, and $4.8 \mathrm{gU} / \mathrm{cc}$.

- Reduced thickness of inner plate fuel meat from $1.52 \mathrm{~mm}(0.060$ inch $)$ to $1.01 \mathrm{~mm}$ (0.040 inch).

- Added $1 \mathrm{~mm}$ Inconel 600-clad Hf ellipse around each experiment tube. (The ellipses are 0.5 -mm Hf with $0.25 \mathrm{~mm}$ thick clad inside and out.)

- Replaced the material for the envelope and pressure tubes with Inconel 600.

- Replaced Al spacers with hollow (0.5-mm/0.020-inch wall) Inconel 600.

- Adjusted envelope and pressure tube dimensions to be closer to minimum required thicknesses - both are 0.125 in $(0.2921 \mathrm{~cm})$.

- Experiment tubes were equally spaced on a $1.795 "$ circle.

- BFA has 2-mm (0.079-inch) gap between sideplates, 5.76-mm (0.227-inch) sideplates, and 2.41-mm (0.095-inch) gap between sideplate and fuel meat.

- Added gas lines and thermocouple tubes in test region.

The cross section of that model as implemented in MCNP is shown in Figure 7.

MCNP5 Version 1.40, a monte-carlo neutronics code, was used in the analysis.[7] Its use has been validated at the INL. It was run on the Helios computer cluster at INL. Reactor lobe powers were assumed as shown in Table 1. This is the same reference case used in prior calculations using this baseline GTL configuration (Figure 1).

Table 1. ATR power distribution assumed for initial physics calculations.

\begin{tabular}{|c|c|c|}
\hline Lobe & Power (MW) & Fraction \\
\hline NW & 52.36 & $37.4 \%$ \\
\hline NE & 15.21 & $10.9 \%$ \\
\hline C & 33.68 & $24.1 \%$ \\
\hline sW & 20.50 & $14.6 \%$ \\
\hline SE & 18.25 & $13.0 \%$ \\
\hline Total & 140 & $100.0 \%$ \\
\hline
\end{tabular}




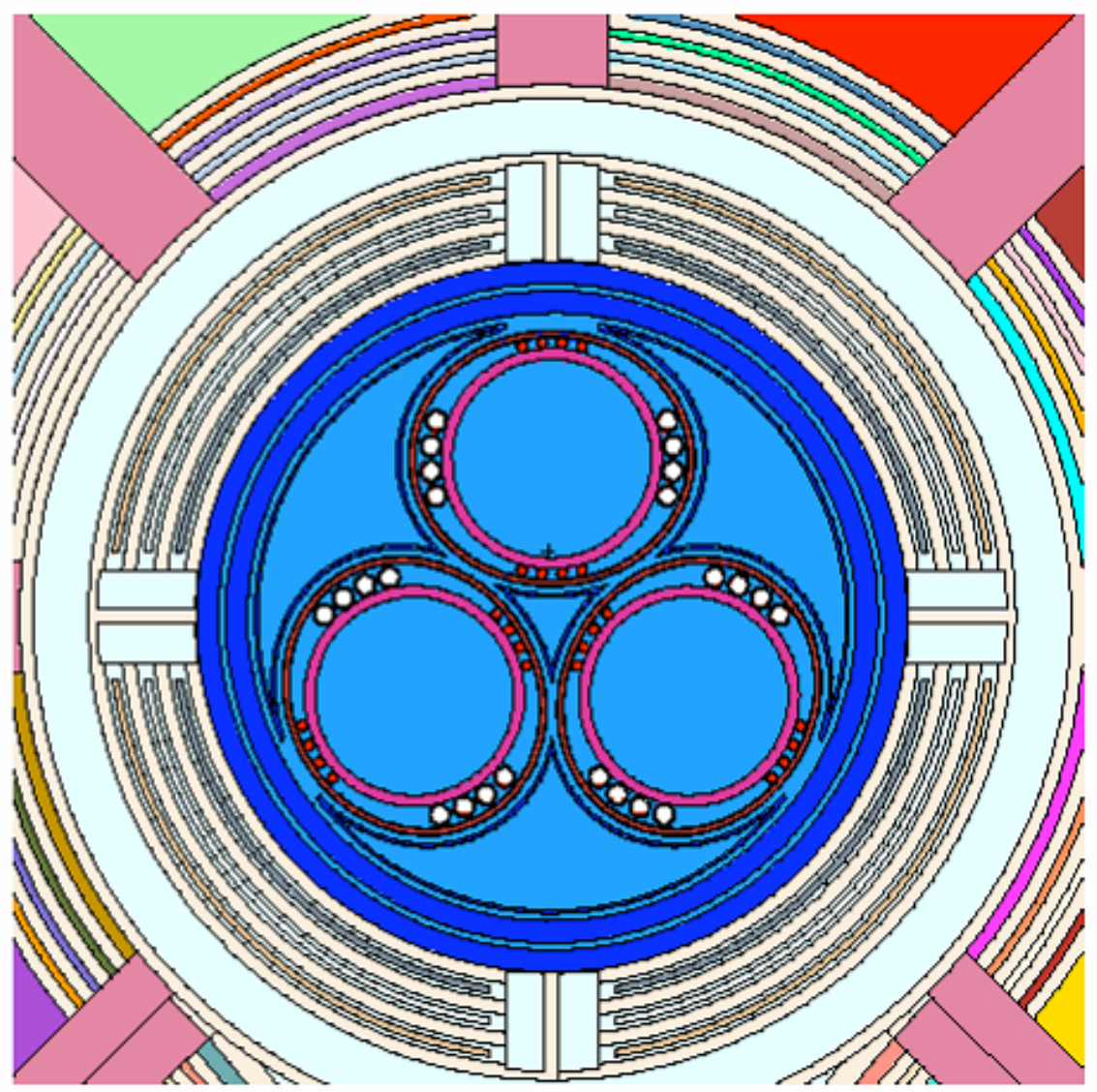

Figure 7. MCNP model of the reference configuration, used to establish a physics baseline.

This baseline configuration was found to have a fast flux (E . 0.1 MeV) in the experiment volumes of $1.03 \mathrm{E}+15 \mathrm{n} / \mathrm{cm} 2-\mathrm{s}$ and a fast-to-thermal ratio $(\mathrm{E}>0.1 \mathrm{MeV} / \mathrm{E}<0.68 \mathrm{eV})$ of 43 .

The model of Figure 7 was then modified as follows:

- Replaced interior structures in the target regions with solid aluminum structures

- Started with solid aluminum in the spaces between the test chambers and only helium in the gas gap (no experiments, thermocouples, etc.)

- No Hafnium sleeves on the experiment chambers

The modified MCNP model is shown in Figure 8. Among the parameters calculated were the fast-to-thermal ratio and the fast flux intensity averaged over the central $40 \mathrm{~cm}$ (16 inches) of the core height. Figure 7 shows how those quantities vary with hafnium content (number fraction) in the aluminum.

These calculations gave a fast flux of $1.04 \mathrm{E}+15 \mathrm{n} / \mathrm{cm} 2-\mathrm{s}$ and a fast-to-thermal ratio of 20.4 even with no hafnium in the aluminum filler. The high fast-to-thermal ratio appears to be a consequence of having the booster fuel close to the experiment chambers and the absorption of thermal neutrons by the Inconel 600 .

The model of Figure 8 was then modified by adding in increments hafnium to the aluminum filler surrounding the test spaces. Results are shown in Figure 9. 


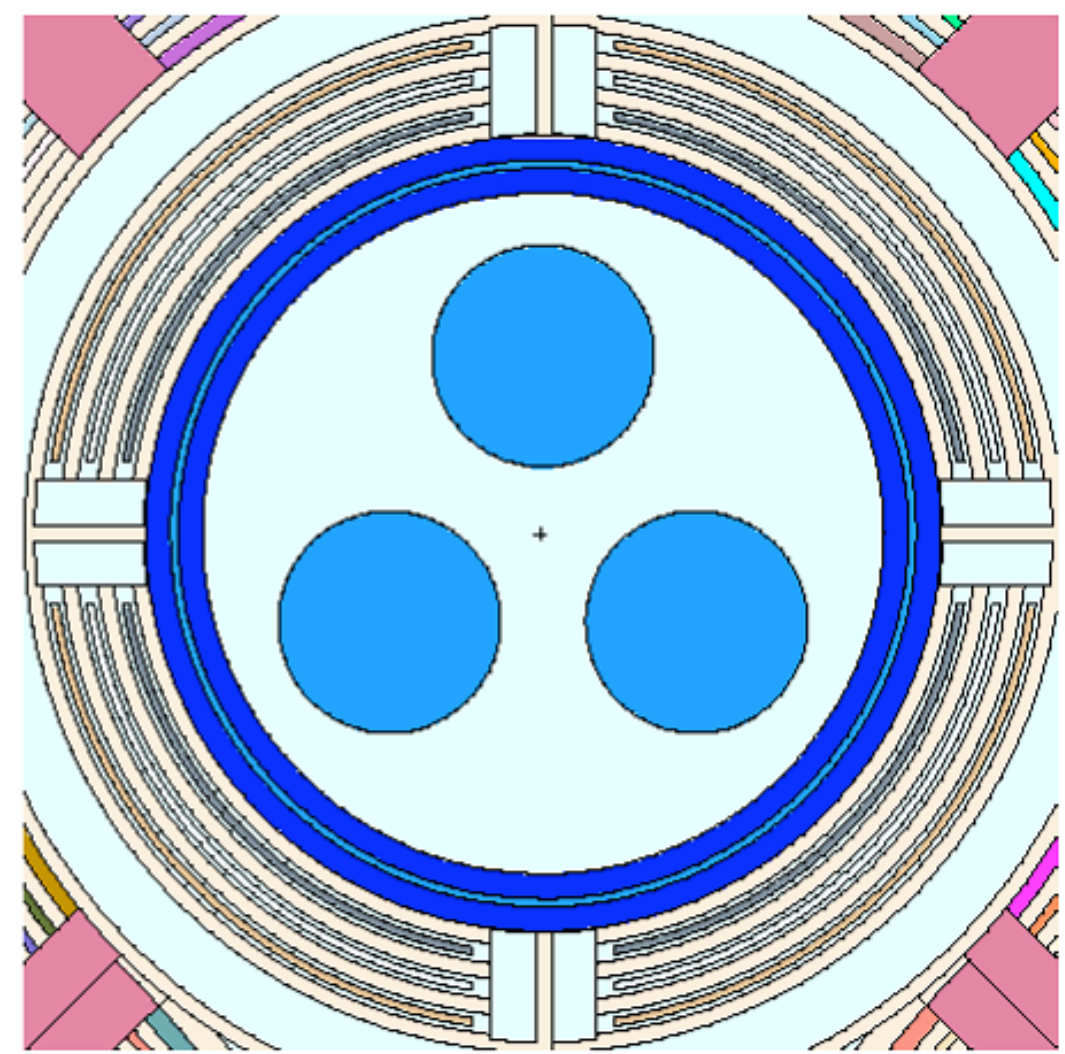

Figure 8. First modification to MCNP model to explore hafnium content effects on performance.

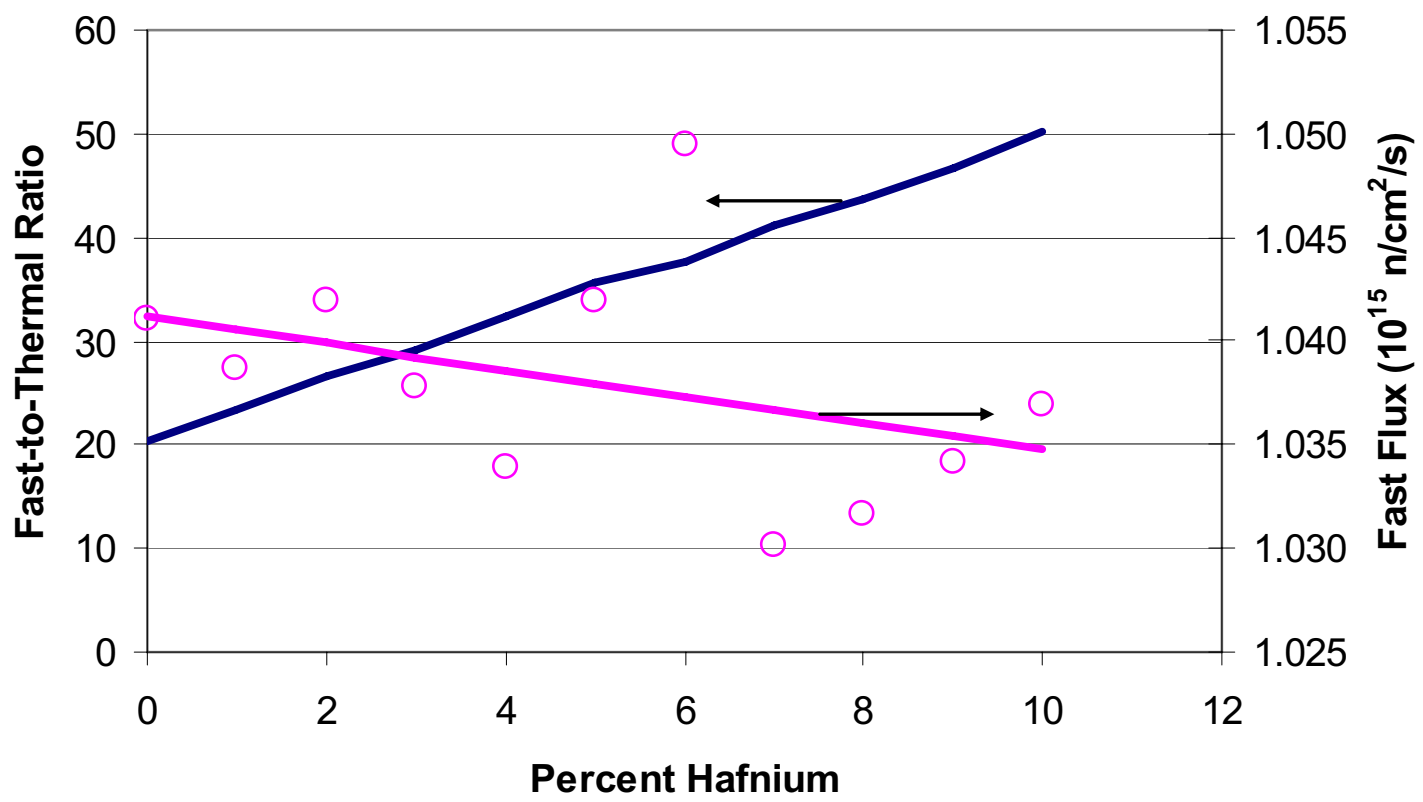

Figure 9. Sensitivity of fast-to-thermal ratio and fast flux intensity to hafnium content in the aluminum central filler piece (absorber). 
It is intuitive that the greater the presence of hafnium in the aluminum, the greater would be the fraction of thermal neutrons that are removed. It is likewise intuitive that the greater the presence of hafnium, the fewer neutrons generally will enter the target regions. The data points in the fast flux results show considerable scatter about the best fit line. This scatter is a consequence of numerical convergence error in the code, but the line shown should be consistent with the actual flux.

Heating rates in the hafnium-aluminum were also calculated as a function of the hafnium concentration in the absorber. These rates are shown, averaged over the central $40 \mathrm{~cm}$ (16 inches) of core height, in Figure 10. The actual vertical heat profile will be a chopped cosine function, following the neutron flux intensity. The heating rate, a measure of neutron absorption, appears to saturate at about $6-7 \%$ hafnium, which suggests that may be an optimum hafnium loading. Volumetric heating density continues to increase with increasing hafnium loading as more and more thermal neutrons are captured because of the greater abundance of hafnium in the absorber. This appears to saturate at a hafnium concentration of $12 \%$ (1/e value $3.4 \%$ ) at a heating density of $52 \mathrm{~W} / \mathrm{cm}^{3}$, when effectively all of the thermal neutrons are absorbed.

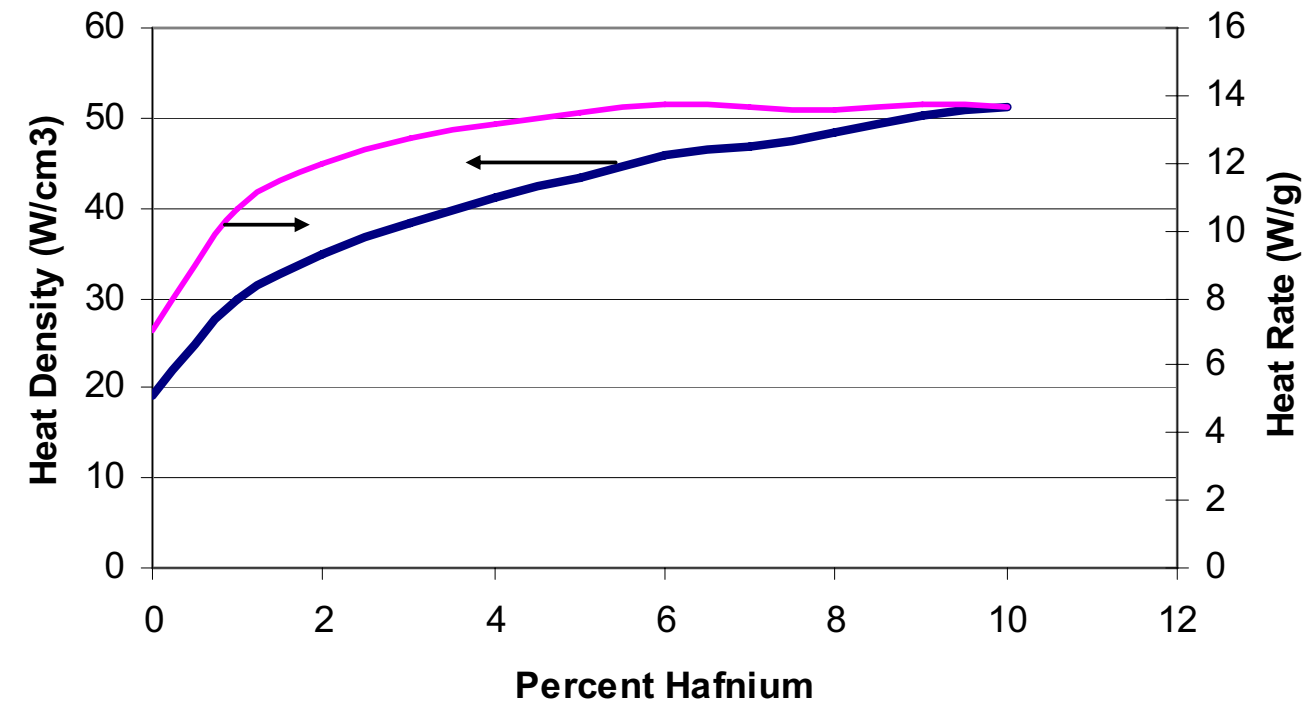

Figure 10. The heating rate and heat density of the hafnium-aluminum averaged over the central $40 \mathrm{~cm}$ (16 inches) of the core height.

A second series of calculations sought to evaluate the extent to which the amount of water in the cooling channels would influence the performance of this configuration. These calculations were performed on each of the configurations shown in Figures 4 through 6 . Results are plotted in Figure 11 as a function of the cross sectional area of water in the figures. It did not seem to make much difference which configuration was used in comparison with the total amount of water in the system.

It is clear from Figure 11 that the more the water in the system, the less is the fast neutron flux. This is a natural consequence of the thermalizing effect of the water on neutron energies. The fast-to-thermal ratio also declines with increasing water in the system. Again, more water 


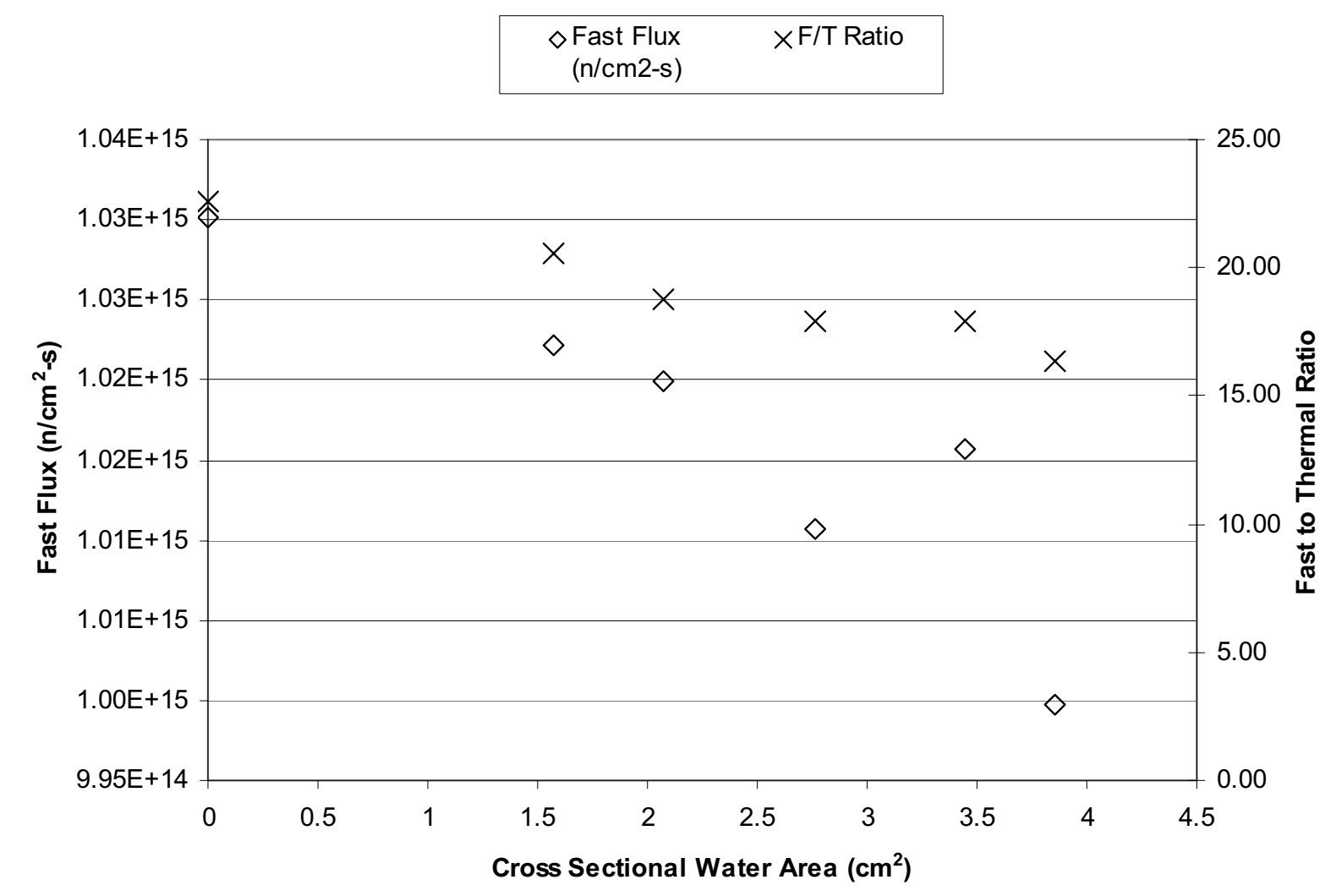

Figure 11. Effect of water presence on the performance of the hafnium-aluminum thermal neutron absorber.

reduces the number of fast neutrons available because of thermalization. Absorption of thermal neutrons is effectively constant.

It is concluded from these calculations that it is possible to achieve the same level of performance in the alternatively cooled concept as was estimated in the original gas-cooled concept, namely a fast flux in excess of $1.0 \mathrm{E}+15 \mathrm{n} / \mathrm{cm} 2-\mathrm{s}$ and a fast-to-thermal ratio in the vicinity of 40. It appears further that a hafnium atom fraction in the vicinity of $7 \%$ may be optimal. Finally, the configuration of the water cooling channels does not appear to make much difference in the neutronic performance in comparison with the amount of water inside the pressure boundary.

\subsubsection{Thermal/hydraulic Analysis}

\subsubsection{Model Setup and Boundary Conditions}

A thermal hydraulic model of one BFFL configuration was constructed and evaluated to determine whether the proposed configuration is capable of cooling a set of experiments located in the NW Lobe of the ATR. A model was created using ABAQUS version 6.6-3 [8] to determine component temperatures. The conductive cooling system consists of the following components:

- Conduction heat sink and thermal neutron absorber 
- Coolant channels

- Envelope tube

- Pressure tube

- Helium gas gap

- Oxide layers

Figure 12 illustrates the BFFL configuration that was analyzed. A conduction heat sink fabricated from a Al-7 wt\% $\mathrm{Hf}$ alloy serves a dual role as a neutron filter and a medium to conduct heat away from the experiments. The heat sink surrounds three $3.17-\mathrm{cm}(1.25$-inch) diameter experiment tubes situated on a 4.56-cm (1.795-inch) circle. Four 6.35-mm (0.25-inch) diameter water coolant channels are located within the heat sink. Three of the water channels are positioned 120 degrees apart on a 3.09-cm (1.22-inch) circle and the fourth water channel is located at the center. A $0.762-\mathrm{mm}(0.030$-inch) water annulus is located between the heat sink and the pressure tube. Oxide layers $(12.7 \mu \mathrm{m}, 0.0005$ inch thick) are assumed to be present on the surfaces of the heat sink exposed to the water coolant. An envelope tube $(9.591-\mathrm{cm}$, 3.776-inch ID; $10.226 \mathrm{~cm}, 4.026$ inch OD) surrounds the pressure tube $(8.753-\mathrm{cm}, 3.446$-inch ID; $9.388-\mathrm{cm}, 3.696-$ inch OD) with a $1.016-\mathrm{mm}$ (0.040 inch) helium gas gap in between for the purpose of leak detection monitoring. Both tubes are constructed of $3.175-\mathrm{mm}(1 / 8$-inch) thick Inconel-600.

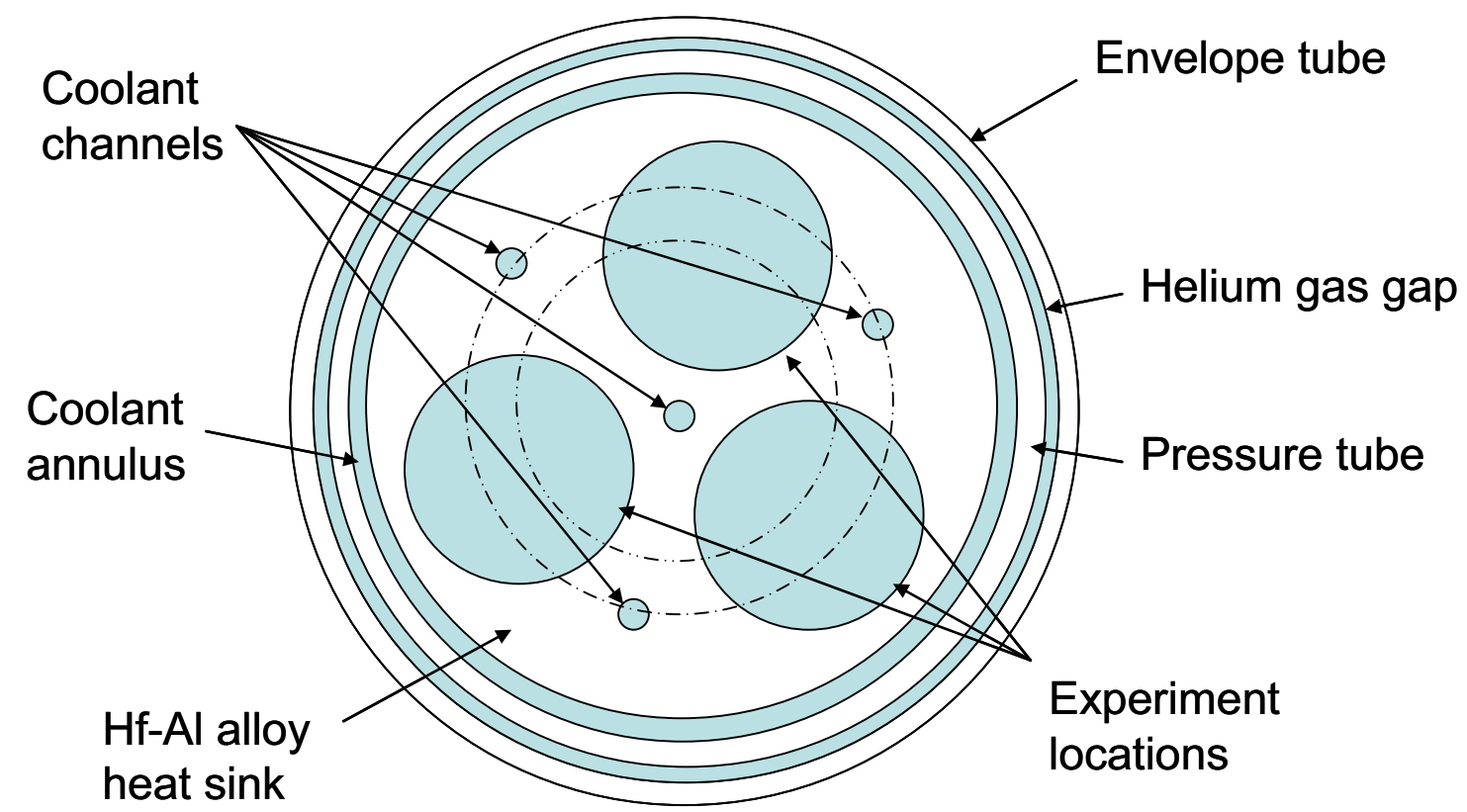

Figure 12. Proposed BFFL Conduction Cooling Configuration (not to scale).

The envelope tube, pressure tube and oxide layers were modeled as shells. The water channels, water annulus and heat sink were modeled as 3D solids. The 3D model is comprised of 115,592 elements. All components in the model have a length of $1.219 \mathrm{~m}$ (48 inches).

Coolant water to the annulus and cylindrical water channels is supplied by the $2 \mathrm{~A}$ pressurized water loop at $12.4 \mathrm{MPa}(1800 \mathrm{psia})$. The inlet water temperature and component initial temperature are assumed to be $110^{\circ} \mathrm{C}\left(230^{\circ} \mathrm{F}\right)$. Coolant flows through the annulus at a flow rate 
of $90 \mathrm{~L} / \mathrm{min}(23.8 \mathrm{gpm})$ and through the water holes at $116.9 \mathrm{~L} / \mathrm{min}(30.9 \mathrm{gpm})$. The annulus and water channel mass flow rates are specified as $0.687 \mathrm{~kg} / \mathrm{s}-\mathrm{cm}^{2}\left(9.76 \mathrm{lbm} / \mathrm{s}-\mathrm{in}^{2}\right)$ and $1.464 \mathrm{~kg} / \mathrm{s}-$ $\mathrm{cm}^{2}\left(20.81 \mathrm{lbm} / \mathrm{s}-\mathrm{in}^{2}\right)$, respectively. The total volume of water is $4.076 \times 10^{-4} \mathrm{~m}^{3}\left(24.87 \mathrm{in}^{3}\right)$, with $0.2532 \mathrm{~L}\left(15.45 \mathrm{in}^{3}\right)$ in the annulus and $0.1544 \mathrm{~L}\left(9.422 \mathrm{in}^{3}\right)$ in the four cylindrical water channels.

Results from RELAP5-3D [9] were used to specify the convection boundary condition at the outside of the envelope tube. The external surface of the envelope tube is cooled by ATR primary coolant flowing at a velocity of $13.59 \mathrm{~m} / \mathrm{s}(44.6 \mathrm{ft} / \mathrm{s})$ with an average coolant temperature of $82.2^{\circ} \mathrm{C}\left(180^{\circ} \mathrm{F}\right)$.

To facilitate specification of heat loads, the geometry was partitioned into 12 axial sections, with six 10.16-cm (4-inch) sections above and below the core mid-plane. The following calculation shows how the axial power profile was calculated.

Normalized power curve based on ATR axial flux profile.

$\mathrm{i}:=0 . .5$

$\Delta \mathrm{x}:=4.0 \cdot \mathrm{in}$

$x_{i}:=(i+0.5) \cdot \Delta x$

$x=\left(\begin{array}{c}2 \\ 6 \\ 10 \\ 14 \\ 18 \\ 22\end{array}\right)$ in

$\mathrm{P}_{\text {norm }_{\mathrm{i}}}:=1.41 \cdot \cos \left(0.058 \frac{1}{\text { in }} \cdot \mathrm{x}_{\mathrm{i}}\right)$

$P_{\text {norm }}=\left(\begin{array}{c}1.401 \\ 1.325 \\ 1.179 \\ 0.97 \\ 0.709 \\ 0.41\end{array}\right)$
Eight axial segments on each side of core centerline

Length of each segment

Distance from core centerline (center point of each axial segment)

Normalized power in each segment 
Table 2 lists the average heat loads for the system components. A surface heat flux representing the thermal loads from the experiments were applied at the three cylindrical surfaces inside which the experiments will be located. Body heat fluxes to account for gamma heating were applied in the structural components. The average heat loads were multiplied by the power profile calculated above and applied symmetrically to the six segments above and six segments below the core mid-plane. Detailed calculations for the model components are provided in Appendix A. The applied loads are higher near the core mid-plane, and decrease with distance from the core mid-plane.

Table 2. Average heat loads for each model component.

\begin{tabular}{|l|l|l|}
\hline \multicolumn{1}{|c|}{ Component } & \multicolumn{1}{|c|}{$\begin{array}{c}\text { Average } \\
\text { Heat Load (kW) }\end{array}$} & Heat Flux Condition \\
\hline Experiment Tubes & 70 each/210 total & Surface \\
\hline Heat Sink & 40.3 & Body \\
\hline Pressure Tube & 58.32 & Body \\
\hline Envelope Tube & 70.5 & Body \\
\hline Cylindrical Water Channels & 3.741 & Body \\
\hline Water Annulus & 6.135 & Body \\
\hline
\end{tabular}

An additional case was analyzed which was identical to the one just described except that an additional surface heat load from each of the three experiment chambers of $58 \mathrm{~kW}(174 \mathrm{~kW}$ total) was assumed. This alternate configuration may be representative of leaving the hafnium filter sleeves of Figure 1 in place or of additional heating from the irradiation targets themselves.

\subsubsection{Results}

The results from the ABAQUS base case thermal analysis are shown in Figures 11 through 18.

Figure 13 shows the temperature distribution on the inside surface of the envelope tube. The maximum temperature $\left(116.4^{\circ} \mathrm{C}, 239.7^{\circ} \mathrm{F}\right)$ in the envelope tube occurs in the mid-core region at the inner diameter. The outer diameter of this component is convectively cooled by ATR primary coolant, whereas the inner diameter is effectively insulated by the $1.016-\mathrm{mm}(0.040$-inch) helium gap, which causes the temperatures to be higher on the inner surface. 


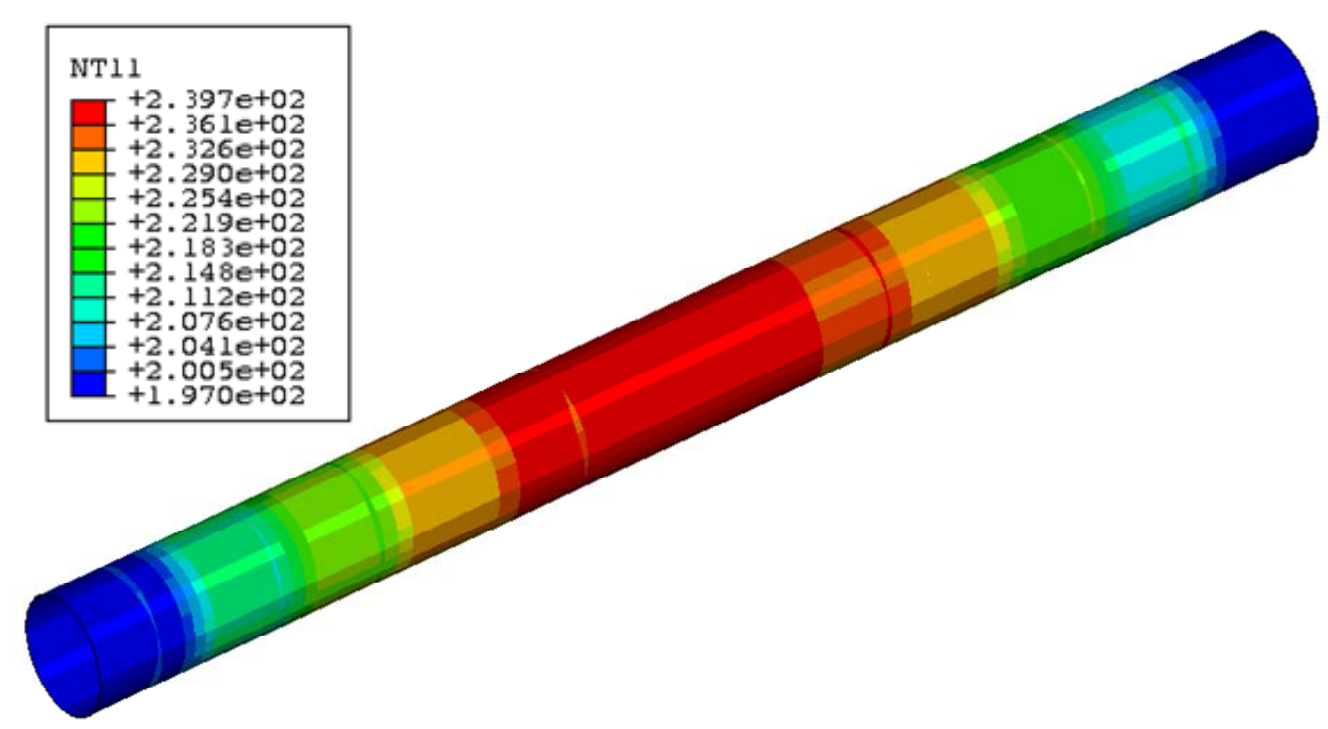

Figure 13. Temperature distribution $\left({ }^{\circ} \mathrm{F}\right)$ on inner surface of envelope tube (base case).

Figure 14 shows the temperature distribution on the outer surface of the pressure tube. The maximum temperature $\left(160^{\circ} \mathrm{C}, 320^{\circ} \mathrm{F}\right)$ in the pressure tube occurs just below the mid-core region. The outer surface is hotter than the inner surface, due to the presence of the helium gas gap at the outer surface, which serves to insulate. The inner surface is convectively cooled by pressurized water coolant flowing through the annulus between the pressure tube and heat sink. A 120 degree section cutaway is shown - the sections are symmetric.

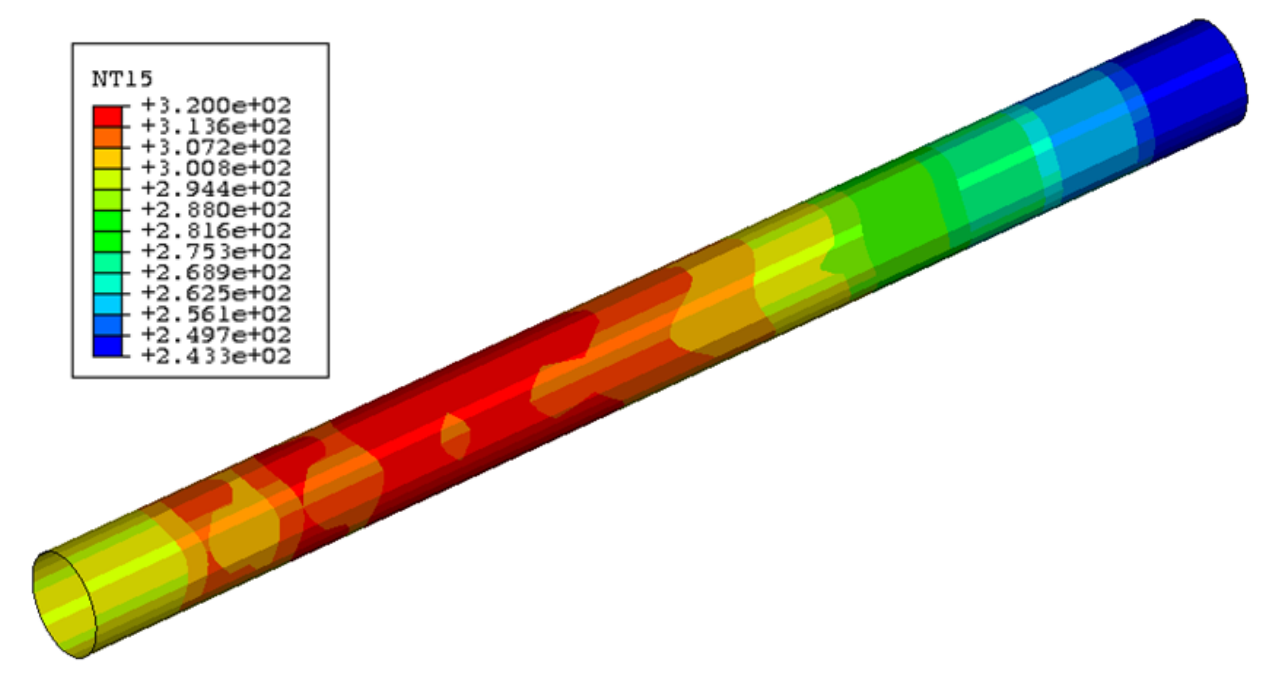

Figure 14. Temperature distribution $\left({ }^{\circ} \mathrm{F}\right)$ on outer surface of pressure tube (base case).

Figures 15 and 16 show the temperature distribution in the hafnium aluminum absorber. The three large holes in Figure 15 are locations of the experiment tubes and the four smaller holes contain the water coolant channels. From the cutaway view shown in Figure 16, it can be seen that the temperature in the heat sink reaches a maximum of $224.2{ }^{\circ} \mathrm{C}\left(435.6^{\circ} \mathrm{F}\right)$ in the regions between the experiment tubes near the core mid-plane. 


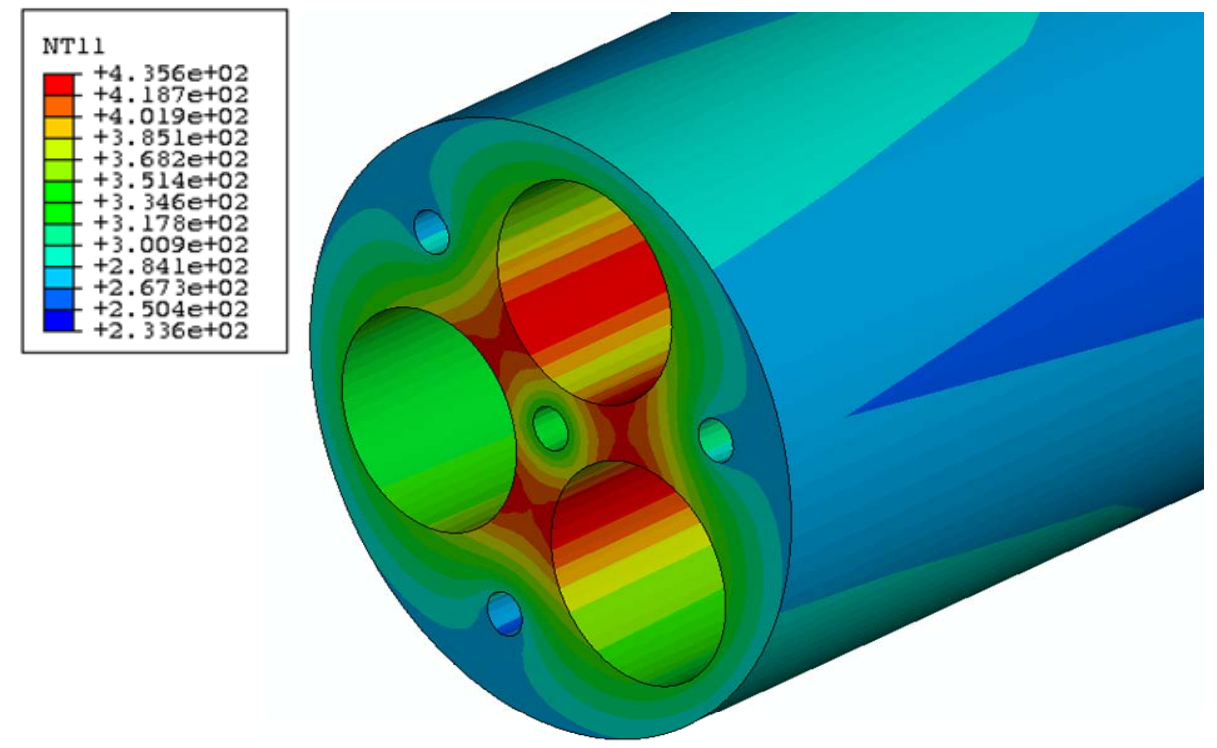

Figure 15. Radial temperature distribution $\left({ }^{\circ} \mathrm{F}\right)$ in the heat sink (base case).

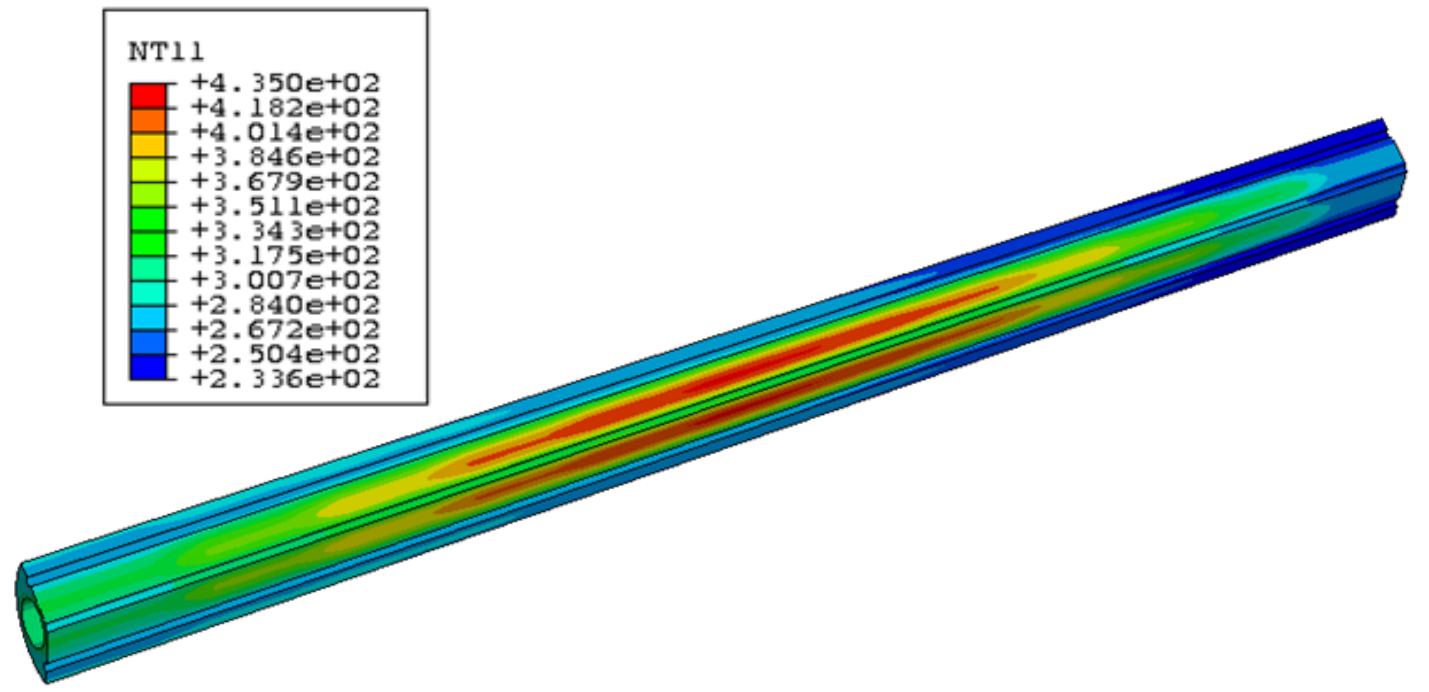

Figure 16. Axial temperature distribution $\left({ }^{\circ} \mathrm{F}\right)$ in the hafnium aluminum absorber (base case).

Figure 17 shows the temperature distribution in the oxide layers at the coolant-heat sink interface. In this cutaway view, the oxide layers adjacent to the annulus, the center channel, and two off-center water channels are shown. The maximum oxide temperature $\left(156^{\circ} \mathrm{C}, 312.8^{\circ} \mathrm{F}\right)$ occurs below the core mid-plane in the oxide layer adjacent to the center water channel. 


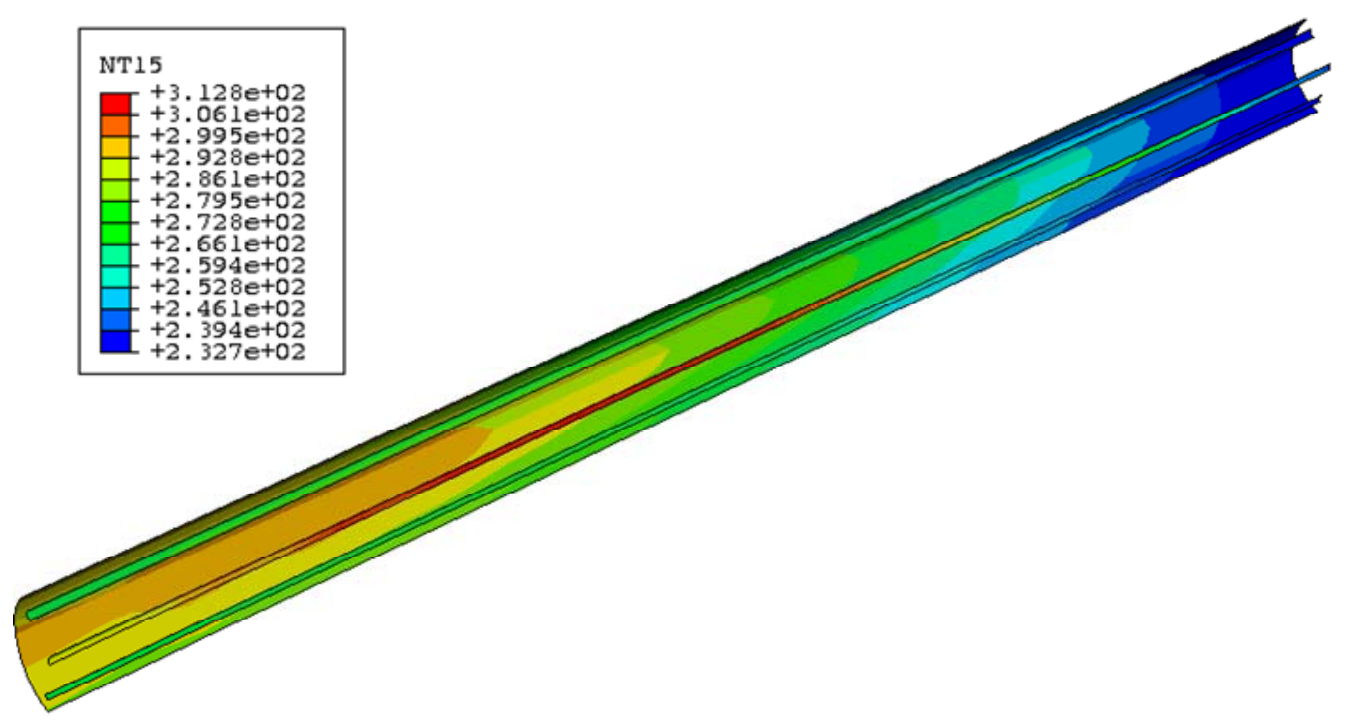

Figure 17. Temperature distribution $\left({ }^{\circ} \mathrm{F}\right)$ in the oxide layers (base case).

Figure 18 shows the temperature distribution in the water coolant (a 120 degree sector of the model is displayed). The model is oriented with the water flowing from right to left. The maximum water channel temperatures are listed in Table 3 . The temperature rise in the coolant is $32.7^{\circ} \mathrm{C}\left(58.8^{\circ} \mathrm{F}\right)$ for the annulus, $25.6^{\circ} \mathrm{C}\left(46.1^{\circ} \mathrm{F}\right)$ for the center water channel, and $14.9^{\circ} \mathrm{C}$ $\left(26.8^{\circ} \mathrm{F}\right)$ in the off-center water channels. At a coolant pressure of $12.4 \mathrm{MPa}(1800 \mathrm{psia})$, the saturation temperature for water is $323^{\circ} \mathrm{C}\left(614^{\circ} \mathrm{F}\right)$.

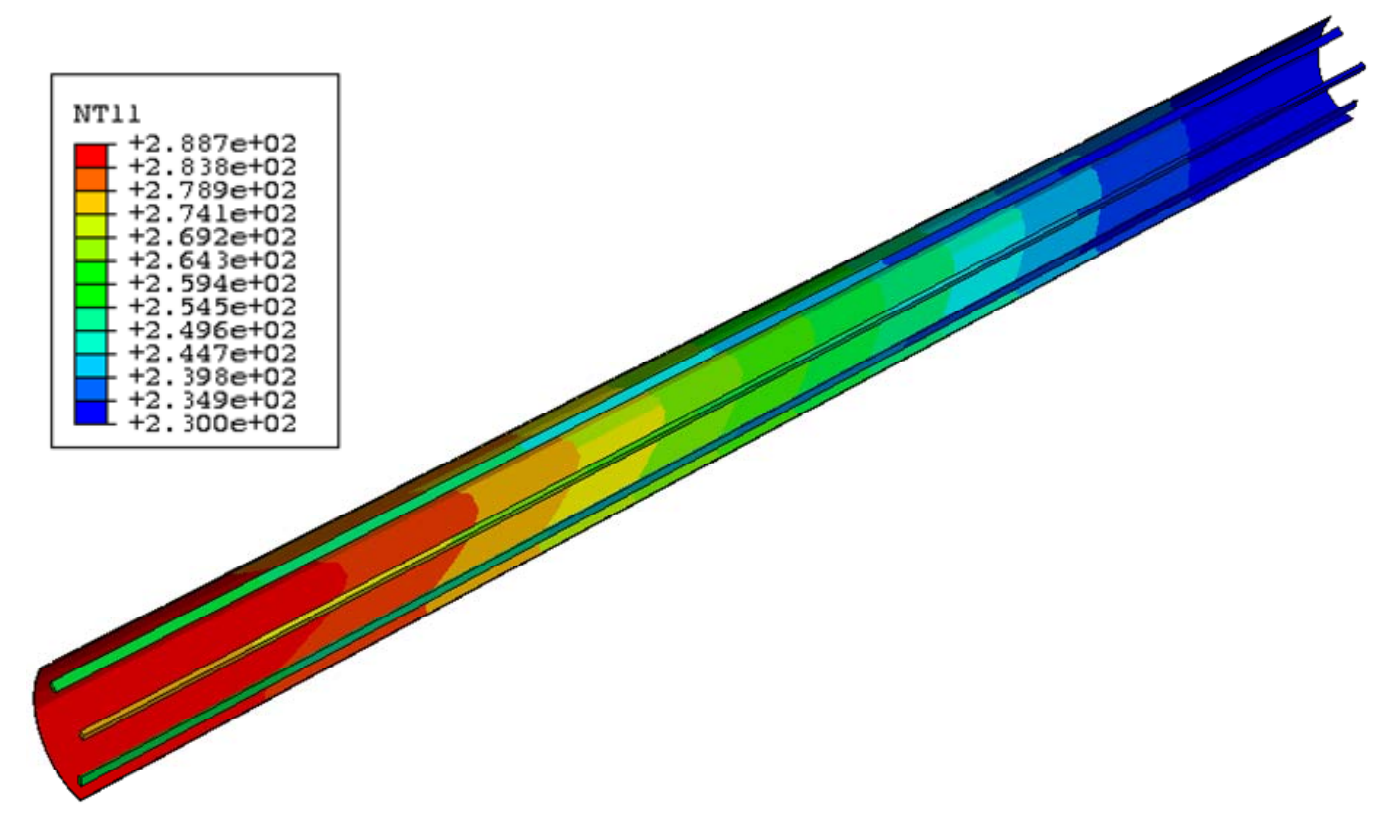

Figure 18. Temperature distribution $\left({ }^{\circ} \mathrm{F}\right)$ in the water coolant (base case). 
Table 3. Computed water channel outlet temperatures.

\begin{tabular}{|l|l|}
\hline \multicolumn{1}{|c|}{ Location } & \multicolumn{1}{|c|}{$\mathbf{T}_{\max }\left({ }^{\circ} \mathbf{C} /{ }^{\circ} \mathbf{F}\right)$} \\
\hline Water annulus & $142.7 / 288.8$ \\
\hline Center water channel & $135.6 / 276.1$ \\
\hline Three off-center water channels & $124.9 / 256.8$ \\
\hline
\end{tabular}

Figures 19 and 20 show the heat flux distributions at the pressure tube and oxide surfaces. The magnitude of heat flux is negative for the pressure tube since heat flows out of this component. The maximum oxide layer heat flux occurs at core mid-plane and is the highest in the oxide layer adjacent to the center water channel. The maximum surface heat fluxes are given in Table 4 .

Table 4. Computed maximum surface heat flux.

\begin{tabular}{|l|c|}
\hline \multicolumn{1}{|c|}{ Location } & $\begin{array}{c}\mathbf{q}_{\mathbf{m a x}}{ }^{\prime} \\
\left(\mathbf{W} / \mathbf{c m}^{2} / \mathbf{B T U} / \mathbf{s}-\mathbf{i n}^{2}\right)\end{array}$ \\
\hline Oxide surface contacting water annulus & $77.04 / 0.4714$ \\
\hline Oxide surface contacting center water channel & $291.1 / 1.781$ \\
\hline Oxide surface contacting off-center water channels & $221.0 / 1.352$ \\
\hline Pressure tube surface contacting water annulus & $-22.88 /-0.1406$ \\
\hline
\end{tabular}

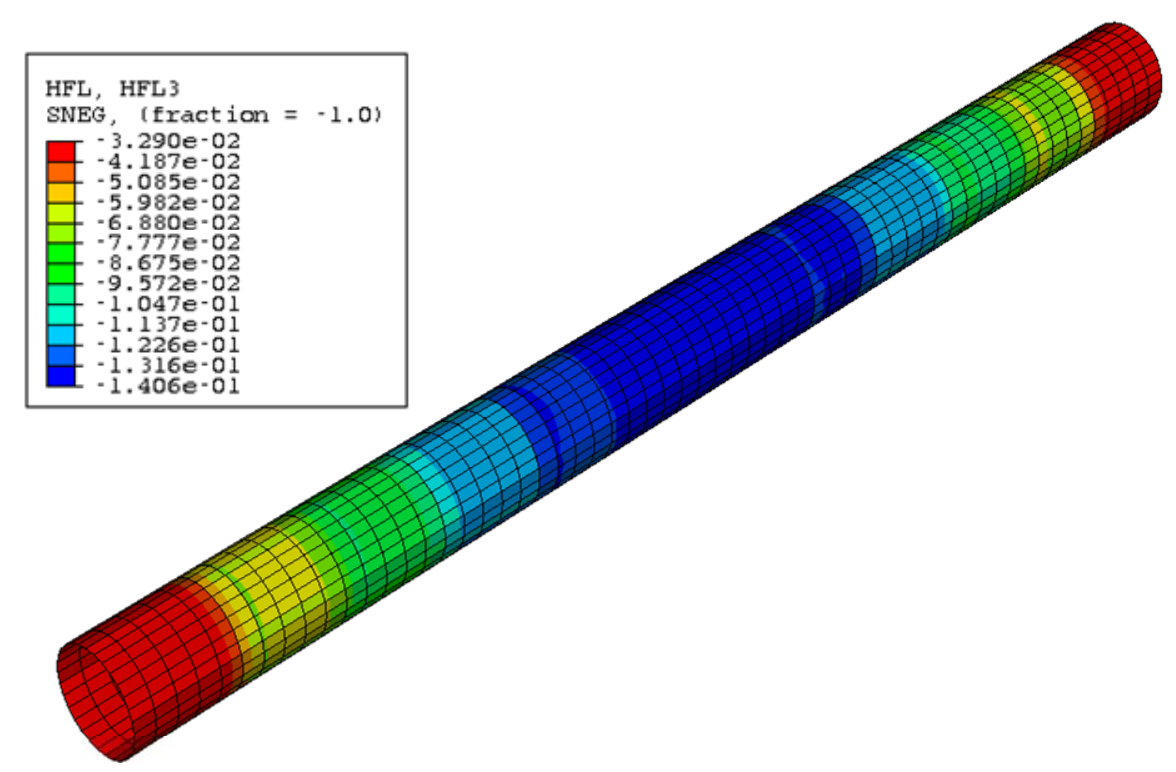

Figure 19. Distribution of surface heat flux $\left(\mathrm{BTU} / \mathrm{s}-\mathrm{in}^{2}\right)$ at the pressure tube (base case). 


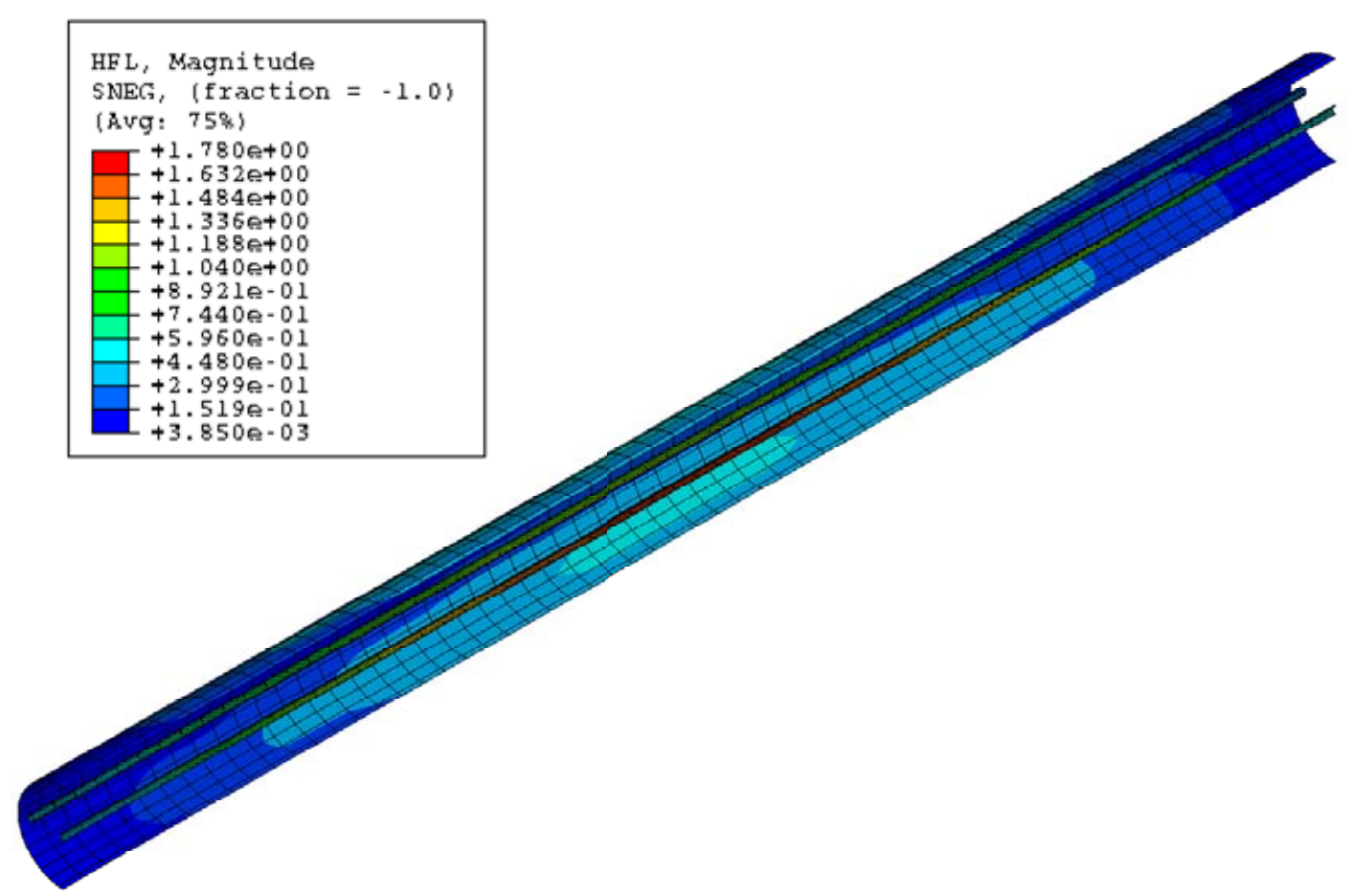

Figure 20. Distribution of surface heat flux (BTU/s-in ${ }^{2}$ ) at the oxide surfaces (base case).

The calculated flow instability ratio (FIR) and departure from nucleate boiling ratio (DNBR) for this configuration under nominal conditions are 6.5 and 8.0, respectively. These FIR and DNBR estimates are scoping calculations to show design feasibility under nominal conditions. Once the design is finalized, the FIR and DNBR should be evaluated at pump coast-down conditions with a safety factor on reactor power.

For the alternate configuration, with the added heat flux coming from the experiment chambers, temperatures were expectedly higher. Tables 5 and 6 list the outlet water temperature and the maximum surface heat flux for this configuration. Graphical depictions of these temperature distributions are provided in Appendix B.

Table 5. Computed water channel outlet temperatures for the alternate (added heat flux) configuration.

\begin{tabular}{|l|l|}
\hline \multicolumn{1}{|c|}{ Location } & \multicolumn{1}{|c|}{$\mathbf{T}_{\max }\left({ }^{\circ} \mathbf{C} /{ }^{\circ} \mathbf{F}\right)$} \\
\hline Water annulus & $158.3 / 316.9$ \\
\hline Center water channel & $153.4 / 308.1$ \\
\hline Three off-center water channels & $133.4 / 272.1$ \\
\hline
\end{tabular}


Table 6. Computed maximum surface heat flux for the alternate (added heat flux) configuration.

\begin{tabular}{|l|c|}
\hline \multicolumn{1}{|c|}{ Location } & $\begin{array}{c}\mathbf{q}_{\mathbf{m a x}}{ }^{\circ} \\
\left(\mathbf{W} / \mathbf{c m}^{\mathbf{2}} / \mathbf{B T U} / \mathbf{s}-\mathbf{i n}^{\mathbf{2}}\right)\end{array}$ \\
\hline Oxide surface contacting water annulus & $134.1 / 0.8219$ \\
\hline Oxide surface contacting center water channel & $510.2 / 3.120$ \\
\hline Oxide surface contacting off-center water channels & $379.9 / 2.323$ \\
\hline
\end{tabular}

\subsubsection{Conclusions from Thermal Analysis}

The design of the water coolant and hafnium aluminum absorber presented here is capable of maintaining all system components below their maximum temperature limits. The maximum temperature of this conduction cooling system, $224.2^{\circ} \mathrm{C}\left(435.6^{\circ} \mathrm{F}\right)$ occurs in a small, localized region in the heat sink structure near the core mid-plane. The calculated Flow Instability Ratio and Departure from Nucleate Boiling Ratio for this configuration under nominal conditions are 6.5 and 8.0, respectively, which safely exceed the minimum values of 2.0. For the alternate (added heating) configuration, the maximum temperature of the cooling system was $306.4^{\circ} \mathrm{C}$ $\left(583.5^{\circ} \mathrm{F}\right)$ in the same location. Either of these temperatures is well below the melting temperature of the aluminum $\left(660^{\circ} \mathrm{C}\right)$. The total coolant flow rate requirement for this configuration is $207 \mathrm{~L} / \mathrm{min}$ (54.7 gpm). The design can be further optimized to reduce the amount of pressurized water coolant. Achieving a minimum total volume of water coolant is desirable from a neutronics standpoint since water is a neutron moderator and will thermalize the neutrons.

\subsection{Materials Issues}

The use of hafnium to harden the neutron spectrum for the Gas Test Loop presented some design challenges to provide cooling. Solid hafnium produces a great deal of heat density and appeared to be difficult to cool with the gas coolant previously designed into the GTL. The alternative presented here uses solid aluminum as a cooling medium (the Al itself is water cooled) with the hafnium (Hf) dispersed throughout the aluminum. The use of this combination of materials presents several issues that should be discussed.

- Can the Hf be encased in Al in a stable form?

- What should be the Hf content?

- What should be the Hf distribution (particle size and distribution)?

- Can a machinable block of the composite material be fabricated?

- Can the block be machined or fabricated with coolant channels?

- What are the thermal/mechanical properties of the component materials?

- Will the composite be susceptible to corrosion as water passes through it. 
Answers to these questions are now discussed.

\subsubsection{Can the $\mathrm{Hf}$ be encased in $\mathrm{Al}$ in a stable form?}

The goal is to make a dispersion/solution of Hf in Al. The options appear to be (1) mixed powders of Hf and Al, pressed together and machined or extruded,(2) a 2-phase aluminide and aluminum single block created by similarly mixing powders ( $\mathrm{Al}$ and aluminide) or by melt alloying $\mathrm{Hf}$ with $\mathrm{Al}$, followed by a subsequent heat treatment, or (3) mixed powders of $\mathrm{HfO}_{2}$ and $\mathrm{Al}$, pressed and machined or extruded.

The potential problems are (1) fabricability, (2) phase stability during fabrication and irradiation, (3) thermal conductivity of the various phases, and material property stability in reactor. Fabricability issues include creating composite material shapes with long, narrow flow channels and stability of aluminide phases or of $\mathrm{HfO}_{2}$ compared to the $\mathrm{Al}$ matrix (this is also an operational issue), .

\section{Hf-Al Mixtures:}

The binary phase diagram (see Figure 21 below [10]) indicates that there is very little or no solubility of $\mathrm{Hf}$ in Al; intermetallics form across nearly the entire binary diagram. Knowing there will be free aluminum (excess $\mathrm{Al}$ ) in the composite, the important intermetallic phase is that containing the least amount of $\mathrm{Hf}$, namely $\mathrm{Al}_{3} \mathrm{Hf}$. The phase diagram indicates that a 5-10 at.\% Hf mixture should consist of $\mathrm{Al}_{3} \mathrm{Hf}$ in $\mathrm{Al}$, the $\mathrm{Al}_{3} \mathrm{Hf}$ being stable. The only question is whether in the as-fabricated state there are metastable conditions to be addressed.

Other things that the phase diagram indicate include that this mixture of $\mathrm{Al}_{3} \mathrm{Hf}$ and $\mathrm{Al}$ is stable up to the melting temperature of $\mathrm{Al}$, so the limiting condition is to maintain operating temperatures below the melting temperature of Al, a condition that is required by ATR anyway. Also, the phase diagram indicates that a mixture of $\mathrm{Hf}$ and $\mathrm{Al}$ would not be stable, that the intermetallic would form anyway, perhaps in a series of intermetallics. In addition, the intermetallic formation results in $\mathrm{Al}_{3} \mathrm{Hf}$ with a density of $6.4 \mathrm{~g} / \mathrm{cm} 3$ as calculated from the single crystal volume [11] and number of $\mathrm{Hf}$ and $\mathrm{Al}$ atoms in a unit cell, 12 and 4 [12], respectively. By rule of mixtures the density should be $5.3 \mathrm{~g} / \mathrm{cm} 3$, so the mixture of materials increases in density as it forms the intermetallic, and thus would create voids/defects in the material as it precipitates.

These factors suggest that:

1. $\mathrm{Al}_{3} \mathrm{Hf}$ is stable in an $\mathrm{Al}$ matrix.

2. The $\mathrm{Al}$ and $\mathrm{Al}_{3} \mathrm{Hf}$ composite should not be created by mixing $\mathrm{Hf}$ and $\mathrm{Al}$ powders and reacting in the bulk because defects would form.

\section{$\mathrm{HfO}_{2}$ in Aluminum:}

Another potential composite material that could be used as the neutron flux hardener could be $\mathrm{HfO}_{2}$ in $\mathrm{Al}$. The $\mathrm{HfO}_{2}$ is dense/heavy $\left(9.7 \mathrm{~g} / \mathrm{cm}^{3}\right.$ ) compared to $\mathrm{Al}$ (Note that $\mathrm{Al}$ has a density of $2.7 \mathrm{~g} / \mathrm{cm}^{3}$, Hf is $13.1 \mathrm{~g} / \mathrm{cm}^{3}$, and $\mathrm{Al}_{3} \mathrm{Hf}$ is $\left.6.4 \mathrm{~g} / \mathrm{cm}^{3}\right)$. A large difference in density can be a challenge in mixing the powders for pressing compacts, and maintaining a uniform dispersion. This could dictate a small range of usable oxide particle sizes.

Another potentially more serious problem is whether the $\mathrm{HfO}_{2}$ is stable compared to $\mathrm{Al}_{2} \mathrm{O}_{3}$. This issue has arisen previously when uranium oxide and neptunium oxide were studied for use in an 
aluminum matrix, as a fuel and as a target to form $\mathrm{Pu}-238$, respectively. All three elements, Hf, $\mathrm{Np}$, and $\mathrm{U}$, are included in Figure 22 below, the diagram indicating the relative stability of

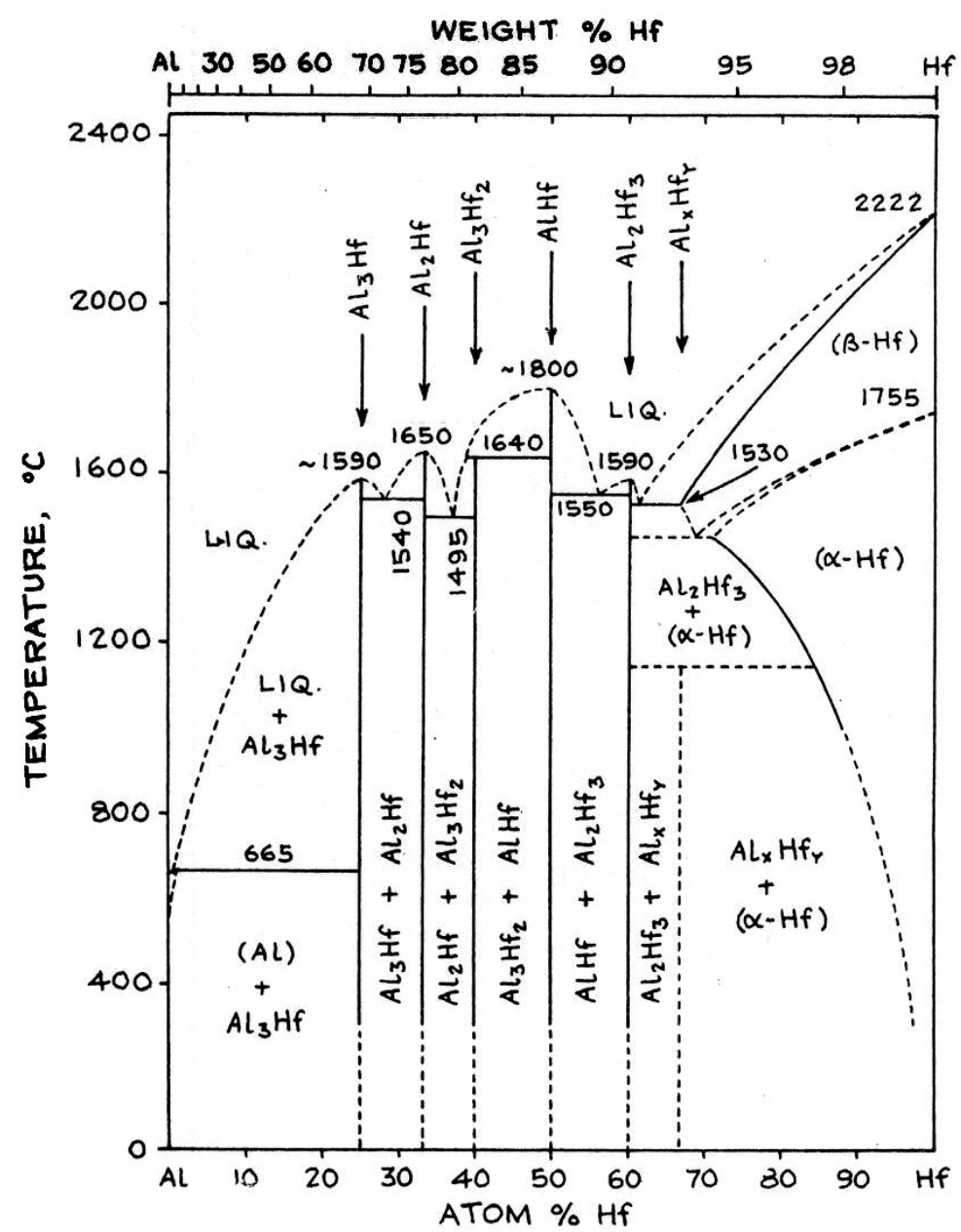

Figure 21. Aluminum-Hafnium Phase Diagram.

the oxides. $\mathrm{NpO}_{2}$ appears to be the least stable. In fact, $\mathrm{NpO}_{2}$ reduction problems during fabrication of $\mathrm{NpO} 2 / \mathrm{Al}$ targets were observed.[13]

In addition, uranium oxide in aluminum has long been used as a fuel type (for example, in HFIR). Early in the development of a fuel, ORNL workers [14] noted that Al would reduce $\mathrm{UO}_{2}$ at $600^{\circ} \mathrm{C}$ and form $\mathrm{UAl}_{4}$. A net volume increase, as much as 20-30\%, accompanied the reaction. They subsequently used $\mathrm{U}_{3} \mathrm{O}_{8}$ in $\mathrm{Al}$ as fuel [15], the $\mathrm{U}_{3} \mathrm{O}_{8}$ being a more stable oxide. These experiences, with $\mathrm{Np}$ and $\mathrm{U}$, suggest that there may also be problems with the stability of $\mathrm{HfO}_{2}$ in Al. 


\section{Conclusions}

The recommended composite material is $\mathrm{Al}_{3} \mathrm{Hf}$ in an $\mathrm{Al}$ matrix. This has a good chance of being very stable and may also be fabricable, using a mixture of $\mathrm{Al}_{3} \mathrm{Hf}$ and $\mathrm{Al}$ powders, compacting and hot pressing, or extruding.

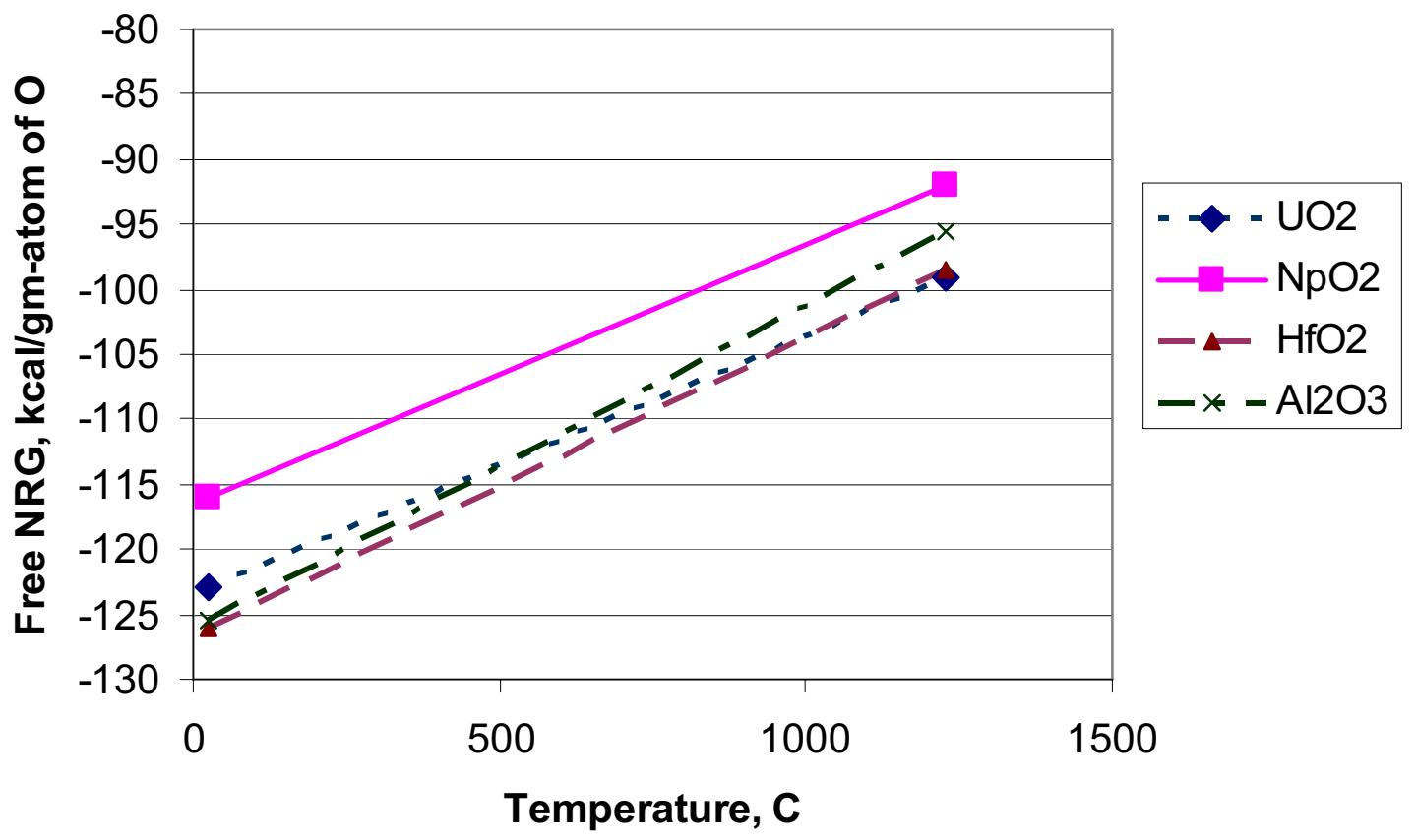

Figure 22. Free energy of formation of aluminum, uranium, neptunium, and hafnium oxides as a function of temperature.

\subsubsection{What should be the $\mathrm{Hf}\left(\mathrm{Al}_{3} \mathrm{Hf}\right)$ content?}

Recall from the "Physics" section of this report that the optimum Hf content is $\sim 7$ at. \%. Assuming this atomic fraction is represented in the form of $\mathrm{Al}_{3} \mathrm{Hf}$ in $\mathrm{Al}$, the volume percentage of $\mathrm{Al}_{3} \mathrm{Hf}$ required is about $23 \%$.

\subsubsection{What should be the Hf distribution (particle size and distribution)?}

From a fabricability standpoint, namely to achieve a successful and relatively stable mixture of $\mathrm{Al}_{3} \mathrm{Hf}$ and $\mathrm{Al}$ powders, the relative sizes of the particles requires consideration. The $\mathrm{Al}_{3} \mathrm{Hf}$ material is more than twice as dense as the Al, so un-mixing can be a problem. Mitigation may require equal sized powders, or much larger $\mathrm{Al}_{3} \mathrm{Hf}$ powders. The theory behind the latter is that the large $\mathrm{Al}_{3} \mathrm{Hf}$ particles need to displace a great many $\mathrm{Al}$ particles in order to un-mix the mixed powders; there remains a driving force for un-mixing but the process is more difficult and the unmixing rate is slowed. 


\subsubsection{Can a machinable block of the composite material be fabricated and lor can the block be machined or fabricated with coolant channels?}

There are several potential methods of fabricating the $7 \mathrm{~cm}(2.8$-inch) diameter cylinder of the composite and assembling one piece or several joined pieces into a four-foot length, complete with a number of small flow channels, and three larger channels to hold the test fuel samples. Ideas included:

1. Pressing composites of that diameter in short lengths, machining to size, drilling, and welding the pieces together. Problems include ensuring that the flow channels have no leaks, and welding with the composites.

2. Extruding a solid cylinder of the composite and then machining the coolant and sample channels, as well as the outer dimension. The obvious challenge is to machine the flow channels over the distance required.

3. Extruding the cylinder with the flow channels in-place, resulting from a complex extrusion. Machine the outer dimensions if required. The challenge results from the fact complex extrusions like this require points where the billet is split and reformed together through pressure welding. This is often done with aluminum extrusions, but the effects of the presence of the intermetallic on the welding process, and vice versa, are unknown. This, however, appears the most promising method.

Of course a simpler extrusion can be used if the cylinder is made of three sections (an alternate design), with the coolant water flowing between the flats of the sections. Machining can be used to finish the sections. The final extrusion process can be prescribed when the design is set.

It should be pointed out here that there is a precedent for machining long cooling channel flow channels. The beryllium reflector blocks that surround the ATR fuel have such holes machined in them. These blocks are the full (1.2-m) core height and the holes are drilled all the way through. The company that does this machining for the ATR blocks has indicated that some investigation would be needed on this different material to find the best way to drill such holes in the hafnium-aluminum.[16]

\subsubsection{What are the thermal/mechanical properties of the component materials?}

The matrix material is aluminum and certainly all of its relevant properties are known, including any effects of irradiation on the properties. The intermetallic, $\mathrm{Al}_{3} \mathrm{Hf}$ is another matter. There is some thermodynamic information concerning enthalpy changes during decomposition and vapor pressure [17], but very little else is available concerning other properties.

\section{Thermal Conductivity}

The thermal conductivity has apparently not been measured. $\mathrm{Al}_{3} \mathrm{Hf}$ does, however, possess the same crystal structure as $\mathrm{Al}_{3} \mathrm{Zr}$, tetragonal, $\mathrm{D}_{23}[11,18]$. At temperatures greater than $650^{\circ} \mathrm{C}$ $\mathrm{Al}_{3} \mathrm{Hf}$ transforms to $\mathrm{DO}_{22}$ [11], also tetragonal but with less tetragonality $(\mathrm{a} \sim \mathrm{c})$. The material should not be operating above $650^{\circ} \mathrm{C}$ without perhaps encroaching on the melting temperature of the aluminum matrix. It has been assumed for this assessment that the structure is $\mathrm{D} 0_{23}$. The thermal conductivity of $\mathrm{Al}_{3} \mathrm{Zr}$ was measured at room temperature [19]. The value was found to be $42 \mathrm{~W} / \mathrm{m} /{ }^{\circ} \mathrm{K}\left(24.3 \mathrm{Btu} / \mathrm{h} / \mathrm{ft} /{ }^{\circ} \mathrm{F}\right)$. 
The thermal conductivity of the composite material ( $\mathrm{Al}$ with $\mathrm{Al}_{3} \mathrm{Hf}$ ) may also be important. The thermal conductivity of a composite with uranium and uranium aluminide $\left(\mathrm{UAl}_{4}\right)$ has been measured [20]. As with $\mathrm{Hf}$ in $\mathrm{Al}, \mathrm{U}$ in $\mathrm{Al}$ has no solubility at temperatures less than $640{ }^{\circ} \mathrm{C}$ so it may be assumed, by inspection of the phase diagram, the samples were mixtures of 'pure' uranium and $\mathrm{a} \mathrm{UAl}_{4}$ intermetallic. The thermal conductivities shown below in Figure 23 were measured at $338{ }^{\circ} \mathrm{K}\left(65^{\circ} \mathrm{C}\right)$. The maximum $\mathrm{U}$ content in the samples was 7.7 at. \%; with $\mathrm{U}$ in $\mathrm{UAl}_{4}$ being 20 at. $\%$, ideally $38.7 \%$ of the phase mixture would be the intermetallic phase.

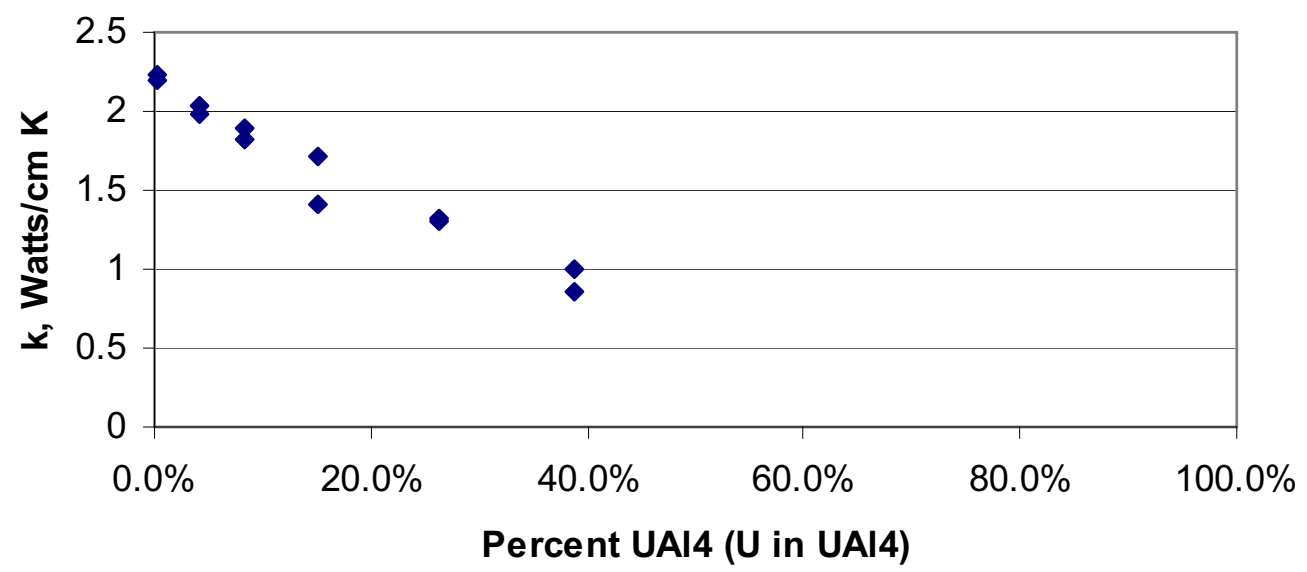

Figure 23. Measured Thermal Conductivity of $\mathrm{Al}-\mathrm{Al}_{4} \mathrm{U}$ Composite Material. The percentage of $\mathrm{Al}_{4} \mathrm{U}$ is presented in at.\%, or vol. \% if the density can be approximated by rule of mixtures of the two elements, $\mathrm{U}$ and $\mathrm{Al}$.

The dependency of thermal conductivity on the phase mixture shown below has been shown to fit a model, and this same model could be used to estimate the thermal conductivity of the Al$\mathrm{Al}_{3} \mathrm{Hf}$ composite. If the thermal conductivity of $\mathrm{Al}_{3} \mathrm{Hf}$ is nearly the same as the conductivity of $\mathrm{Al}_{3} \mathrm{Zr}$ then one would expect the $23 \%$ (by volume) $\mathrm{Al}_{3} \mathrm{Hf}$ composite to have a thermal conductivity a little more than half that of pure Al.

Note that pure Hf has a thermal conductivity of $0.22 \mathrm{~W} / \mathrm{cm}^{\circ} \mathrm{K} @ 338{ }^{\circ} \mathrm{K}$.

Samples of $\mathrm{Al}_{3} \mathrm{Hf}$ have been produced for this project and thermal conductivities will be measured at temperatures between room temperature and $600^{\circ} \mathrm{C}$. Having that knowledge, we can model the composite and predict the conductivity as a function of temperature.

\section{Mechanical Properties}

Intermetallic phases are usually very brittle materials. Examining specific intermetallics, it is known that those with more symmetric crystal structures (for example, cubic structures) and those with smaller lattice parameters are more ductile [21]. In this case the $\mathrm{D}_{23}$ structure has reasonable symmetry, but it is not as likely to have the ductility of the higher temperature phase, $\mathrm{DO}_{22}$, as the crystal structure is very nearly cubic $(\mathrm{a} \sim \mathrm{c})$. The consequence of having a brittle intermetallic phase may be that the particles break as the composite is extruded, and it may be difficult to pressure bond to the surface of an $\mathrm{Al}_{3} \mathrm{Hf}$ particle. Break-up of particles should be no problem, and the 'pressure welding' can be tested. 


\section{Effects of Irradiation}

The radiation effects that are commonly associated with intermetallic phases are amorphization and phase stability (increased or decreased). While $\mathrm{Zr}_{3} \mathrm{Al}$ has been irradiated in a number of studies, and found to be very sensitive to amorphization $[22,23]$, its structure is not the same as $\mathrm{Al}_{3} \mathrm{Zr}$, or $\mathrm{Al}_{3} \mathrm{Hf}$. There does not seem to be a great deal of information concerning intermetallics with structural similarity to $\mathrm{Al}_{3} \mathrm{Hf}$. Amorphization would not seem to be a particular problem for this application, although it could affect physical properties such as thermal conductivity. Resolution of the phase into the aluminum matrix would also not seem to be a problem.

To help resolve this uncertainty, small coupons of the Hf-Al material will be included in booster fuel mini-plate testing being conducted for the GTL/BFFL. In those tests, small samples $2.54 \mathrm{~cm}$ ( 1 inch) wide, $2.54 \mathrm{~mm}(0.100 \mathrm{inch})$ thick and of lengths up to $10.16 \mathrm{~cm}$ (4 inches) of one or more Hf-Al compositions will be included in capsules containing samples of the GTL/BFFL booster fuel material, irradiated for approximately 60 days, and examined for material changes.

\subsubsection{Will the composite be susceptible to corrosion as water passes through it?}

The water in the coolant loop should operate well below $300^{\circ} \mathrm{C}$; the saturation temperature for 12.4-MPa (1800-psi) water is slightly greater than $300^{\circ} \mathrm{C}$. Moreover, boehmite, or diaspore (high pressure/temperature phase) layers are not effective corrosion protection at temperatures greater than $300^{\circ} \mathrm{C}$. We will assume that pure or low-alloy aluminum can be used exposed to the coolant channel water. Samples of the hafnium aluminum material will be included in mini-plate irradiation tests currently planned to examine booster fuel corrosion.

Another issue is the potential that the $\mathrm{Al}-\mathrm{Al}_{3} \mathrm{Hf}$ interface could create electric potentials or stresses from thermal expansion mismatch that would encourage corrosion at the interface. The particles could be loosened from the matrix and lost to the water. Also, the particles of aluminide themselves may not be corrosion resistant.

While the loss of small amounts of Hf to the water would be unacceptable if lost to the reactor coolant, the water that the material is exposed to in this case is contained within a loop.

Nonetheless, it would be prudent to mitigate any corrosion, especially if corrosion is so severe to put the flow channels in jeopardy.

Assuming the $\mathrm{Al}-\mathrm{Al}_{3} \mathrm{Hf}$ material alone is expected to corrode at an unacceptable rate, mitigating steps could take the form of lining the coolant channels - another fabrication challenge. Another design, where the center block is fabricated in three pieces, and the water flows between the flats mating each of the three segments, may be amenable to cladding, but for this report we assume that the coolant flows through cylindrical channels in the composite block.

Another suggestion intended to avoid corrosion issues was to use zirconium and to incorporate hafnium in solution. The problem with this is the relatively low thermal conductivity of $\mathrm{Zr}$ compared to $\mathrm{Al}$ and its alloys (see Table 7 below). All of the aluminum-based materials, including the alloys, have much better thermal conductivity than $\mathrm{Zr}$ or Hf. 
Table 7. Thermal Conductivity of Candidate Materials for Thermal Neutron Absorber

\begin{tabular}{|c|c|c|}
\hline Material & $\begin{array}{l}\text { Thermal Conductivity, } \mathrm{W} / \mathrm{m}^{\circ} \mathrm{K} \text {, } \\
@ 25^{\circ} \mathrm{C}\end{array}$ & $\begin{array}{l}\text { Thermal Conductivity, } \mathrm{W} / \mathrm{m}^{\circ} \mathrm{K} \text {, } \\
@ 300^{\circ} \mathrm{C}\end{array}$ \\
\hline $\mathrm{Al}[24]$ & 250 & 200 \\
\hline $\mathrm{Zr}[25]$ & 21 & 19 \\
\hline $\mathrm{Hf}[26]$ & 22 & 21 \\
\hline $6063 \mathrm{Al}[27]$ & 200 & 200 \\
\hline $5456-\mathrm{H} 343 \mathrm{Al}[28]$ & 110 & 130 \\
\hline
\end{tabular}

It will be assumed for the present that un-coated/clad $\mathrm{Al}-\mathrm{Al}_{3} \mathrm{Hf}$ will be used and will provide sufficient corrosion resistance. An extrusion process will be used to fabricate the design, either a simple extrusion, one in which pressure welding as part of a more complex extrusion process. The method will be prescribed dependent on the final design characteristics (cylinder with flow channels or three-section cylinder) of the body. To help ensure acceptable corrosion properties, the material will be irradiation tested, as indicated in the previous section, and corrosion will be examined in the post irradiation examination. Further corrosion issues can be investigated by proof testing when the design is more mature and mitigating features added if required.

It should be observed also that because of Hf burn-out, the hafnium-aluminum absorber will require replacement at regular intervals to maintain the thermal neutron absorber efficiency required for testing. Exact replacement frequency will be determined by the final design and by utilization and reactor operating history, but it may be as often as every 3 or 4 reactor operating cycles. Hence, the resistance to corrosion need not be perfect, so long as no significant performance changes take place during the absorber lifetime. Let it also be observed that the transmutation product of Hf, after multiple stages of neutron absorption in Hf, is mainly Ta-181, which is stable, and that corrosion would mainly impact thermal hydraulic performance, not primary coolant contamination with fission products.

\subsection{IMPLEMENTATION}

Besides the issues associated with functional performance of the BFFL as an entity in the reactor, there are a number of interfaces with the reactor and other systems at ATR that require resolution before the concept can be declared a success. Some of these remained issues for the earlier GTL configuration.

\subsection{Secondary Coolant System}

A key assumption to this point has been the availability of a secondary coolant system that sustains nominally $12.4 \mathrm{MPa}(1,800 \mathrm{psi})$ water flows at flow rates adequate to achieve the required cooling. Several options exist for supplying that coolant.

First, a potential installation location for the BFFL in the ATR is the NW lobe. The experiment presently occupying that lobe makes use of a pressurized water secondary coolant system that is already installed and that would be fully capable of providing the required cooling with a $681 \mathrm{~L} / \mathrm{min}$ (180 gpm) flow capability. That system is owned by the Naval Reactors Program. If it is left in place and available when the existing in-pile hardware is removed, it would provide the most cost-effective supply of pressurized secondary coolant. 
If that is not feasible or if we use the NE Lobe instead, another pressurized water system, the one in the 2A cubicle, is being restored to service as part of the operating contract agreement between DOE and Battelle Energy Alliance. That restoration is planned for completion about the same time as the BFFL will be coming on line. At the present time, no other programs that would make use of this pressurized cooling system have been identified, and it should be available for use, should it be needed. Running the coolant lines from the reactor vessel penetration to the BFFL experiment and back would be the responsibility of the BFFL project. The available flow rate for this system is $227 \mathrm{~L} / \mathrm{min}(60 \mathrm{gpm})$.

A third pressurized cooling system exists in the $1 \mathrm{D}$ cubicle. Its available flow rate is only $151 \mathrm{~L} / \mathrm{min}(40 \mathrm{gpm})$, but is also capable of pressures in excess of $12.4 \mathrm{MPa}(1,800 \mathrm{psig})$.

\subsection{Temperature Control Gas System}

As with the GTL, the BFFL will make use of a mixed-gas experiment temperature control system. This technique has been used for many years as a means of controlling temperatures in lead-type experiments. Using this approach, a narrow gas gap is installed between the experiment capsule and the cooling medium for removing heat from the experiment. This gap is filled with a mixture of helium and a heavy gas such as neon or argon. When pure helium is present, the thermal conductivity of the gas in the gap is much greater than when the heavier gas is present. Temperature feedback to the gas mixing system provides the ability to adjust the mixture and thus achieve control of the experiment temperature, even when heating rates vary because of reactor power variations or other factors.

The number of channels of temperature control needed remains to be fixed by BFFL design, but the GTL conceptual design had as many as 15 , five in each of the three irradiation columns. In this aspect it was similar to the Irradiation Test Vehicle (ITV), which had been installed in the center flux trap but has recently been removed. With the ITV, as will doubtless be the case with BFFL, the specific implementation of temperature control was unique to the individual experiments.[6] The temperature control gas system was then set up to meet the needs of the individual experiments. The temperature control gas system from the ITV has been removed, but it could be restored and adapted for use on BFFL. If that proves infeasible, there are other projects making use of such systems. The engineering of these systems has been completed, and it would be straightforward to adapt the design to the needs of the BFFL.

\subsection{System Interfaces}

A non-trivial engineering challenge remaining to be worked through in the BFFL concept is the interfacing of the secondary cooling system with the temperature control gas system. Both of these will be interior to the ASME Section III pressure boundary between the BFFL experiment and the ATR Primary Cooling System. Existing experiments using pressurized secondary cooing systems have engineered solutions to the need for inserting experiments inside the pressure tube interface. It is expected that those same solutions will be applicable to BFFL. The resolving of these engineering issues is not part of the scope of this feasibility study.

\subsection{COST IMPACT}

The primary objective in undertaking this investigation was to seek a technically viable configuration that would result in overall savings in system cost. A detailed cost estimate had 
been prepared for the prior GTL configuration that resulted in a total project cost rounded to $\$ 84 \mathrm{M}$. Uncertainties and project delays since that estimate led to a more practical cost range of \$80-100M.

The detailed GTL cost estimate was the point of departure for preparing a revised estimate for the BFFL total system cost. Many elements of the earlier estimate were carried forward unchanged, for example the cost of developing the booster fuel used in both configurations. Some elements in the earlier estimate, such as the pressurized gas cooling system, did not appear at all in the new estimate. Other costs, such as connecting to the pressurized water loop were new in the BFFL estimate, not appearing in the earlier GTL estimate. One other category of costs shown in both estimates, although it may not really be required, is the cost of neutrons for irradiation testing of booster fuel plates and the complete BFFL system in the ATR prior to considering it a completed project. It is not known at this time whether such irradiation charges will be incurred by the project, but they probably will appear somewhere, at some level, in overall system acquisition, so they were included in the estimate.

The total project cost summary report is provided in Appendix C. The bottom line comparison of the BFFL cost with the GTL cost shows a reduction of approximately $\$ 25-30 \mathrm{M}$ by changing to the BFFL configuration. Even with irradiation charges for single plate irradiation and firstoperation demonstration tests of more than $\$ 11 \mathrm{M}$ included, the project cost is now estimated at between $\$ 50 \mathrm{M}$ and $\$ 75 \mathrm{M}$. The estimated cost with a $25 \%$ contingency was $\$ 63.4 \mathrm{M}$. The $\$ 50 \mathrm{M}$ figure is a nominal cost without contingency and the higher $\$ 75 \mathrm{M}$ figure is with about $50 \%$ contingency, which would not be unreasonable for this stage of concept development. Hence, this investigation has shown that a technically viable alternatively cooled configuration can be produced that results in substantial total cost savings over the original GTL design.

\section{REFERENCES}

1. Idaho National Engineering and Environmental Laboratory, "Justification of Mission need for the Gas Test Loop,” INEEL/EXT-04-02018 (June 28, 2004).

2. G.R. Longhurst, S. T. Khericha, and J. L. Jones, "Gas Test loop Technical and Functional Requirements," INEEL/EXT-04-02273 (September 2004).

3. W. F. Skerjanc and G. R. Longhurst, "Gas Test Loop Facilities Alternatives Assessment Report," INL/EXT-05000263, Rev. 1 (July 2005).

4. Gas Test Loop Project Staff, “Gas Test Loop Conceptual Design Report,” Draft, INL/EXT05-00261, Rev. B (September 13, 2005).

5. G. R. Longhurst and L. C. Brown, "Experimenter's Reference Guide for the Advanced Test Reactor," INEEL/INT-02-01177, Idaho National Laboratory (September 2002).

6. D. N. Bybee and F. W. Ingram, "Design, Functional and Operational Requirements for the Development of an Advanced Test Reactor (ATR) Irradiation Test Vehicle (ITV)," ES51579, Idaho National Engineering Laboratory (August 4, 1995). 
7. J. F. Briesmeister (ed.), "MCNP - A general Monte Carlo N-Particle Transport Code, Version-4C," LA-13709-M, Los Alamos National Laboratory (March 2000).

8. Hibbitt, Karlsson, \& Sorensen, Inc., ABAQUS/Standard, Version 6.3-1, Pawtuckett, Rhode Island.

9. RELAP5-3D Code Development Team, "RELAP5-3D Code Manual. Idaho National Laboratory Report,” INEEL-EXT-98-00834, Revision 2.3, Idaho Falls, ID, USA, http://www.inel.gov/relap5/r5manuals.htm (April 2005).

10. I. A. Tsyganova, M.A. Tylina, and E.M. Savitskiy, "Phase Diagram of the Hf-Al System," Russian Metallurgy (Metally) 1970 No.2, pp. 107-109.

11. S. K. Das, “Al-Rich Intermetallics in Aluminum Alloys,” Chapter 8 in Structural Applications of Intermetallic Alloys, Ed. Westbrook and Fleischer, 1195, John Wiley and Sons Ltd (1995).

12. Taylor and Kagle, Crystallographic Data on Metal and Alloy Structures, Dover Publications (1963).

13. R. E. Myrick and R.L. Folger, "Fabrication of targets for Neutron Irradiation of Neptunium Oxide," I\&EC Process design and Development 3, 4 (1964) pp.309-313.

14. R. C. Waugh, "Reaction and Growth of Uranium Dioxide-Aluminum Fuel Plates and Compacts," ORNL-2701 (1959).

15. W. J. Werner and J.A. Barkman, "Characterization and Production of U3O8 for the High Flux Isotope Reactor,” ORNL-4052 (1967).

16. D. Gossett, Axsys Technologies, private conversation with G. R. Longhurst at Idaho National Laboratory, July 18, 2007.

17. G. Balducci, et al, "Thermodynamic Study of Intermetallic Phases in the Hf-Al System," Journal of Alloys and Compounds 220 (1995) pp.117-121.

18. C. Colinet and A. Pasturel, "Phase Stability and Electronic Structure of the HfAl3 Compound, Physical Review B 64, 205102.

19. G. V. Samsonov, et al, "Physical Properties of Aluminides of Titanium, Zirconium, and Vanadium,” ЦВЕТНАЯ МЕТАЛЛУРГИЯ, n. 1, (1964) - in Russian.

20. T. I. Jones, K.N. Street, J.A. Scoberg, and J.A. Baird, Canadian Metallurgical Quarterly $\underline{\mathbf{2}}$, 2 (1963) pp. 53-72.

21. P. Plaufler, in Intermetallische Phasen(eds Autorenkollektiv). VEB Deutcher Verlag fur Grundstaffindustrie, Leipzig (1976) pp.165-187. 
22. L. M. Howe and M.H. Rainville, "A Sudy of the Irradiation Behaviour of Zr3Al," Journal of Nuclear Materials 68 (1977), pp.215-234.

23. Y. Limoge and A Barbu, "Amorphization Mechanism in Metallic Crystalline Solids Under Irradiation," Physical Review B 30, 4 (1984), pp.2212-2215.

24. C. C. Bidwell and C.L. Hogan, Journal of Applied Physics 18 (1947) pp. 776-779.

25. J. K. Fink and L.Leibowitz, "thermal Conductivity of Zirconium," Journal of Nuclear Materials 226 (1) (1995) pp. 44-50.

26. Y. S. Touloukian, et al, eds., Thermophysical Properties of Matter, 1 (Thermal Conductivity), (1970) p.141.

27. R. W. Powers, J.B. Ziegler and H.L. Johnson, USAF TR 264-7, (1951) pp. 1-10.

28. B. L. Rhodes, C.E. Moeller and H.J. Sauer, Cryogenics (GB), 5, 1 (1965) pp.17-20. 



\section{APPENDIX A \\ DETAILED CALCULATIONS USED IN THERMAL ANALYSIS}




\section{APPENDIX A}

Table A-1. Material Properties used in analysis.

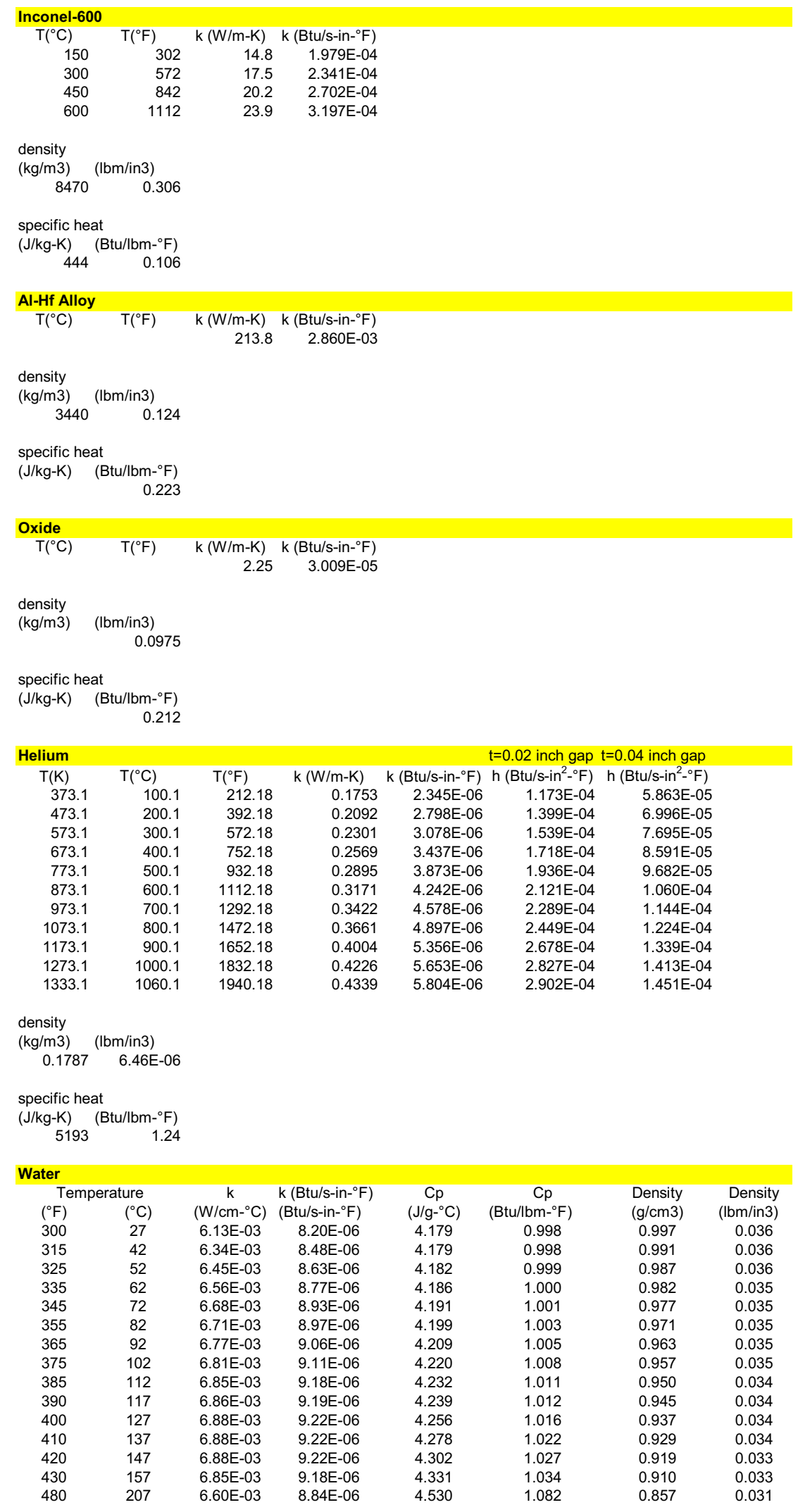




\section{APPENDIX A}

Axial heat load distribution in annulus:

$\mathrm{q}_{\text {total }}:=6135 \cdot \mathrm{W}$

Total heating rate in tube

$\mathrm{D}_{\mathrm{O}}:=3.446$ in

Outside diameter of tube

$\mathrm{D}_{\mathrm{i}}:=\mathrm{D}_{\mathrm{o}}-0.06$ in

Inside diameter of tube

$\mathrm{D}_{\mathrm{i}}=3.386 \mathrm{in}$

$\mathrm{A}_{\mathrm{W}}:=\frac{\pi}{4} \cdot\left(\mathrm{D}_{\mathrm{o}}^{2}-\mathrm{D}_{\mathrm{i}}^{2}\right)$

Cross-sectional area of tube

$\mathrm{q}_{\mathrm{W}}:=\frac{0.5 \cdot \mathrm{q}_{\text {total }}}{\mathrm{A}_{\mathrm{w}} \cdot \Delta \mathrm{x}} \cdot \frac{\mathrm{P}_{\text {norm }}}{\sum \mathrm{P}_{\text {norm }}}$

Heating rate in tube axial segments

$\mathrm{q}_{\mathrm{W}}=\left(\begin{array}{c|c}0.528 \\ 0.499 \\ 0.444 \\ 0.365\end{array}\right) \frac{1}{\mathrm{~s}} \frac{\mathrm{BTU}}{\mathrm{in}^{3}}$

$\mathrm{q}_{\mathrm{avg}}:=\frac{\mathrm{q}_{\text {total }}}{\mathrm{A}_{\mathrm{w}} \cdot 48 \cdot \mathrm{in}} \quad \mathrm{q}_{\mathrm{avg}}=0.376 \frac{1}{\mathrm{~s}} \frac{\mathrm{BTU}}{\mathrm{in}^{3}}$

$\mathrm{q}_{\mathrm{W}}:=\mathrm{q}_{\mathrm{avg}} \cdot \mathrm{P}_{\text {norm }} \quad \mathrm{q}_{\mathrm{W}}=\left(\begin{array}{c}0.527 \\ 0.499 \\ 0.444 \\ 0.365 \\ 0.267 \\ 0.154\end{array}\right) \frac{1}{\mathrm{~s}} \frac{\mathrm{BTU}}{\text { in }^{3}}$ 


\section{APPENDIX A}

Axial heat load distribution in Water Channels.

$\mathrm{q}_{\text {total }}:=3860 \mathrm{~W}$

$\mathrm{D}_{\text {water }}:=.25$. in

$\mathrm{A}_{\mathrm{w}}:=\frac{\pi}{4} \cdot \mathrm{D}_{\mathrm{water}}{ }^{2}$

$\mathrm{q}_{\mathrm{W}}:=\frac{0.5 \cdot \mathrm{q}_{\text {total }}}{\mathrm{A}_{\mathrm{w}} \cdot \Delta \mathrm{x}} \cdot \frac{\mathrm{P}_{\text {norm }}}{\sum \mathrm{P}_{\text {norm }}}$

$\mathrm{q}_{\mathrm{W}}=\left(\begin{array}{c}2.2 \\ 2.1 \\ 1.8 \\ 1.5 \\ 1.1 \\ 0.6\end{array}\right) \frac{1}{\mathrm{~s}} \frac{\mathrm{BTU}}{\mathrm{in}^{3}}$

$q_{\text {avg }}:=\frac{q_{\text {total }}}{A_{w} \cdot 48 \cdot \text { in }}$

$\mathrm{q}_{\mathrm{W}}:=\mathrm{q}_{\mathrm{avg}} \cdot \mathrm{P}_{\text {norm }} \quad \mathrm{q}_{\mathrm{W}}=\left(\begin{array}{c}2.175 \\ 2.058 \\ 1.831 \\ 1.506 \\ 1.101 \\ 0.636\end{array}\right) \frac{1}{\mathrm{~s}} \frac{\mathrm{BTU}}{\mathrm{in}^{3}}$

$\mathrm{q}_{\mathrm{avg}}=1.553 \frac{1}{\mathrm{~s}} \frac{\mathrm{BTU}}{\mathrm{in}^{3}}$
Total heating rate

Outside diameter of tube

Cross-sectional area of tube

$\mathrm{A}_{\mathrm{W}}=0.049 \mathrm{in}^{2}$

Heating rate in tube axial segments 


\section{APPENDIX A}

Axial heat load distribution in envelope tube.
$\mathrm{q}_{\text {total }}:=70500 \mathrm{~W}$
Total heating rate in tube
$\mathrm{D}_{\mathrm{i}}:=3.776 \mathrm{in}$
Inside diameter of tube
$\mathrm{D}_{\mathrm{O}}:=4.026 \mathrm{in}$
Outside diameter of tube
$\mathrm{A}_{\mathrm{w}}:=\frac{\pi}{4} \cdot\left(\mathrm{D}_{\mathrm{o}}^{2}-\mathrm{D}_{\mathrm{i}}^{2}\right)$
Cross-sectional area of tube
$\mathrm{q}_{\mathrm{W}}:=\frac{0.5 \cdot \mathrm{q}_{\text {total }}}{\mathrm{A}_{\mathrm{w}} \cdot \Delta \mathrm{x}} \cdot \frac{\mathrm{P}_{\text {norm }}}{\sum \mathrm{P}_{\text {norm }}}$
Heating rate in tube axial segments

$\mathrm{q}_{\mathrm{W}}=\left(\begin{array}{c}1.3 \\ 1.2 \\ 1.1 \\ 0.9 \\ 0.6 \\ 0.4\end{array}\right) \frac{1}{\mathrm{~s}} \frac{\mathrm{BTU}}{\mathrm{in}^{3}}$

$\mathrm{q}_{\mathrm{avg}}:=\frac{\mathrm{q}_{\text {total }}}{\mathrm{A}_{\mathrm{w}} \cdot 48 \cdot \mathrm{in}} \quad \mathrm{q}_{\mathrm{avg}}=0.909 \frac{1}{\mathrm{~s}} \frac{\mathrm{BTU}}{\mathrm{in}^{3}}$
$\mathrm{q}_{\mathrm{W}}:=\mathrm{q}_{\mathrm{avg}} \cdot \mathrm{P}_{\text {norm }} \quad \mathrm{q}_{\mathrm{W}}=\left(\begin{array}{c}1.273 \\ 1.205 \\ 1.072 \\ 0.882 \\ 0.644 \\ 0.372\end{array}\right) \frac{1}{\mathrm{~s}} \frac{\mathrm{BTU}}{\mathrm{in}^{3}}$ 


\section{APPENDIX A}

Axial heat load distribution in pressure tube.
$\mathrm{q}_{\text {total }}:=58320 \mathrm{~W}$
Total heating rate in tube
$\mathrm{D}_{\mathrm{i}}:=3.446 \mathrm{in}$
Inside diameter of tube
$\mathrm{D}_{\mathrm{O}}:=3.696$ in
Outside diameter of tube
$\mathrm{A}_{\mathrm{W}}:=\frac{\pi}{4} \cdot\left(\mathrm{D}_{\mathrm{o}}^{2}-\mathrm{D}_{\mathrm{i}}^{2}\right)$
Cross-sectional area of tube
$\mathrm{q}_{\mathrm{W}}:=\frac{0.5 \cdot \mathrm{q}_{\text {total }}}{\mathrm{A}_{\mathrm{w}} \cdot \Delta \mathrm{x}} \cdot \frac{\mathrm{P}_{\text {norm }}}{\sum \mathrm{P}_{\text {norm }}}$
Heating rate in tube axial segments

$\mathrm{q}_{\mathrm{W}}=\left(\begin{array}{c}1.2 \\ 1.1 \\ 1 \\ 0.8 \\ 0.6 \\ 0.3\end{array}\right) \frac{1}{\mathrm{~s}} \frac{\mathrm{BTU}}{\mathrm{in}^{3}}$

$\mathrm{q}_{\mathrm{avg}}:=\frac{\mathrm{q}_{\text {total }}}{\mathrm{A}_{\mathrm{w}} \cdot 48 \cdot \mathrm{in}} \quad \mathrm{q}_{\mathrm{avg}}=0.821 \frac{1}{\mathrm{~s}} \frac{\mathrm{BTU}}{\mathrm{in}^{3}}$
$\mathrm{q}_{\mathrm{W}}:=\mathrm{q}_{\mathrm{avg}} \cdot \mathrm{P}_{\text {norm }} \quad \mathrm{q}_{\mathrm{W}}=\left(\begin{array}{c}1.15 \\ 1.088 \\ 0.969 \\ 0.797 \\ 0.582 \\ 0.336\end{array}\right) \frac{1}{\mathrm{~s}} \frac{\mathrm{BTU}}{\mathrm{in}^{3}}$ 


\section{APPENDIX A}

Axial heat load distribution in Al-Hf alloy.

$$
\begin{array}{ll}
\mathrm{q}_{\mathrm{total}}:=40300 \mathrm{~W} & \text { Total heating rate in tube } \\
\mathrm{D}_{\mathrm{pt}}:=3.446 \mathrm{in} & \text { Inside diameter of tube } \\
\mathrm{D}_{\text {expt }}:=1.25 \cdot \mathrm{in} & \text { Outside diameter of tube } \\
\mathrm{D}_{\mathrm{water}}:=0.25 \cdot \mathrm{in} & \mathrm{A}_{\mathrm{W}}=5.449 \text { Cross }^{2} \\
\mathrm{~A}_{\mathrm{W}}:=\frac{\pi}{4} \cdot\left(\mathrm{D}_{\mathrm{pt}}^{2}-3 \cdot \mathrm{D}_{\mathrm{expt}}^{2}-4 \cdot \mathrm{D}_{\mathrm{water}}^{2}\right) & \text { Heating rate in tube axial segments } \\
\mathrm{q}_{\mathrm{W}}:=\frac{0.5 \cdot \mathrm{q}_{\text {total }}}{\mathrm{A}_{\mathrm{w}} \cdot \Delta \mathrm{x}} \cdot \frac{\mathrm{P}_{\text {norm }}}{\sum \mathrm{P}_{\text {norm }}} &
\end{array}
$$$$
\mathrm{q}_{\mathrm{W}}=\left(\begin{array}{c}
0.205 \\
0.194 \\
0.172 \\
0.142 \\
0.104 \\
0.06
\end{array}\right) \frac{1}{\mathrm{~s}} \frac{\mathrm{BTU}}{\mathrm{in}^{3}}
$$

$$
\begin{aligned}
\mathrm{q}_{\mathrm{avg}}:=\frac{\mathrm{q}_{\text {total }}}{\mathrm{A}_{\mathrm{w}} \cdot 48 \cdot \mathrm{in}} \quad \mathrm{q}_{\mathrm{avg}}=0.146 \frac{1}{\mathrm{~s}} \frac{\mathrm{BTU}}{\text { in }^{3}} \\
\mathrm{q}_{\mathrm{W}}:=\mathrm{q}_{\mathrm{avg}} \cdot \mathrm{P}_{\text {norm }} \quad \mathrm{q}_{\mathrm{W}}=\left(\begin{array}{c}
0.205 \\
0.194 \\
0.172 \\
0.142 \\
0.104 \\
0.06
\end{array}\right) \frac{1}{\mathrm{~s}} \frac{\mathrm{BTU}}{\text { in }^{3}}
\end{aligned}
$$




\section{APPENDIX A}

Axial heat load distribution from fuel - surface heat flux.

$\mathrm{q}_{\text {total }}:=70000 \mathrm{~W}$

length $:=4 \cdot$ in

$\mathrm{D}_{\mathrm{O}}:=1.25 \cdot \mathrm{in}$

$\mathrm{A}_{\mathrm{W}}:=\pi \cdot \mathrm{D}_{\mathrm{O}} \cdot$ length

$\mathrm{q}_{\mathrm{W}}:=\frac{0.5 \cdot \mathrm{q}_{\text {total }}}{\mathrm{A}_{\mathrm{W}}} \cdot \frac{\mathrm{P}_{\text {norm }}}{\sum \mathrm{P}_{\text {norm }}}$

$\mathrm{q}_{\mathrm{W}}=\left(\begin{array}{c}0.493 \\ 0.467 \\ 0.416 \\ 0.342 \\ 0.25 \\ 0.144\end{array}\right) \frac{1}{\mathrm{~s}} \frac{\mathrm{BTU}}{\mathrm{in}^{2}}$

$\mathrm{q}_{\text {avg }}:=\frac{\mathrm{q}_{\text {total }}}{12 \mathrm{~A}_{\mathrm{w}}}$

$\mathrm{q}_{\mathrm{avg}}=0.4 \frac{1}{\mathrm{~s}} \frac{\mathrm{BTU}}{\mathrm{in}^{2}}$

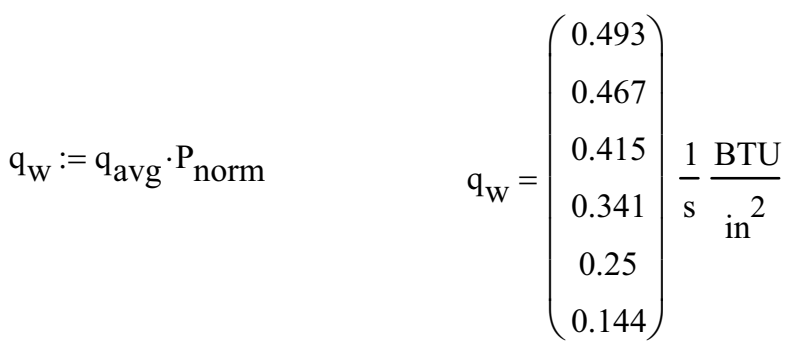

Total heating rate in each

fuel tube

Outside diameter of tube

Cross-sectional area of tube

Heating rate in tube axial segments 
APPENDIX A

Hydraulic Analysis - 1/4 inch coolant channels

$$
\begin{aligned}
& \mathrm{D}_{\mathrm{h}}:=0.25 \cdot \mathrm{in} \quad \mathrm{g}=9.807 \frac{\mathrm{m}}{\mathrm{s}^{2}} \\
& \text { Length }:=48 \cdot \mathrm{in} \\
& \mathrm{P}:=4.9642 \cdot 10^{5} \cdot \mathrm{Pa} \\
& \text { Area }:=\frac{\pi}{4} \cdot \mathrm{D}_{\mathrm{h}}^{2} \\
& \varepsilon:=1.31 \times 10^{-6} \mathrm{~m} \\
& \mathrm{p}:=\frac{\varepsilon}{\mathrm{D}_{\mathrm{h}}} \\
& \text { Guess velocity: } \quad \varepsilon=5.157 \times 10^{-5} \text { in } \\
& \text { vel }:=15.4 \frac{\mathrm{m}}{\mathrm{s}} \quad \mathrm{p}=2.063 \times 10^{-4} \\
& v:=2.48 \times 10^{-3} \cdot \frac{\mathrm{cm}^{2}}{\mathrm{~s}} \quad \rho:=950 \cdot \frac{\mathrm{kg}}{\mathrm{m}^{3}} \\
& \text { Compute Reynolds number: } \\
& \quad \text { Re } \mathrm{d}_{\mathrm{d}}:=\frac{\mathrm{vel} \cdot \mathrm{D}_{\mathrm{h}}}{\mathrm{v}}
\end{aligned}
$$

Compute friction factor:

$$
\begin{array}{cc}
\mathrm{fx}:=-1.8 \cdot \log \left[\left(\frac{\mathrm{p}}{3.7}\right)^{1.11}+\frac{6.9}{\mathrm{Re}_{\mathrm{d}}}\right] & \\
\mathrm{ff}:=\frac{1}{\mathrm{fx}^{2}} & \mathrm{ff}=0.016
\end{array}
$$

Calculate loss coefficient:

$$
\begin{aligned}
& \mathrm{K}_{\text {maj }}:=\text { ff } \cdot \frac{\text { Length }}{\mathrm{D}_{\mathrm{h}}} \\
& \mathrm{K}_{\text {ent }}:=0.5 \\
& \mathrm{~K}_{\text {exit }}:=1.0 \\
& \mathrm{~K}_{\text {tot }}:=\mathrm{K}_{\text {maj }}+\mathrm{K}_{\text {ent }}+\mathrm{K}_{\text {exit }} \quad \mathrm{K}_{\text {tot }}=4.509
\end{aligned}
$$

Calculate flow rate:

$$
\begin{array}{ll}
\mathrm{Q}:=\text { Area } \cdot \sqrt{\frac{2}{\mathrm{~K}_{\mathrm{tot}}} \cdot\left(\mathrm{g} \cdot \text { Length }+\frac{\mathrm{P}}{\rho}\right)} & \mathrm{Q}=4.876 \times 10^{-4} \frac{\mathrm{m}^{3}}{\mathrm{~s}} \quad \mathrm{Q}=7.729 \mathrm{gpm} \\
\text { vel2 }:=\frac{\mathrm{Q}}{\text { Area }} & \mathrm{vel} 2=15.398 \frac{\mathrm{m}}{\mathrm{s}} \\
\mathrm{Vol}:=\text { Area } \cdot \text { Length } & \mathrm{Vol}_{\text {tot }}=1.544 \times 10^{-4} \mathrm{~m}^{3} \\
\mathrm{Vol}_{\text {tot }}:=4 \cdot \mathrm{Vol} & \\
\text { Gamma heating: } & \\
\mathrm{q}_{\text {gamma }}:=3 \cdot\left(8.5 \cdot \frac{\mathrm{W}}{\mathrm{gm}}\right) \cdot \rho \cdot \mathrm{Vol}_{\text {tot }} & \mathrm{q}_{\mathrm{gamma}}=3.741 \times 10^{3} \mathrm{~W}
\end{array}
$$





\section{APPENDIX B \\ ALTERNATE THERMAL CALCULATIONS}

Presented here are temperature distributions calculated for the alternate thermal configuration analyzed, having additional heat load from the experiment chambers. Thermal analysis was performed considering a total heat load of $384 \mathrm{~kW}$ from the three experiment chambers. Similar temperature distributions with elevated magnitudes are seen in the system components. The maximum temperature $\left(306.4^{\circ} \mathrm{C}, 583.5^{\circ} \mathrm{F}\right)$ occurs in the hafnium aluminum absorber. Under nominal operating conditions, the calculated FIR and DNBR under nominal operating conditions are 4.4 and 4.6, respectively, which exceed the minimum value of 2 .

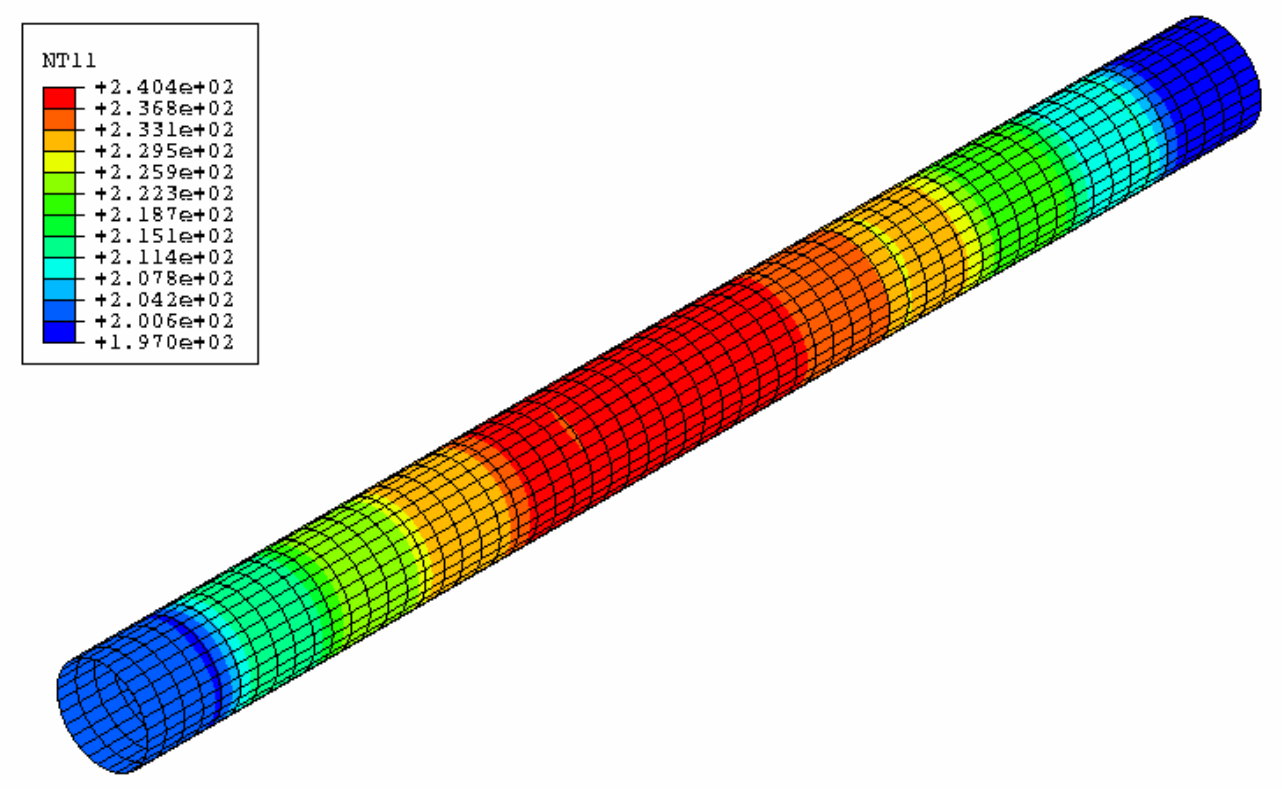

Figure B-1. Temperature distribution $\left({ }^{\circ} \mathrm{F}\right)$ on inner surface of envelope tube. 


\section{APPENDIX B}

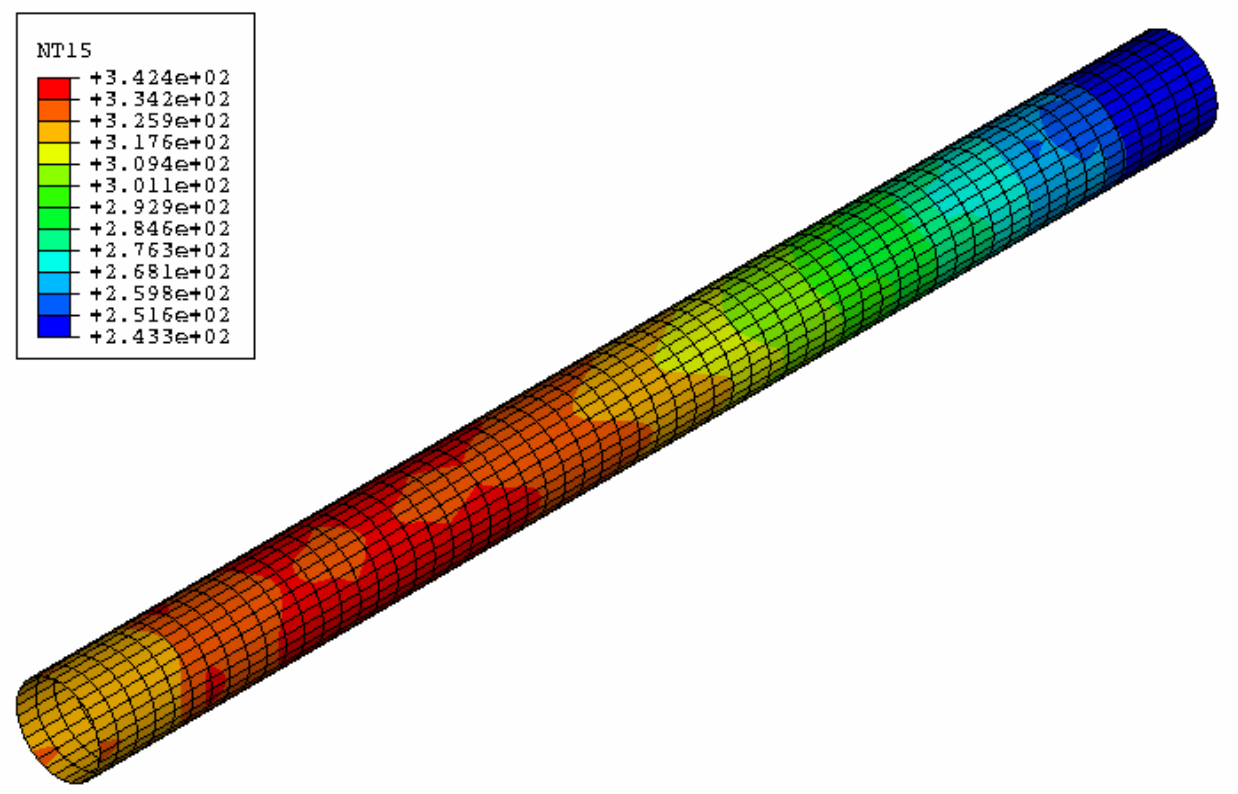

Figure B-2. Temperature distribution $\left({ }^{\circ} \mathrm{F}\right)$ on outer surface of pressure tube.

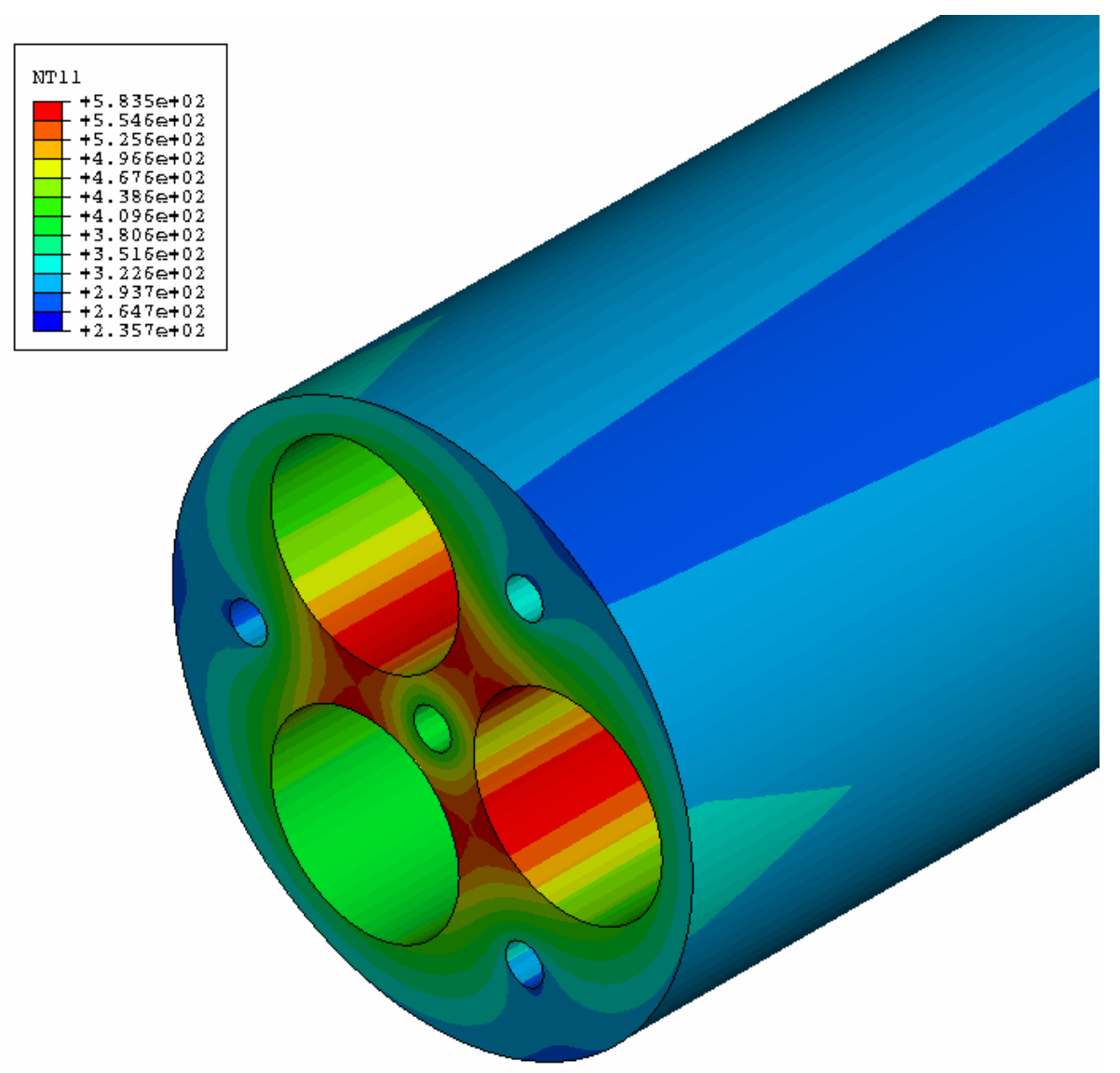

Figure B-3. Radial temperature distribution $\left({ }^{\circ} \mathrm{F}\right)$ in the neutron absorber/heat sink. 


\section{APPENDIX B}

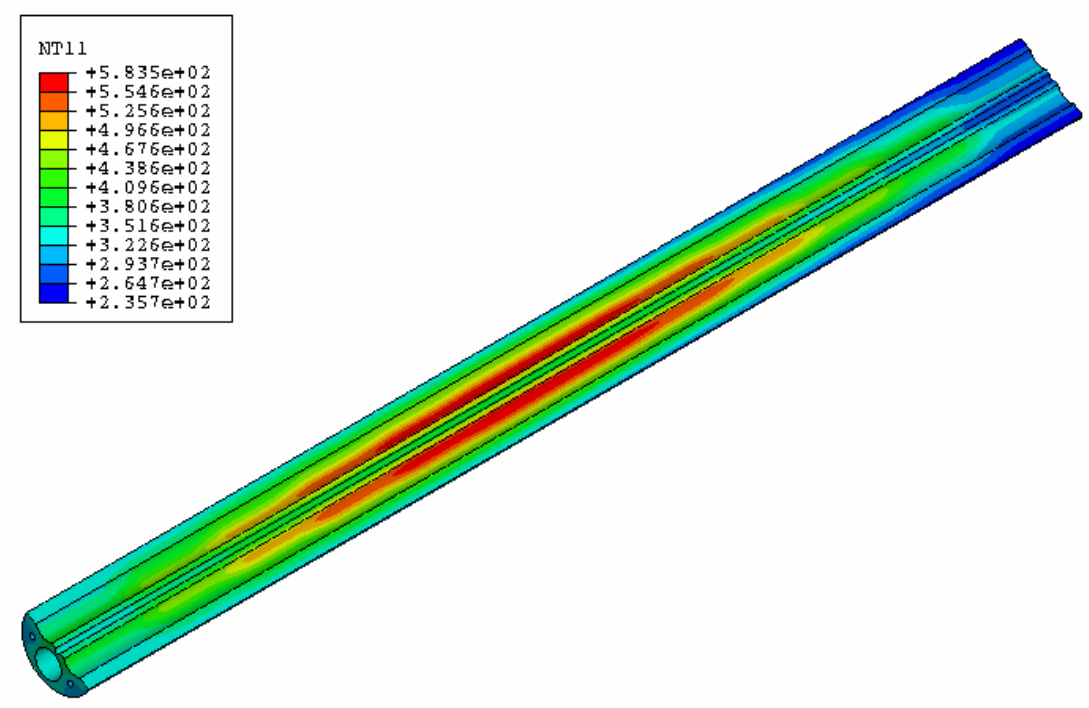

Figure B-4. Axial temperature distribution $\left({ }^{\circ} \mathrm{F}\right)$ in the hafnium aluminum absorber.

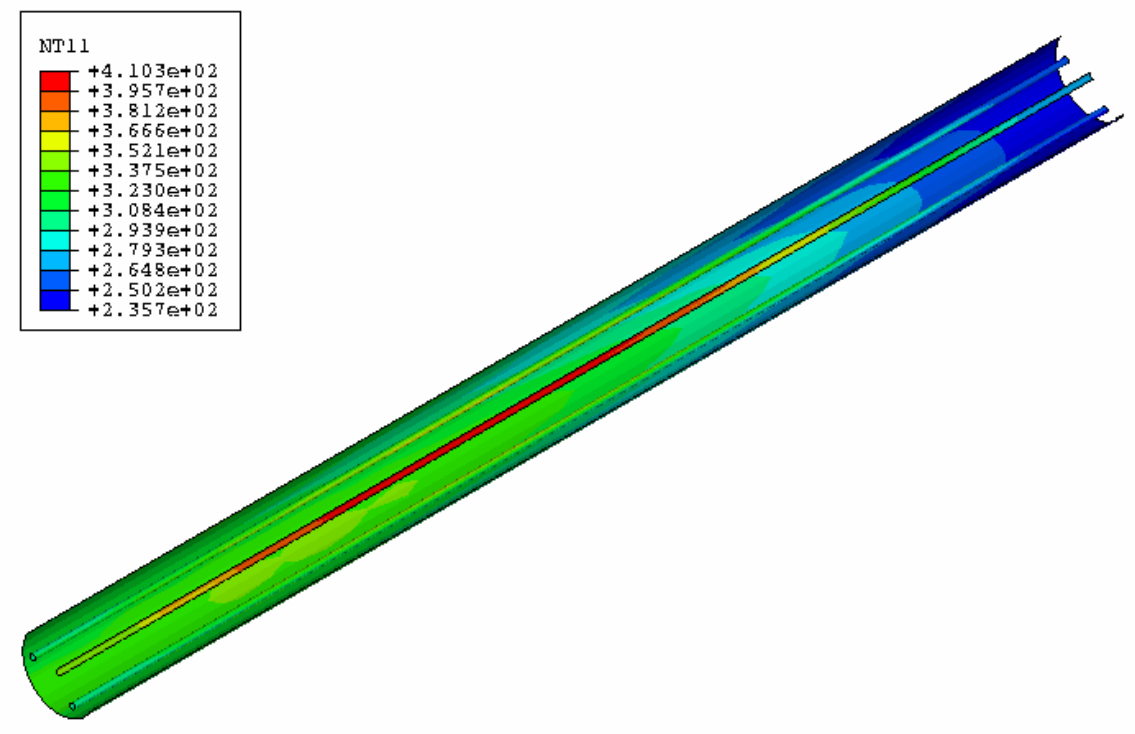

Figure B-5. Temperature distribution $\left({ }^{\circ} \mathrm{F}\right)$ in the oxide layers. 


\section{APPENDIX B}

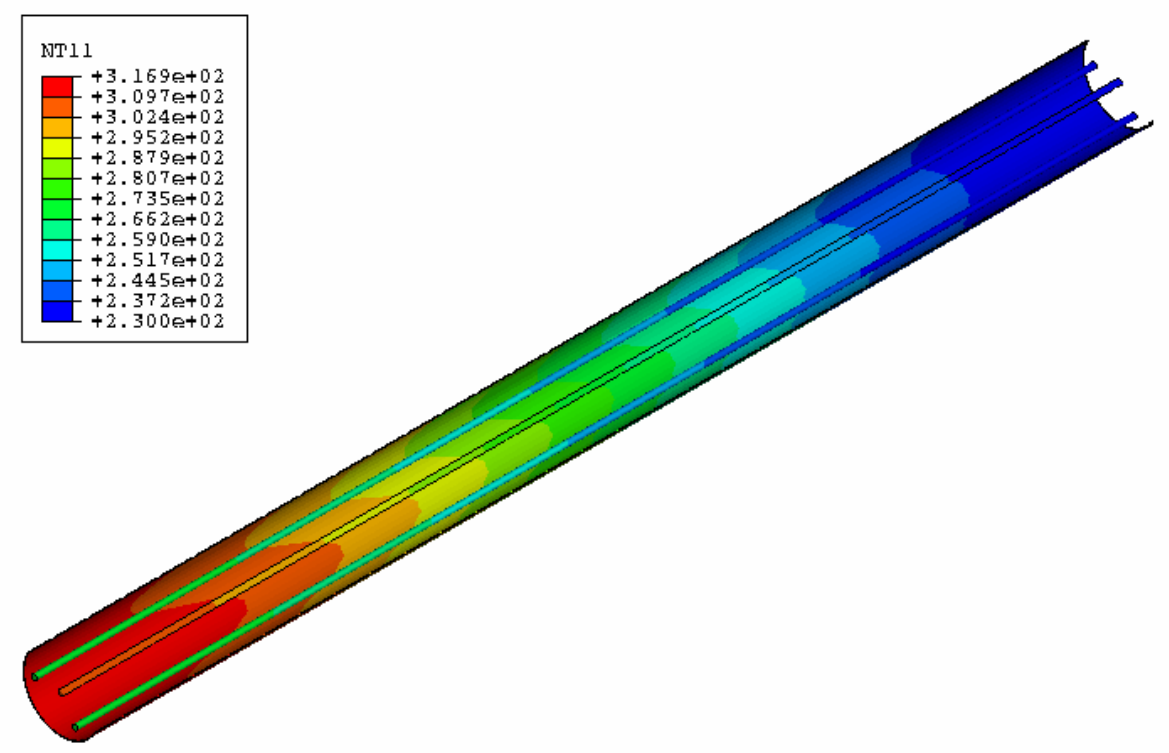

Figure B-6. Temperature distribution $\left({ }^{\circ} \mathrm{F}\right)$ in the water coolant.

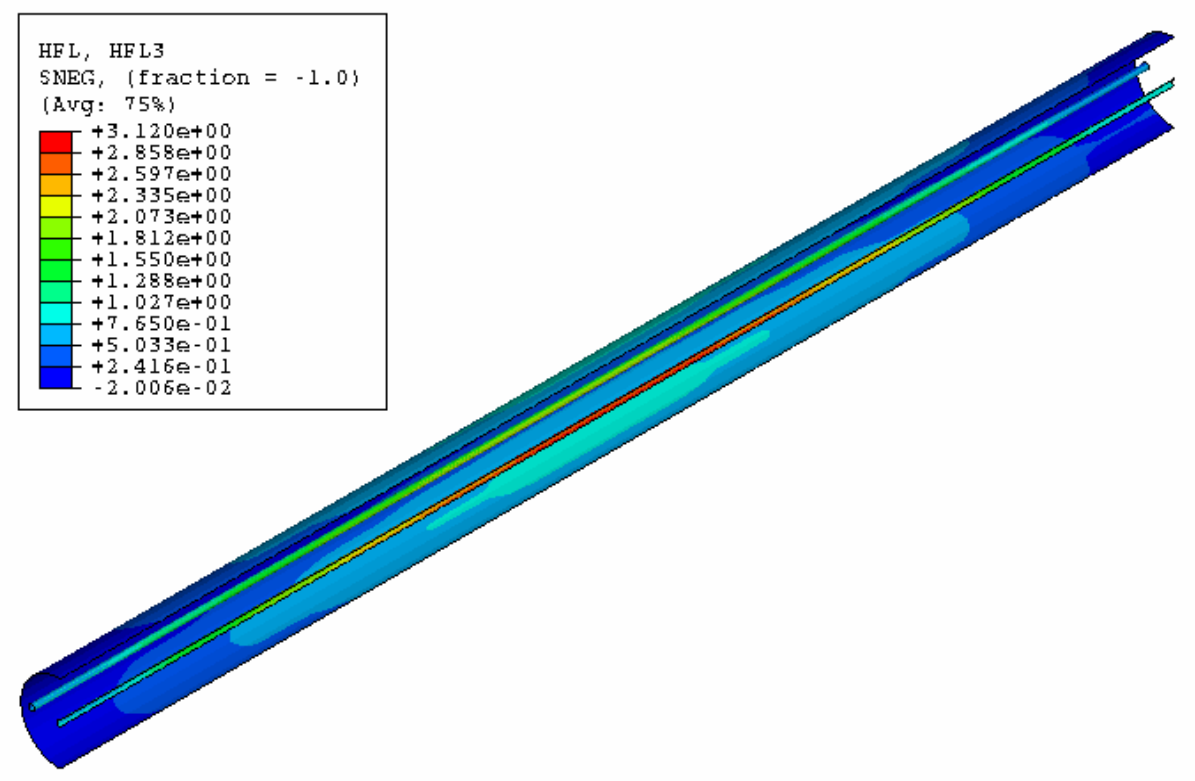

Figure B-7. Distribution of surface heat flux $\left(\mathrm{BTU} / \mathrm{s}-\mathrm{in}^{2}\right)$ at the oxide surfaces. 


\section{APPENDIX C TOTAL PROJECT COST SUMMARY}

Presented here is the Total Project Cost Summary Report for the BFFL alternate cooling concept for the fast flux test capability in the ATR. 


\section{APPENDIX C}

Project Name: Boosted Fast Flux Loop

Project Location: INL - RTC Advanced Test Reactor

Project Number: $7 A 48$

\section{ESTIMATE ELEMENT}

Total Estimated Cost (TEC)

Other Project Cost (OPC)

Total Project Cost (TPC)

Total Project Cost (TPC)
$\$ 5,672,246$

TPC Summary Report

\begin{tabular}{|c|c|c|c|}
\hline Estimate Subtotal & Escalation & Contingency & TOTAL \\
\hline$\$ 17,990,993$ & $\begin{array}{l}12.59 \% \\
\$ 2,265,066\end{array}$ & $\begin{array}{r}25.00 \% \\
\$ 5,064,015\end{array}$ & $\$ 25,320,074$ \\
\hline$\$ 27,062,592$ & $\begin{array}{r}12.59 \% \\
\$ 3,407,180\end{array}$ & $\begin{array}{r}25,00 \% \\
\$ 7,617,443\end{array}$ & $\$ 38,087,215$ \\
\hline \multirow[t]{2}{*}{$\$ 45,053,585$} & $\begin{array}{r}12.59 \% \\
\$ 5,672,246\end{array}$ & $\begin{array}{r}25.00 \% \\
\$ 12,681,458\end{array}$ & $\$ 63,407,289$ \\
\hline & & & $\$ 63,400,000$ \\
\hline
\end{tabular}

\begin{tabular}{|l|l|l|}
\hline Type of Estimate: & Class 4 & Remarks \\
\hline Estimator: & B.W. Wallach MS 3204.526-5896 \\
\hline Checked By:
\end{tabular}

BEA

idaho National Laboratory

08/13/2007 $\quad 16: 04: 54$

Cost Estimating

Page No. 
Battelle Energy Alliance (BEA)

\section{COST ESTIMATE SUPPORT DATA RECAPITULATION}

Project Title: Boosted Fast Flux Loop

Estimator: $\quad$ B. W. Wallace

Date: August 13,2007

Estimate Type: Class 4

File: ${ }^{7 A 48}$ Approved By: Waldoford $8 / 2 / 67 \quad$ Page 1 of 5

1. PURPOSE: Brief description of the intent of how the estimate is to be used, i.e, for engineering study, comparative analysis, DWP, LCB out-year planning, BCP, etc.

The purpose of this cost estimate is to establish a rough order of magnitude (ROM) planning value of the Boosted Fast Flux Loop project for use by the Deparment of Energy in decision making of path forward for this and similar projects.

11. SCOPE OF WORK: Brief statement of the project's objective. Thorough overview and description of the proposed project. Identify work to be accomplished, as well as any specific work to be excluded.

The objective of this project is to design and install a capability in the existing Advanced Test Reactor Facility (ATR) that will provide the test environment necessary for the irradiation testing of advanced reactor fuels and materials requiring an intense fast neutron flux.

The scope of work to achieve the objectives for this project includes research and development, engineering, modifications to certain safety basis and procedures, design, installation, testing, and qualification of the booster fuel.

This estimate specifically excludes:

A. Any life cycle costs after the loop has been accepted for operations.

B. Shipment of the irradiated booster fuel elements from the ATR to NTEC.

C. Any necessary changes to equipment, procedures, safety basis, etc., supporting the shipment of irradiated booster fuel elements from the ATR to INTEC.

D. Costs for the customer to prepare, install and handle test trains.

E. Additional ATR fuel purchase and handling in support of the boosted fast fux loop.

F. Any costs or expenditures prior to the beginning of FY 2008.

G. Management administration and analysis required to move the project to $\mathrm{CD}$.

III. BASIS OF THE ESTIMATE: Overall methodology and rationale of how the estimate was developed. Source documents to include drawings, design reports, engineers' notes andlor other documentation upon which the estimate is originated. Overall explanation of sources for resource pricing. 
This cost estimate is based on Cost Estimating file \#7367-B performed on September 8, 2005. The revisions reflected in this estimate are based on input from the project team in a meeting held on July 24, 2007. Cost Estimating file \# 7367-B was based upon numerous meetings with the project team, input from the project, and the "Gas Test Loop Conceptual Design: 70\% Progress Report" dated March 2005.

IV. $\quad$ ASSUMPTIONS: Condition statements accepted or supposed true without proof of demonstration; statements adding clarification to scope. An assumption has a direct impact on total estimated cost.

A. A performance period addressing CD1 approval through project turnover, beginning in fiscal year 2009 and extending through fiscal year 2012 has been identified for the project.

B. There will be no changes to the attractiveness levels of the special nuclear facilities.

C. Customers will provide all transportation of experimental material to the INL. Onsite transportation of experiments, before and after irradiation, will be included in each experiment's operational cost.

D. The booster fuel will perform as designed in one run and will not require any re-engineering or additional runs.

E. The NMIS storage racks will be constructed of non-combustible materials.

F. The irradiated single plate specimens will be transported from the ATR to the MFC for the post irradiation examination (PIE) in an appropriate cask under a transport plan authorization.

G. The single plate specimens will remain at the MFC for disposal once the PIE has been completed. The cost for this disposal at the MFC has been included in the PIE costs.

H. There will be no significant equipment changes or modifications to the ATR unless otherwise stated within the body of this estimate.

I. System will be designed to support three individual test trains. Each test train space will be designed for five capsules each with supporting control gas and instrumentation to support these 15 individual specimen environments.

J. Three dummy test trains with minimal instrumentation to support system operational testing will be developed and installed.

$\mathrm{K}$. One third of the spare mechanical components are covered by this estimate, the remaining two thirds are considered life cycle costs.

L. BWXT can successfully fabricate the single plate specimens.

M. The booster fuel can be qualified.

N. The Boosted Fast Flux Loop System will consist of a single gas system; the "Specimen Environment Control and Sample Carrier System" primarily used as temperature and environmental control of the experiment. 


\section{COST ESTIMATE SUPPORT DATA RECAPITULATION}

- Continued -

Project Title: Boosted Fast Flux Loop

File: $\quad$ 7A48

Page 3 of 5

O. Primary heat removal will be performed using the existing pressurized water system at ATR. It is assumed and reflected in the estimate that this system will be available for use by this project.

P. The sample system associated with the "Specimen Environment Control and Sample Carrier System" will be specific to the test sponsor needs and will not be part of this design. Concepts for the sample system will be considered and adequate space and adaptability will be provided in the design to allow for future additions. The distribution system will be designed such that the sample system can easily be integrated into the system in the future.

Q. The majority of the gas system mechanical equipment will be located in shielded Cubicle $2 \mathrm{E}$ and in the surrounding area of this cubicle within the ATR second basement. It is assumed adequate space is available in the shielded cubicle for equipment that has the potential of being a radiation source.

R. The flow rates, pressure requirements, and gas media for the "Specimen Environment Control and Sample Carrier System" will be comparable to other "Instrumented Lead" type experiments that have previously been conducted at ATR. The gas blend will be made up of helium and neon.

S. From previous test experience it is estimated that the flow rate for the "Specimen Environment Control and Sample Carrier System" will be around $60 \mathrm{sccm}$ at system inlet pressure of less than 50 psi. The system will be designed as a single pass system; the gas blend exiting the experiment capsule will be delayed, as appropriate for fission product decay, and then will be released to the ATR stack.

T. It is estimated that the "Boosted Fast Flux Loop" will be required to remove approximately $200 \mathrm{~kW}$ from the experiment area.

U. Further analysis associated with specific experiment design, allowable capsule temperatures, and actual heat loads, will need to be performed to determine the actual gas flow parameters. Also, methods will be used to optimize the experiment capsule design for heat transfer and to minimize the required gas flow rate.

V. Adequate high and low pressure demineralized water will be provided from existing ATR systems.

W. Gas Purification/Filtration will be provided for clean up of the "Boosted Fast Flux Loop" gas if it becomes contaminated.

$\mathrm{X}$. The gas supply, gas quality, mass flow indication/control and mixing, and gas purification sub-systems of the "Specimen Environment Control and Sample Carrier System" will not require shielding and will be located in available space surrounding the shielded cubicle.

Y. The control system will be similar to that in use for other testing programs. It will be independent from existing ATR communications systems and control system networks. The control system consists of vendor-supplied distributed control system (DCS) components, hardware and software, uninterruptible power supply and system power, thermocouple readouts and associated cabling, and process input and output cabling. 
Project Title: Boosted Fast Flux Loop

File: $\quad$ 7A48

Z. The temperature control system will be capable of displaying the temperature within each capsule. The control system and associated work station will be located in the corridor near the shielded cubicle.

AA. There will be methods available for experiment handling capability, before and after irradiation, as part of transportation interfaces at the ATR.

BB. An acceptable technique, such as leak-before-break technology, can be readily (without significant R\&D) developed and incorporated into the Advanced Test Reactor safety basis to justify sustained long-term reactor operation at the increased lobe power necessary to support the boosted fast flux loop fast neutron flux objective.

CC. The Boosted Fast Flux Loop can be operated with dummy booster fuel elements instead of actual booster fuel elements in situations not requiring the irradiation benefits of actual booster fuel.

V. CONTINGENCY GUIDELINE IMPLEMENTATION: Explanation of methodology used in determining overall contingency. Identify any specific drivers or items of concern.

At this time this project contains $25 \%$ contingency as determined by the requester and the project team. Some areas of concern for this project include:

A. This never performed work represents research and development activities. The ability for success of this project is contingent on the theories as laid out in the conceptual design at this time.

B. Single plate specimens will be irradiated in one of the ATR Flux Traps, visually inspected, and, after cooling, sent to HFEF for PIE. The possibility of needed design modifications may require a second round of single plate specimen irradiation testing, but costs for that are not in the estimate.

C. Success, as gauged by the visual evaluation of the mini plate test, would support $\mathrm{CD}-1$, allowing design to start. Final verification of performance of the loop will not be obtained until after the testing of the loop in the ATR.

D. Main booster fuel assembly development would start with success in single plate testing. Parts of that development would be delayed if failure was evident in the first single-plate specimen test.

E. Results from the single plate test can impact the schedule.

F. The project would be accepted with completion of visual examination of complete booster fuel elements after testing in ATR. The need to perform PIE on those elements is not foreseen or budgeted.

G. Limited resources could delay or increase the cost of the project.

H. ATR operational issues can directly impact the project.

I. The operation of the Boosted Fast Flux Loop changes the operation of the ATR. Higher power and shorter run times may impact the safety analysis. 


\section{COST ESTIMATE SUPPORT DATA RECAPITULATION}

- Continued -

Project Title: Boosted Fast Flux Loop

File:

J. Should there be no methods for the experiment handling capability, before and after irradiation, as part of transportation interfaces at the ATR, costs could increase.

VI. ESTIMATE SUMMARY: Total dollars/hours and Rough Order Magnitude (ROM) allocations of the methodologies used to develop the cost estimate.

\begin{tabular}{|l|l|}
\hline Estimate Methodology & $\begin{array}{l}\text { ROM } \\
\text { Percentage \% }\end{array}$ \\
\hline \hline Project Team & 100 \\
\hline Recorded Actuals & 0 \\
\hline Parametric & 0 \\
\hline Vendor Quotes & 0 \\
\hline Other & 0 \\
\hline & \\
\hline TOTAL & 100 \\
\hline
\end{tabular}

VII. OTHER COMMENTS/CONCERNS SPECIFIC TO THE ESTIMATE:

A. All labor resources reflect current burdened BEA labor rates.

B. Escalation for the project reflects a March midpoint of 2011. 


\section{APPENDIX C}

Project Name: Boosted Fast Flux Loop

Project Summary Report

Project Location: INL - RTC Advanced Test Reactor

Estimate Number: 7A48

\begin{tabular}{|c|c|}
\hline Level & Description \\
\hline$\overline{\mathrm{OPC} 1000}$ & Project Management and Support During Operational Activities \\
\hline OPC1000.10 & ....Project Management, Administration, and Analysis Prior to CD1 \\
\hline OPC1000.20 & ....Project Management and Support During Operational Activities \\
\hline OPC2000 & Develop RTC Facilities Safety Analysis for the GTL \\
\hline OPC 3000 & Operating Procedures \\
\hline OPC 3000.10 & .... Management Self Assessment (MSA) \\
\hline OPC 3000.20 & .... Documentation for the GTL System and Misc. Expenses \\
\hline OPC 3000.30 & .... Operating Procedures for the GTL System \\
\hline CAP1000 & Project Management and Support During Capital Activities \\
\hline OPC4000 & Booster Fuel \\
\hline OPC4000.10 & .... Technical Committee Review \\
\hline OPC4000.30 & ....Plate Specimen Fabrication @ BWXT \\
\hline OPC4000.40 & .... Booster Fuel Fabrication \\
\hline OPC4000.40.10 & ....... Fabricate the Booster Fuel Elements \& Dummies \\
\hline OPC4000.40.20 & ...... Oversight of the Booster Fuel Fabrication \\
\hline OPC4000.50 & .... Shipment of the Plate Specimens \\
\hline OPC4000.50.10 & ........ Ship Fresh Fuel Plate Specimens from BWXT to ATR \\
\hline OPC4000.50.20 & ....... Ship Irradiated Fuel Plate Specimens from ATR to MFC for PIE \\
\hline OPC4000.50.20.10 & $\ldots \ldots \ldots$. (A) Standard Hazardous Category 2 Transport Plan \\
\hline OPC4000.50.20.20 & $\ldots \ldots \ldots \ldots$ (E) Loading Operations at ATR \\
\hline OPC4000.50.20.30 & ........... (B) Standard Transport Operating Cost for Transporting Under A Transport Plan \\
\hline OPC4000.50.20.40 & $\ldots \ldots \ldots$ (F) Unloading Operations at MFC/HFEF \\
\hline OPC4000.80 & .... Booster Fuel Element Irradiation Unit (IU) Charges @ RTC \\
\hline OPC4100 & Nuclear Testing \\
\hline OPC4100.20 & .... ATRC Testing for BFFL System \\
\hline
\end{tabular}

$B E A$

08/07/2007 15:04:03

Cost Estimating
Client: $\quad$ W. D. Ridgway, MS 3750, 526-4790 Prepared By: $\quad$ B. W. Wallace, MS 3204, 526-5896 Estimate Type: Class 4

Estimate Subtotal
$\$ 4,221,770$
$\$ 1,022,600$
$\$ 3,199,170$
$\$ 4,003,816$
$\$ 4,811,821$
$\$ 648,655$
$\$ 2,637,067$
$\$ 1,526,099$
$\$ 3,649,097$
$\$ 8,360,226$
$\$ 131,262$
$\$ 340,668$
$\$ 478,462$
$\$ 385,074$
$\$ 93,388$
$\$ 409,833$
$\$ 108,612$
$\$ 301,221$
$\$ 214,784$
$\$ 51,074$
$\$ 7,801$
$\$ 27,561$
$\$ 7,000,000$
$\$ 2,861,199$
$\$ 453,099$

Escalation

Contingency

$\$ 1,188,323$

Contingency

$\$ 531,521$

$\frac{\%}{25.00 \%}$

$25.00 \%$

$\$ 287,836$

$25.00 \%$

$\$ 1,439,182$

$\$ 402,776$

$\$ 504,080$

$\$ 900,48$

$25.00 \%$

$\$ 4,502,432$

$\$ 5,634,870$

$\$ 605,808$

$25.00 \%$

$\$ 6,772,037$

$\$ 81,666$

$\$ 332,007$

$\$ 182,580$

$25.00 \%$

$\$ 912,901$

$\$ 742,269 \quad 25.00 \%$

$\$ 3,711,343$

$\$ 192,136$

$\$ 429,559$

$25.00 \%$

$\$ 2,147,793$

$\$ 459,421$

$\$ 1,027,130$

$25.00 \%$

$\$ 5,135,648$

$\$ 1,052,552$

$\$ 2,353,195$

$25.00 \%$

$25.00 \%$

$\$ 11,765,973$

$\$ 36,947$

$\$ 95,890$

$25.00 \%$

$\$ 184,735$

$\$ 42,890$

$\$ 60,238$

$\$ 48,481$

$\$ 134,675$

$25.00 \%$

$25.00 \%$

$\$ 479,448$

$\$ 673,376$

$\$ 541,943$

$\$ 26,286 \quad 25.00 \% \quad \$ 131,432$

$\$ 115,358$

$\$ 30,572$

$\$ 84,786$

$25.00 \%$

$25.00 \%$

$25.00 \%$

$25.00 \%$

$25.00 \%$

$25.00 \%$

$25.00 \%$

$25.00 \%$

$25.00 \%$

$25.00 \%$
$\$ 576,789$

$\$ 152,858$

$\$ 423,931$

$\$ 302,282$

$\$ 71,881$

$\$ 10,979$

$\$ 38,789$

$\$ 9,851,625$

$\$ 4,026,780$

$\$ 637,680$ 


\section{APPENDIX C}

\section{Project Summary Report}

Project Location: INL - RTC Advanced Test Reactor Estimate Number: $7 A 48$

\begin{tabular}{|c|c|}
\hline$\frac{\text { Level }}{\text { OPC4100.30 }}$ & .... $\frac{\text { Description }}{\text { ATRC Testing for the Plate Specimens }}$ \\
\hline OPC4100.40 & .... Plate Specimens Section Testing in ATR Flux Trap \\
\hline OPC4100.50 & ....P Plate Specimen Irradiation Unit (IU) Charges @ RTC \\
\hline OPC5000 & Hafnium-Aluminum Block Development/Production \\
\hline OPC5000.10 & .... Hafnium-Aluminum Block Development/Production \\
\hline CAP4000 & ATR Gas System and Hardware \\
\hline CAP4000.05 & .... Captial Design \\
\hline CAP4000.10 & ....Project Analyses \\
\hline CAP4000.20 & ..... System Testing \\
\hline CAP4000.40 & .... Temperature Control, Sampling System, and He Monitoring and Insulation Gap \\
\hline CAP4000.50 & .... Electrical, Instrumentation and Control Systems \\
\hline CAP4000.60 & .... Tank Hardware \\
\hline CAP4000.70 & .... Modifications for Installation of the GTL in a Corner Lobe \\
\hline CAP5000 & Facility Modifications \\
\hline CAP5000.10 & .....Racks @ NMIS \\
\hline CAP5000.30 & ....Canal Fuel Storage \\
\hline OPC6000 & Operations \\
\hline OPC6000.10 & .... Operations \\
\hline OPC7000 & Performance Testing \\
\hline OPC7000.10 & .... Execute the Performance Test \\
\hline OPC7000.20 & ....Plate Specimen Post Irradiation Examination (PIE) @ MFC \\
\hline OPC7000.30 & .... Canal Visual Examination (VE) of the Booster Fuel Elements \\
\hline OPC8000 & Other Operational Adders \\
\hline
\end{tabular}

OPC8000.10
Client: $\quad$ W. D. Ridgway, MS 3750, 526-4790 Prepared By: $\quad$ B. W. Wallace, MS 3204, 526-5896 Estimate Type: Class 4

\begin{tabular}{rrrr} 
& \multicolumn{3}{c}{ Contingency } \\
\cline { 3 - 5 } Escalation & Contingency & \multicolumn{1}{c}{ TOTAL } \\
\cline { 3 - 5 }$\$ 38,642$ & $\$ 86,391$ & $25.00 \%$ & $\$ 431,957$ \\
$\$ 138,638$ & $\$ 309,954$ & $25.00 \%$ & $\$ 1,549,768$ \\
$\$ 125,900$ & $\$ 281,475$ & $25.00 \%$ & $\$ 1,407,375$ \\
$\$ 158,362$ & $\$ 354,051$ & $25.00 \%$ & $\$ 1,770,255$ \\
$\$ 158,362$ & $\$ 354,051$ & $25.00 \%$ & $\$ 1,770,255$ \\
$\$ 1,608,688$ & $\$ 3,596,549$ & $25.00 \%$ & $\$ 17,982,747$ \\
$\$ 564,279$ & $\$ 1,261,561$ & $25.00 \%$ & $\$ 6,307,803$ \\
$\$ 275,686$ & $\$ 616,352$ & $25.00 \%$ & $\$ 3,081,762$ \\
$\$ 60,165$ & $\$ 134,510$ & $25.00 \%$ & $\$ 672,551$ \\
$\$ 226,163$ & $\$ 505,633$ & $25.00 \%$ & $\$ 2,528,167$ \\
$\$ 341,403$ & $\$ 763,275$ & $25.00 \%$ & $\$ 3,816,375$ \\
$\$ 90,420$ & $\$ 202,152$ & $25.00 \%$ & $\$ 1,010,758$ \\
$\$ 50,573$ & $\$ 113,066$ & $25.00 \%$ & $\$ 565,331$ \\
$\$ 121,863$ & $\$ 272,449$ & $25.00 \%$ & $\$ 1,362,245$ \\
$\$ 18,034$ & $\$ 40,318$ & $25.00 \%$ & $\$ 201,591$ \\
$\$ 103,829$ & $\$ 232,131$ & $25.00 \%$ & $\$ 1,160,654$ \\
$\$ 60,168$ & $\$ 134,519$ & $25.00 \%$ & $\$ 672,593$ \\
$\$ 60,168$ & $\$ 134,519$ & $25.00 \%$ & $\$ 672,593$ \\
$\$ 113,207$ & $\$ 253,098$ & $25.00 \%$ & $\$ 1,265,490$ \\
$\$ 32,902$ & $\$ 73,560$ & $25.00 \%$ & $\$ 367,798$ \\
$\$ 74,869$ & $\$ 167,385$ & $25.00 \%$ & $\$ 836,924$ \\
$\$ 5,436$ & $\$ 12,154$ & $25.00 \%$ & $\$ 60,768$ \\
$\$ 21,255$ & $\$ 47,521$ & $25.00 \%$ & $\$ 237,604$ \\
$\$ 8,125$ & $\$ 18,165$ & $25.00 \%$ & $\$ 90,826$
\end{tabular}

BEA 


\section{APPENDIX C}

Project Summary Report

Project Name: Boosted Fast Flux Loop

Project Location: INL - RTC Advanced Test Reactor

Estimate Number: $7 A 48$

Level

OPC8000.20

Description

OPC8000.20.10

.... Project Acceptance and Closeout

OPC 8000.20 .20

OPC8000.20.30

....... Records Disposition

........ Material Disposition

CAP 9000

........ Complete Closeout PM Checklist

CAP9000.10

Other Capital Adders

.... BEA Material Handling and G\&A Fees - Capital

Client: $\quad$ W. D. Ridgway, MS 3750, 526-4790 Prepared By: $\quad$ B. W. Wallace, MS 3204, 526-5896 Estimate Type: Class 4

\begin{tabular}{|c|c|c|c|c|}
\hline$\frac{\text { Estimate Subtotal }}{\$ 104,292}$ & $\frac{\text { Escalation }}{\$ 13,130}$ & $\frac{\text { Contingency }}{\$ 29,356}$ & $\begin{array}{c}\text { Contingency } \\
\frac{\%}{25.00 \%}\end{array}$ & $\frac{\text { TOTAL }}{\$ 146,778}$ \\
\hline$\$ 27,549$ & $\$ 3,468$ & $\$ 7,754$ & $25.00 \%$ & $\$ 38,771$ \\
\hline$\$ 6,513$ & $\$ 820$ & $\$ 1,833$ & $25.00 \%$ & $\$ 9,166$ \\
\hline$\$ 70,230$ & $\$ 8,842$ & $\$ 19,768$ & $25.00 \%$ & $\$ 98,840$ \\
\hline$\$ 596,454$ & $\$ 75,094$ & $\$ 167,887$ & $25.00 \%$ & $\$ 839,435$ \\
\hline$\$ 596,454$ & $\$ 75,094$ & $\$ 167,887$ & $25.00 \%$ & $\$ 839,435$ \\
\hline
\end{tabular}

$\$ 45,053,585$

$\$ 5,672,246$

$\$ 12,681,458$

$25.00 \%$

$\$ 63,407,289$

Total Boosted Fast Flux Loop

BEA 